\title{
Training Techniques Used to Prepare National FFA Officer Candidates for the National FFA Officer Selection Process
}

\author{
Becky L. Berkebile \\ West Virginia University
}

Follow this and additional works at: https://researchrepository.wvu.edu/etd

\section{Recommended Citation}

Berkebile, Becky L., "Training Techniques Used to Prepare National FFA Officer Candidates for the National FFA Officer Selection Process" (2011). Graduate Theses, Dissertations, and Problem Reports. 3355.

https://researchrepository.wvu.edu/etd/3355

This Thesis is protected by copyright and/or related rights. It has been brought to you by the The Research Repository @ WVU with permission from the rights-holder(s). You are free to use this Thesis in any way that is permitted by the copyright and related rights legislation that applies to your use. For other uses you must obtain permission from the rights-holder(s) directly, unless additional rights are indicated by a Creative Commons license in the record and/ or on the work itself. This Thesis has been accepted for inclusion in WVU Graduate Theses, Dissertations, and Problem Reports collection by an authorized administrator of The Research Repository @ WVU. For more information, please contact researchrepository@mail.wvu.edu. 
Training Techniques Used to Prepare National FFA Officer Candidates for the National FFA Officer Selection Process

Becky L. Berkebile

Thesis Submitted to the

Davis College of Agriculture, Natural Resources, and Design

at West Virginia University

in partial fulfillment of the requirements

for the degree of

Master of Science

in

Agricultural and Extension Education

Deborah A. Boone, Ph.D. Chair

Harry N. Boone, Jr., Ph.D.

Roger G. Hanshaw, Ph.D.

Division of Resource Management

Morgantown, West Virginia

2011

Keywords: National FFA, Agriculture Education, Officer Training 


\begin{abstract}
Training Techniques Used to Prepare National FFA Officer Candidates for the National FFA Officer Selection Process

Becky L. Berkebile
\end{abstract}

Annually every state has the opportunity to send one candidate to vie for a National FFA Officer position. Candidates spend months preparing for the national selection process where they are evaluated on eight character competencies. The purpose of this study was to look at the training and preparation methods used by candidates to prepare for the National FFA Officer Selection process. The target populations for the study were candidates who competed for a National Office over the last five years from 2006-2010 and State Agriculture Education Supervisors. Data were collected via an online questionnaire. The candidate population consisted of 115 past National Officer Candidate with an accessible population of 94 candidates. Sixty-one (65\%) of the former National Officer Candidates responded to the survey. Thirty-four (65.4\%) of the 52 State Supervisors responded. Some of the most significant findings included the fact that an overwhelming majority of the candidates develop their own preparation method with assistance from other individuals. Most of them are selected between four and seven months prior to the National Selection Process and an overwhelming majority are full time students while preparing to run for a National FFA Office. Other findings included the training activities in which candidates participated, the assistance that was provided to them along with their thoughts and feelings on the competencies and selection process. 


\section{DEDICATION}

I would like to dedicate this research to all of the hard working FFA members that have excelled to the highest honors that can be bestowed by the organization. Running for a National FFA Office is a challenging, trying, and daunting task; physically, mentally, and emotionally to say the least. However, coming from an individual who has personally underwent the preparation process; it is a rewarding learning experience that few have the opportunity to participate in. I wanted to conduct this research to determine what training methods are used to prepare candidates for the experience of a lifetime. It is my hopes that the information I have obtained from this research can be used to prepare candidates of the future and that these methods will eventually be passed down to state and maybe even local chapter officer candidates. In closing I would like to dedicate my thesis to the many candidates who have passed through the National FFA Officer Selection process. To the few candidates that are given an opportunity to lead the nation and to the many whom still volunteer their time to make the organization better for future generations. 


\section{ACKNOWLEDGEMENTS}

I would like to thank all of those individuals who have helped to make this research a success. Thanks to my academic advisor Dr. Deborah Boone for the continued support and motivation to successfully achieve my Master's Degree. Also to the other members of my graduate committee Dr. Harry Boone, Jr. and Dr. Roger Hanshaw for assisting with my plan of study, instrument review, and many thesis edits. Thanks to my family for their consistent support throughout the years. Whether it was running all over

the nation representing the FFA, five years of college or life in general, they have always had my back. To my friends, thanks for the stress relief, and late night talks. And lastly thanks to God for blessing my life with all of these wonderful people. 


\section{TABLE OF CONTENTS}

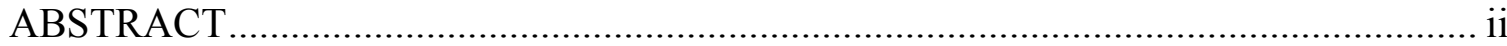

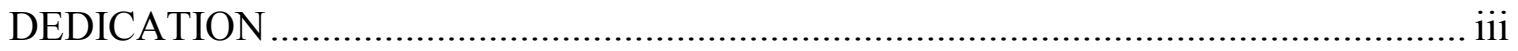

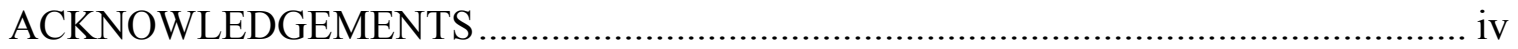

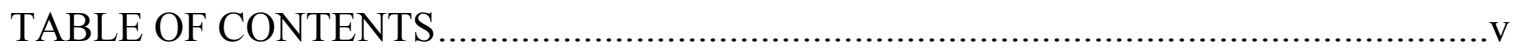

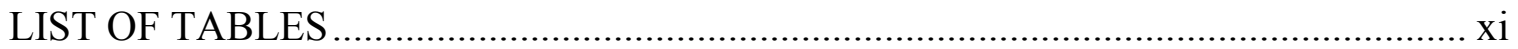

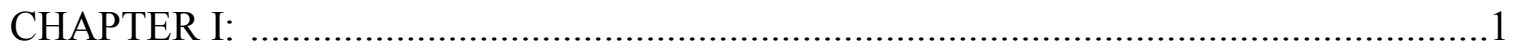

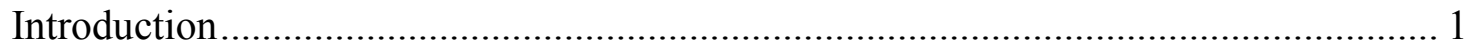

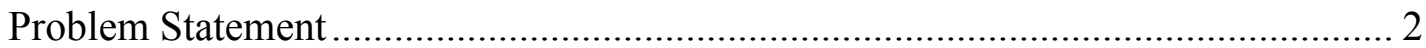

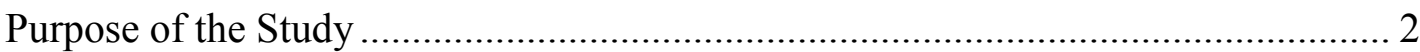

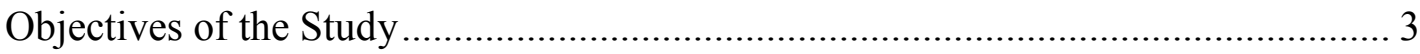

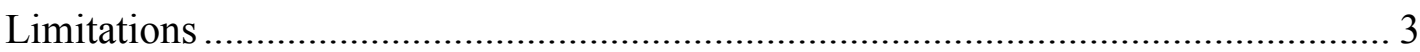

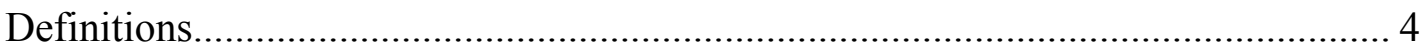

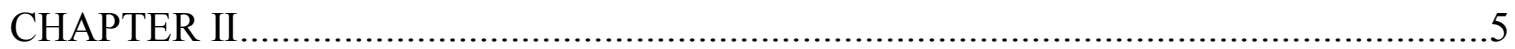

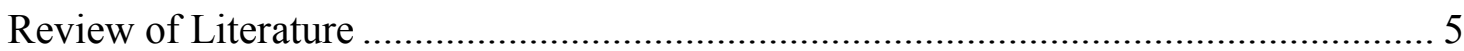

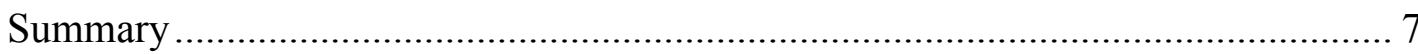

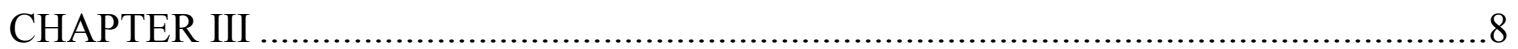

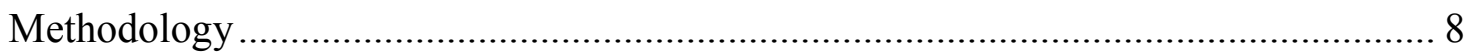

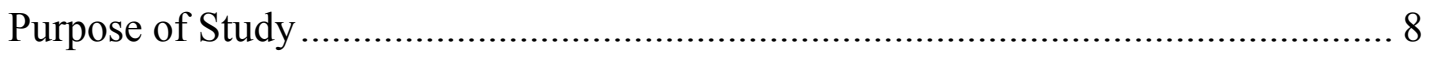

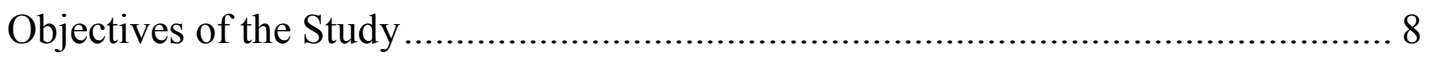

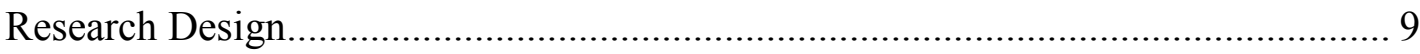

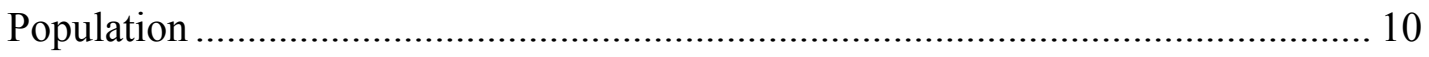

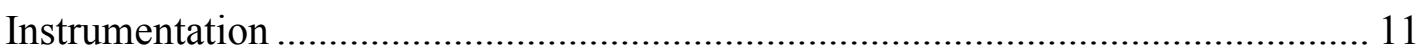

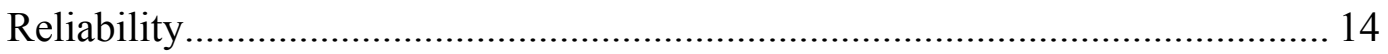

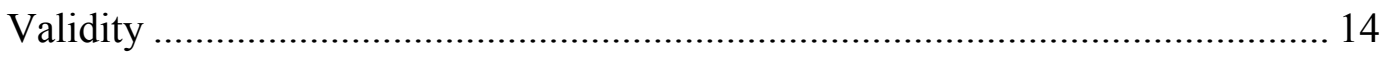

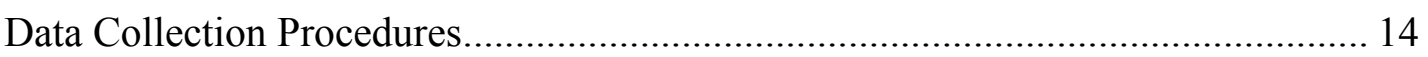

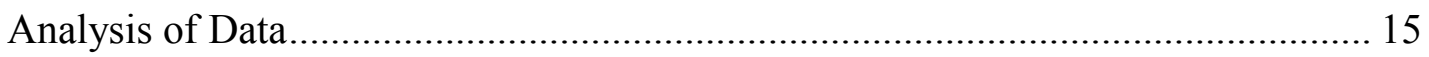

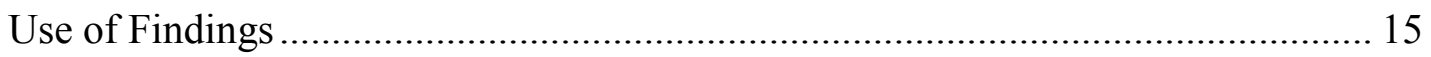

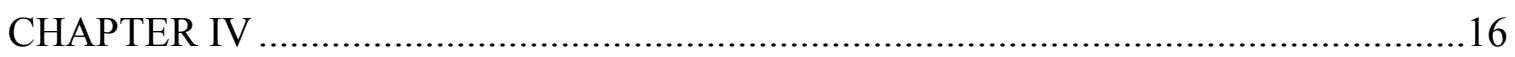

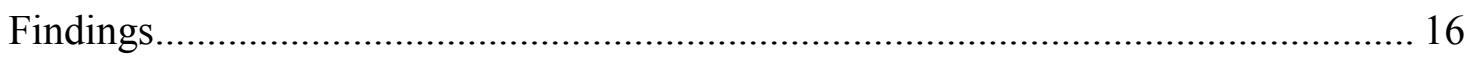

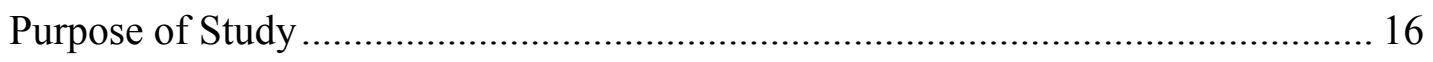

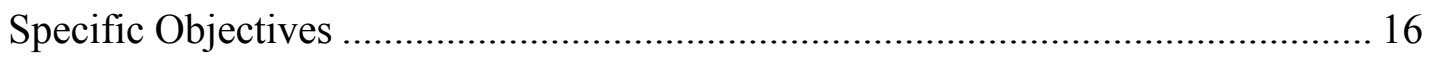

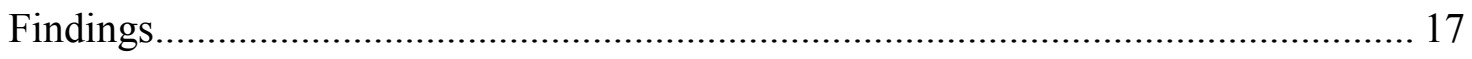

Process Used to Prepare National Officer Candidates............................................. 17 


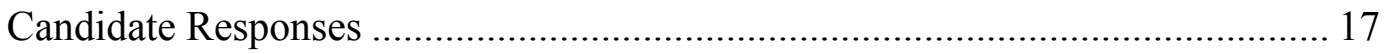

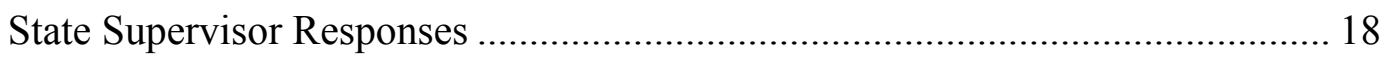

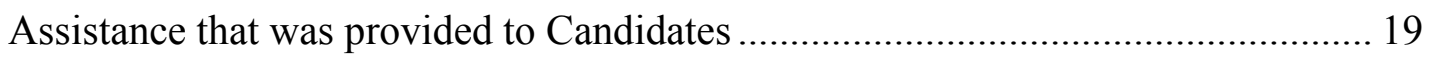

Candidate Responses .................................................................................. 19

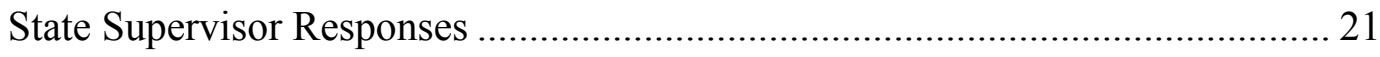

Training Activities in which Candidates Participated ............................................ 22

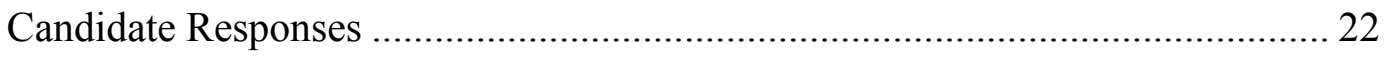

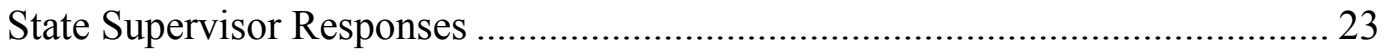

Interview situations in which Candidates Participate ............................................ 25

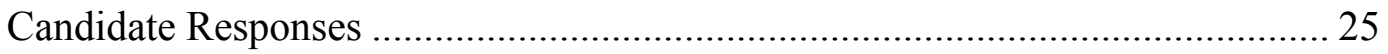

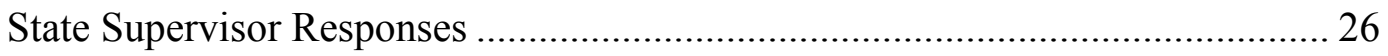

Information that is Being Gathered from Interviews ............................................. 28

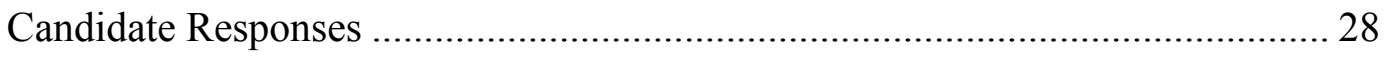

State Supervisor Responses ...................................................................... 30

Interview Skills Candidates Worked to Improve During Preparation ......................... 31

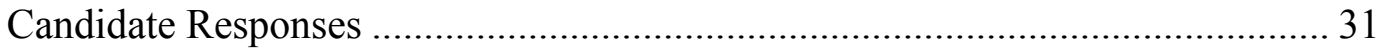

State Supervisor Responses ......................................................................... 33

Rating of the Level of Training Candidates Received in Given Topic Areas .......... 35

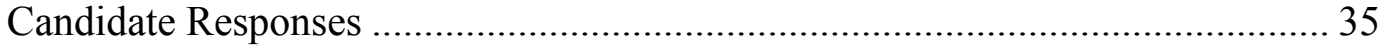

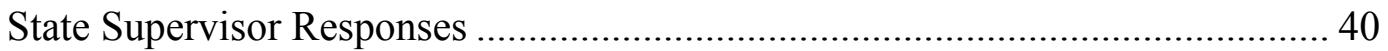

How Closely Mock Interview Questions Relate to Interview Questions asked During the National Selection Process .................................................................. 44

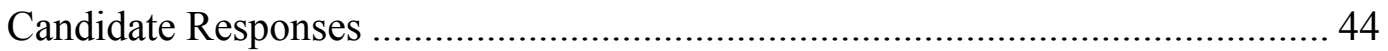

Public Appearances that were the Most Beneficial .................................................. 45

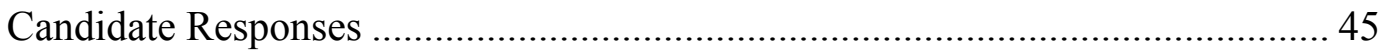

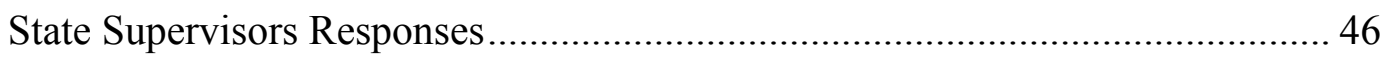

Public Appearances made that were the Least Beneficial .......................................... 47

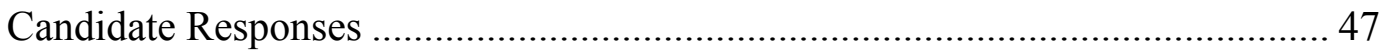

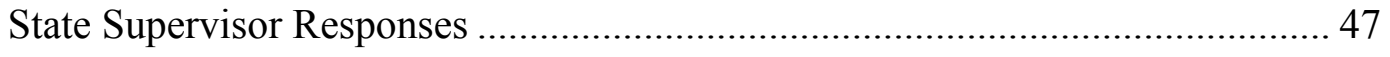

Approximate Amount of Workshops Candidates Presented ....................................... 48

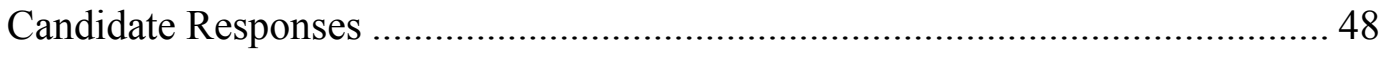

State Supervisor Responses ....................................................................... 49

Topics of Workshops Candidates Presented During Preparation .............................. 50

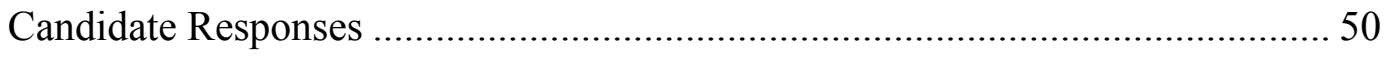

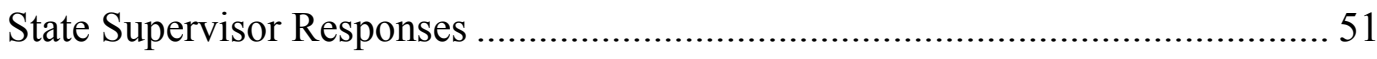


Similarity Between Workshops Presented During Preparation and Workshop

Topics Given During the Selection Process......................................................... 52

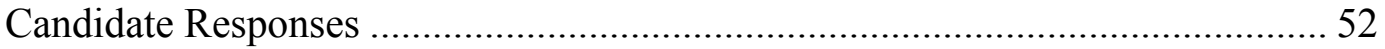

Competencies that were the Most Difficult and Easiest to Prepare for ................... 53

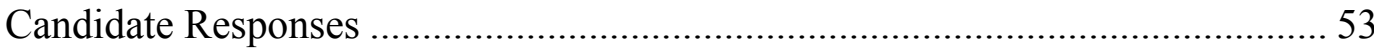

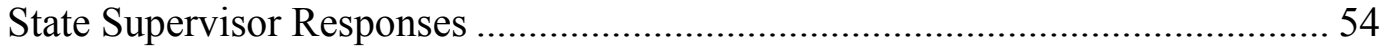

Competencies that were Exhibited the Most After Training was Complete ............ 55

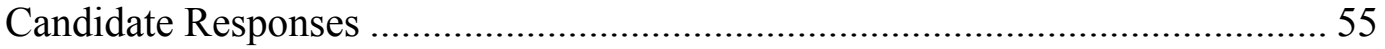

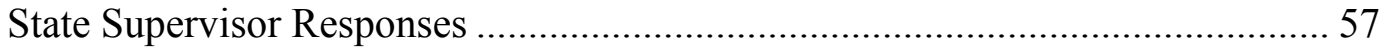

Are the Competencies a Good Basis to be Selected Upon?.................................... 58

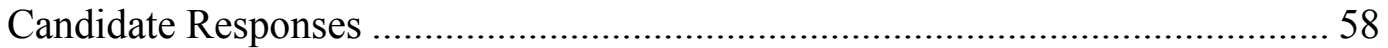

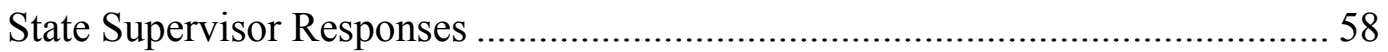

Topics Candidates Researched During Preparation............................................ 59

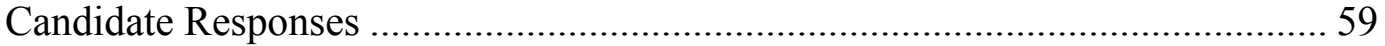

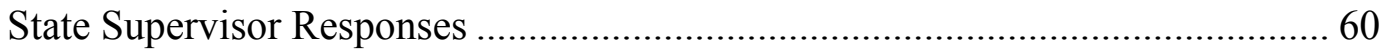

Total Hours of Research Conducted and Approximate Number of Hours Per

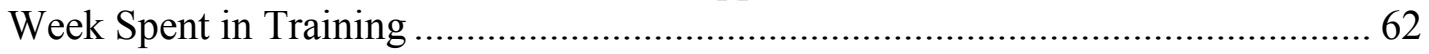

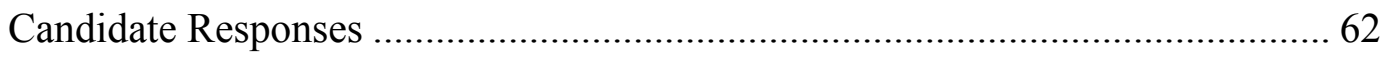

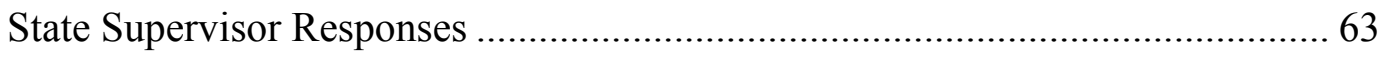

Topics Candidates feel are the Most Important to Research after Completing

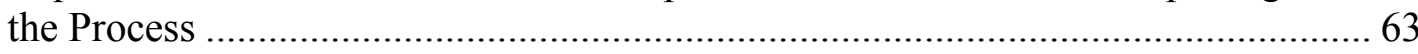

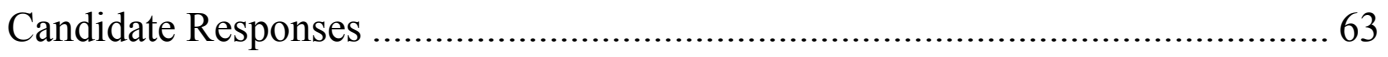

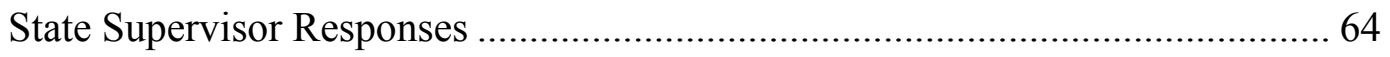

Post-Secondary Enrollment Status of Candidates and College or University

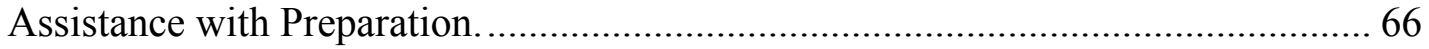

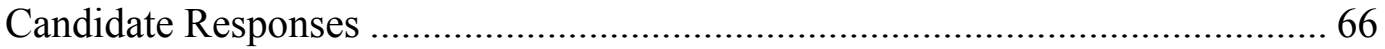

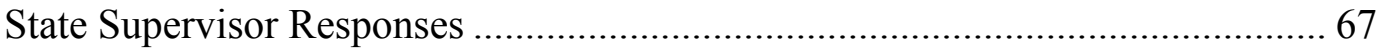

Resources Provided to Candidates by their College or University......................... 69

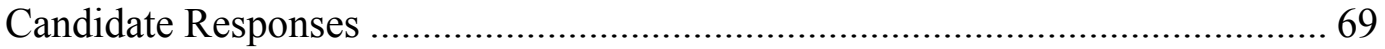

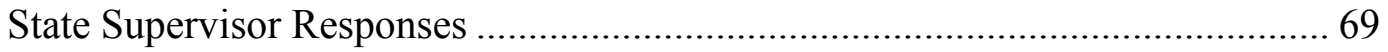

Internships Candidates Participates in During Candidacy .................................... 70

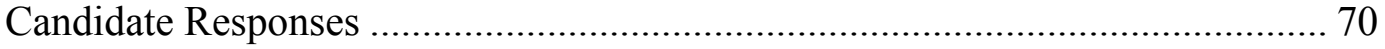

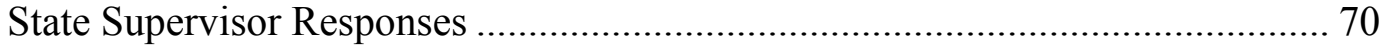

Who Candidates Consulted with for Advice or Feedback about the Selection

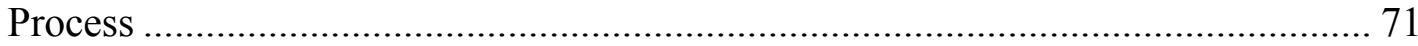

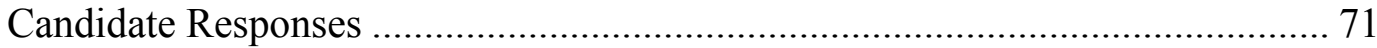




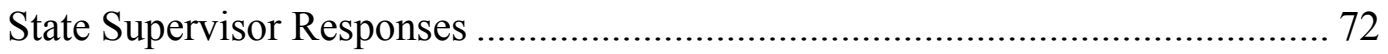

Candidates that were Past Nominating Committee Members .................................. 74

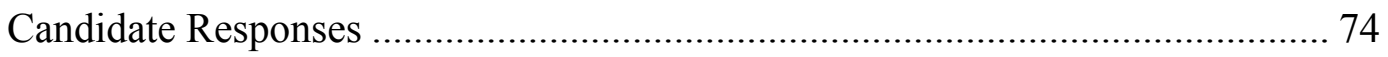

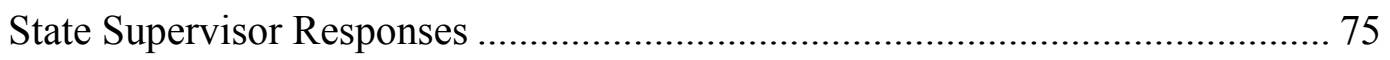

Rating of How Well Candidates Feel they were Prepared for the Process after Looking Back and Reflecting ..................................................................... 76

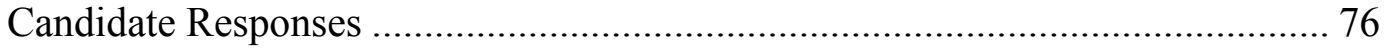

State Supervisor Responses .................................................................... 76

Length of Time Between when Candidates were Selected to Represent their State and the National Selection Process ................................................................... 77

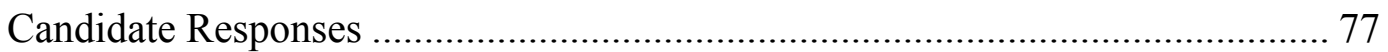

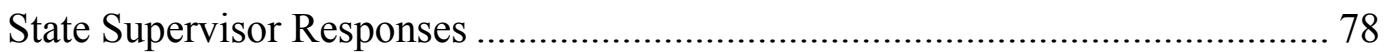

How Closely State Nominating Committee Processes Mirror the National Nominating Committee Process ..................................................................... 79

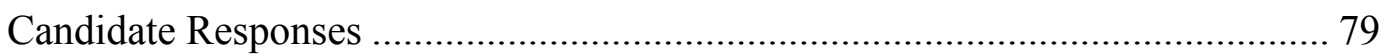

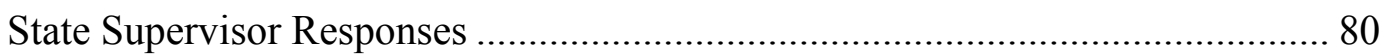

Year or Years Candidates Ran for a National Office and Advanced to the $2^{\text {nd }}$

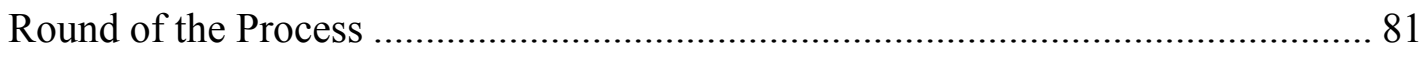

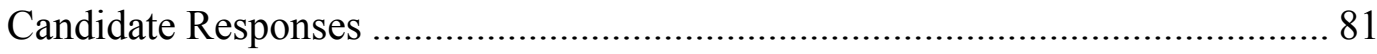

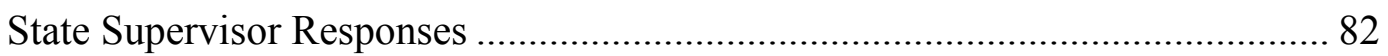

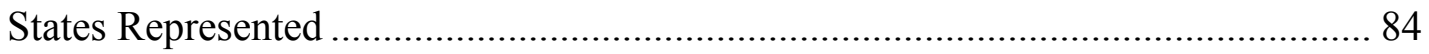

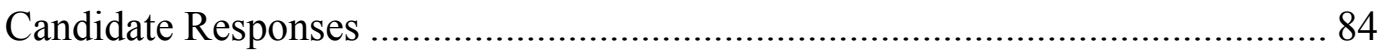

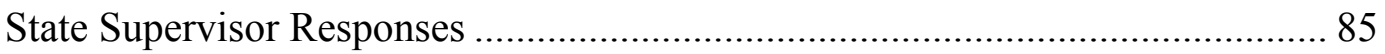

Most Beneficial Skill Received from Preparations as a Candidate ………………... 85

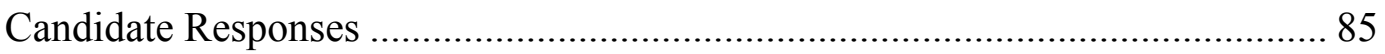

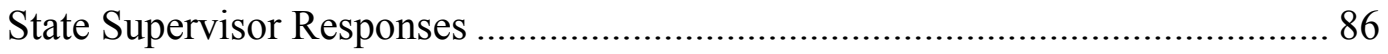

Training Candidates Would have Liked to Received But Did Not Get.................... 86

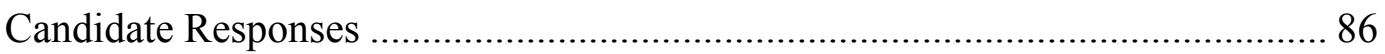

What Most Prepared Candidates for Process.......................................................... 87

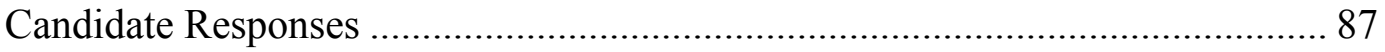

Preparation Methods Candidates Believe they Spent too Much Time On ............... 87

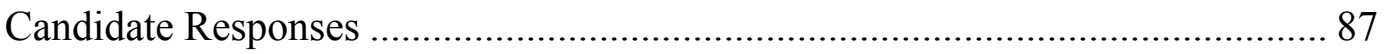

Preparation Methods Candidates would have Liked More Time On ...................... 88

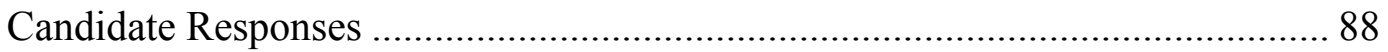

What Candidates Wanted to Gain from the Process other than Being Selected as a National Officer 


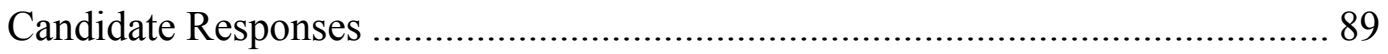

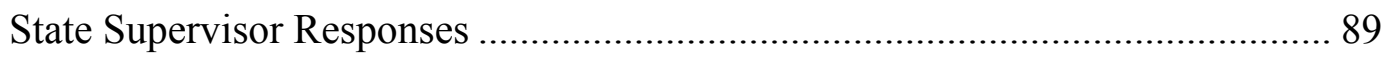

Part of National Selection Process that was the Most Challenging ........................... 90

Candidate Responses .................................................................................. 90

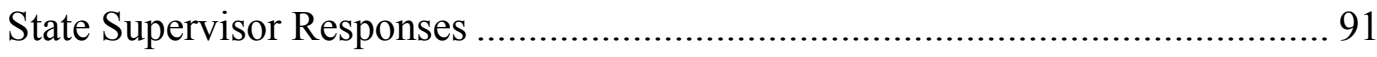

Part of National Selection Process that was the Least Challenging.......................... 92

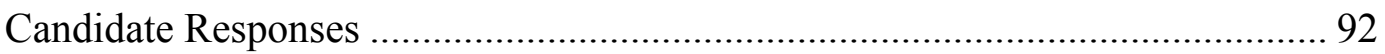

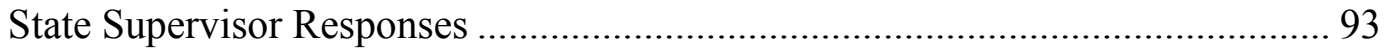

Do Candidates feel the Current Selection Process is a Good Process that Assists the Nominating Committee in selecting the Best Candidates?...................... 94

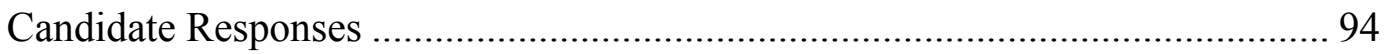

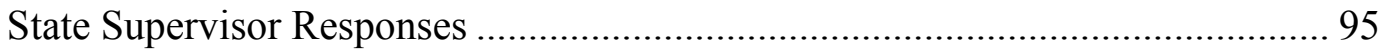

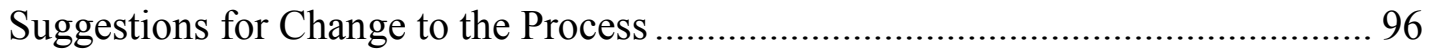

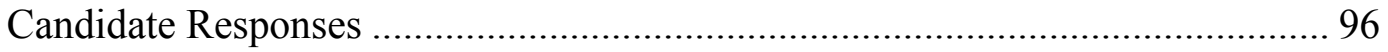

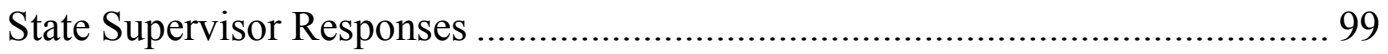

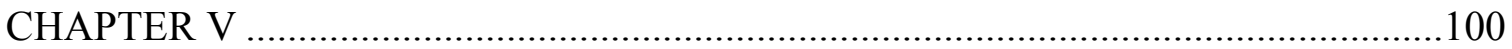

Summary, Conclusions, and Recommendations..................................................... 100

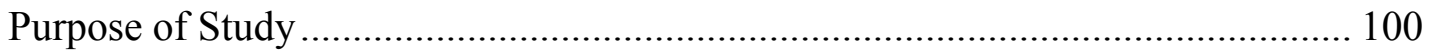

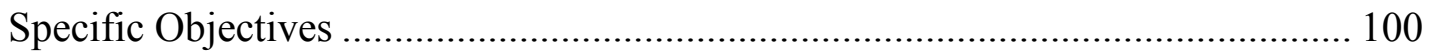

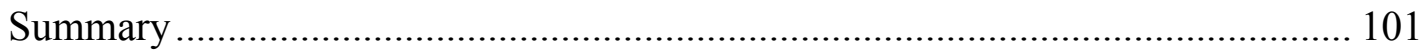

What training processes and activities are utilized by candidates to prepare for the National Officer Selection process? ........................................................ 101

What types of assistance and advice are provided to National Officer

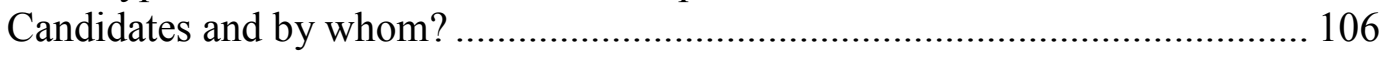

What are the perceptions of candidates and state staff on their state selection process and training techniques as compared to the national process and procedures?

What are the National Officer Candidates and State Staff perceptions of the eight character competencies used in the National Officer Selection process?

What do National Officer Candidates feel they gained from preparing for and participating in the National Officer Selection process?.

What are candidates' opinions on the structure of the current process and recommendations for changes to the selection process?

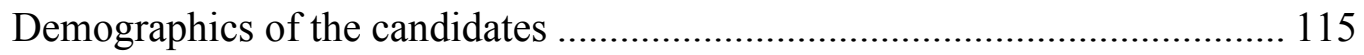

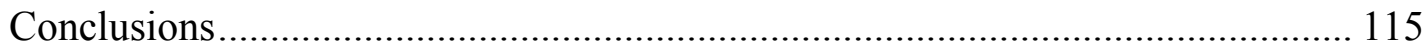

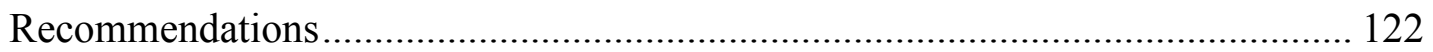




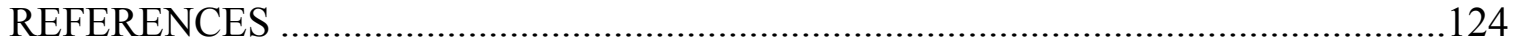

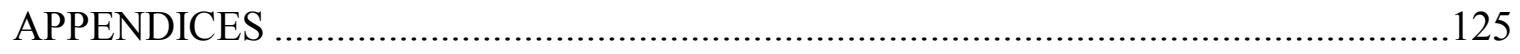

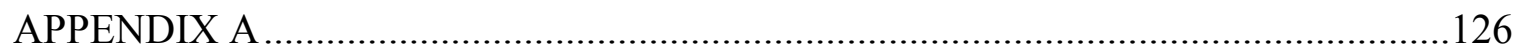

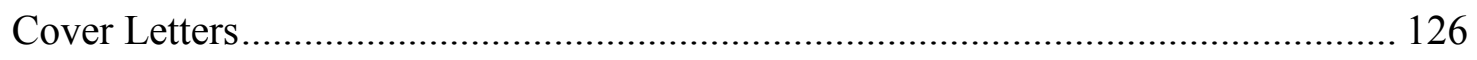

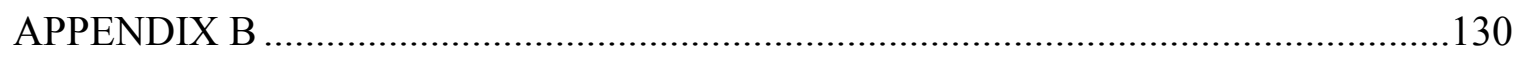

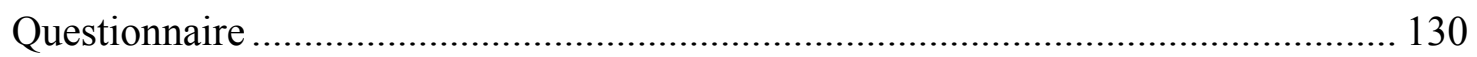

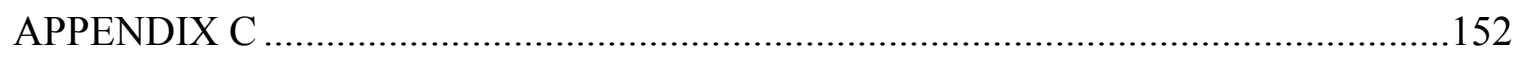

Candidate Open Ended Responses................................................................. 152

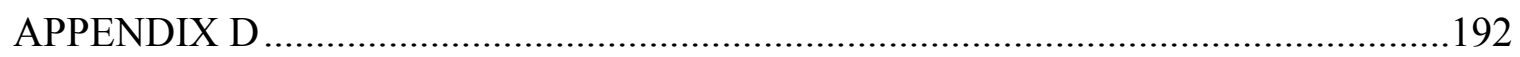

State Staff Open Ended Responses .................................................................... 192

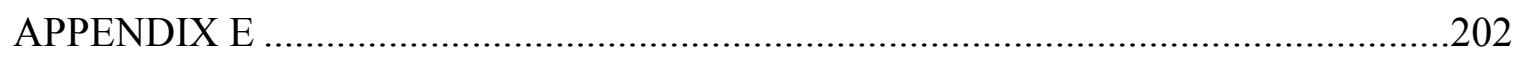

Emails Sent to Candidates and State Staff............................................................. 202 


\section{LIST OF TABLES}

Table Title

Page

1. Process Used to Prepare for National FFA Office ....................................18

2. Process Each State has to Prepare National Officer Candidates ....................19

3. Individuals Candidates Indicate Provided Assistance to Candidates as they Prepared to Run for a National Office.

4. Individuals who State Supervisors Believe Provide Candidates with Assistance During Preparation ...............................................................22

5. Training Activities in which Candidates Participated ................................24

6. Training Activities in which State Supervisors Report Candidates Participation.

7. Interview Situations that Candidates Participated in While Preparing for a National Office.

8. Interview Situations of Candidates as Reported by State Supervisors...........28

9. Information Candidates were Seeking while Interviewing Others ...............29

10. Information State Supervisors Report Candidates were Seeking from Mock Interviews.

11. Interview Skills Candidates Worked to Improve During Preparation .32

12. Interview Skills State Supervisors Reported Candidates Worked to Improve During Preparation ............................................................... 34

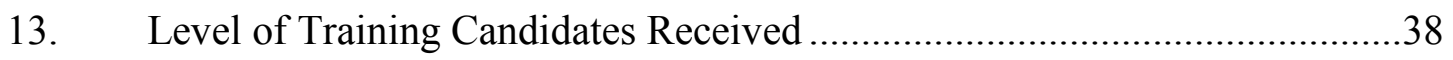

14. Level of Training State Supervisors Believe isProvided to Candidates.........42

15. How Similar Candidates Felt Mock Interview Questions were to Questions Asked During the Selection Process

16. Amount of Workshops Candidates Facilitated Prior to the National Selection Process

17. Number of Workshops State Supervisors Report Candidates Present after Selection as a National Officer Candidate

18. Were Workshops Presented Similar to the Topics Given in the $2^{\text {nd }}$ Round of the National Selection Process? 
19. Competencies that were the Hardest and Easiest in which to Prepare

20. Competencies that were the Hardest and Easiest in which to Prepare

Candidates Mean of on a scale of 1-8 scale with 1being the hardest

21. Competencies Most Exhibited After Training was Complete. Rank 1-

8 with 1 being Exhibited the Most

22. Competencies State Supervisors Believe Candidates Display Most

After Training is Complete.

23. Are the 8 Competencies a Good Basis to use in Selecting a National

FFA Officer.

24. Do States feel Competencies are Good Basis to Select a National

Officer?

25. Topics Candidates Researched During Preparation

26. Topics that State Supervisors felt Candidates Research During

Preparation.

27. Total Number Hours of Research Conducted as well as Approximate

Number of Hours Spent Per Week in Training....

28. Hours State Supervisors say Candidates spend in Training and

Conducting Research

29. Topics Candidates feel are the Most Important to Research after

Having Completed the National Selection Process

30. Topics States feel are the Most Important for Candidates to Research after Having Candidates Compete in the Process

31. Where Candidates Enrolled in Post-Secondary Education During the Semester they ran for a National Office?

32. Did Candidates College or University Provide any Resources to

Assist in Preparation?

33. Post-Secondary Education State Supervisors Indicated Candidates are Enrolled in During the Semester they run for a National Office.

34. Do Colleges or Universities in the State Provide Assistance in

Training Candidates?

35. Type of Internship Participated in by Candidates 
36. Internships State Supervisors say Candidates Participated in during Preparation......

37. Individuals from which Candidates Sought Advice about the Process ..........72

38. Individuals from which Candidates Received Feedback about the National Selection Process

39. Individuals State Supervisors Recommend Candidates Consult with about the National Selection Process

40. Individuals that State Supervisors Indicate Provide Candidates

Feedback on Areas of Improvement

41. Candidates that were a Past Member of the National Nominating

Committee

42. States that had Candidates that were Past Members of the Nominating Committee .75

43. How Well Candidates Felt they were Prepared for the National Selection Process.

44. How Well State SupervisorsFeel their Candidates are Prepared for the Process

45. Length of Time Prior to Selection Process that Candidates were

Selected

46. Length of time Prior to the National Selection Process that Candidates are Selected by States.

47. Candidates Opinions of the Similarity Between State and National Selection Processes.

48. State Supervisors Opinion of the Similarity Between State and National Selection Processes

49. Year in which Candidates Ran for a National Office.

50. Year Candidates Advanced to the Second Round of Selection Process ........82

51. Years State Associations had Candidates for National Office.

52. Years State Supervisors Indicated Candidates Advanced to the

Second Round of the National Selection Process

53. Part of Selection Process that was the Most Challenging for Candidates .... 
54. Part of Process State Supervisors Believe to be the Most Challenging for Candidates.

55. Part of Process that Candidates felt was the Least Challenging..

56. Part of Process State Supervisors Believe to be the Least Challenging for Candidates.

57. Is the Current Selection Process a Good Process for Selecting National Officers and Does it Assist the Nominating Committee Selecting the Best Candidates .95

58. States Supervisors Opinion on Whether or Not the National Selection Process is a Good Process, which Assists the Nominating Committee to Select the Best Candidates 


\section{CHAPTER I}

\section{Introduction}

All national FFA officer candidates have developed extensive leadership skills. One requirement to run for national office is that you must achieve the American FFA degree (National FFA Organization, 2006-2010). Each year this award is only bestowed upon less than one half of $1 \%$ of the membership and requires high quality SAEs as well as leadership and community involvement ( National FFA Organization, 2005, p. 7). Candidates and members who strive to attain the American FFA Degree are active FFA members at the chapter level and develop extensive SAEs often over a six or seven year period before attaining the American FFA Degree ( National FFA Organization, 2005, p.

9).By holding offices, participating in career development events, state and national conventions, and leadership workshops, these select members grow into the organizations strongest leaders. Many organizations offer leadership training to their members, and the FFA is no different. Some of the leadership programs offered by the FFA include; Partners in Active Learning Support, Experiencing Discovery Growth and Excellence, Made for Excellence, Advanced Leadership Development, Washington Leadership Conference and New Century Farmer (National FFA Organization, 2009). Many State Officers attend additional trainings; BLAST OFF, NLCSO, and SPC. Curriculum for many of these focus on topics like successful communication, teamwork, personal growth, individual strengths and weaknesses, overcoming challenges, etc.

National Officer Candidates receive extensive training and preparation on top of the leadership skills they have already developed over their FFA career. The National FFA Officer Selection Process is very competitive; only six members every year will be 
chosen to lead the organization as National Officers (National FFA Organization, 20062010). Every year each state can submit only one candidate to run for an office. National Officer Candidates are evaluated by a student nominating committee through an intensive six day interview process held during the National FFA Convention. Candidates are scored on whether or not they possess eight competencies which include; communication, team player, areas of knowledge, organization, character, passion for success, influence, and critical thinking. Candidates must prepare for a written exam, writing exercises, round robin interviews, stand and deliver, facilitation workshops and group interviews (National FFA Organization, 2006-2010). However, it seems that not all National Officer Candidates appear to receive the same amount of support or training from their states (Hoover \& Atwater, 2005).

\section{Problem Statement}

Each National Officer Candidate comes from a different background and different experiences. In order to understand the various ways in which states assist their National Officer Candidate in preparing for the selection process the profession must examine and understand what is currently being provided by states to the candidates and how the candidates prepare themselves for the process.

\section{Purpose of the Study}

The purpose of this study was to analyze the training and preparation methods used to prepare National FFA Officer Candidates for a National Office. The training and preparation was examined from the perspective of the candidates as well as State 
Supervisors. The results examined methods used to prepare candidates for the National FFA Officer Selection Process.

\section{Objectives of the Study}

The objectives of this study were reflected in the following research questions:

1. What training processes and activities are utilized by candidates to prepare for the National Officer Selection Process?

2. What types of assistance and advice are provided to National Officer Candidates and by whom?

3. What are the perceptions of Candidates and State Supervisors on their state selection process and training techniques as compared to the national process and procedures?

4. What are the National Officer Candidates and State Supervisors perceptions of the eight character competencies used in the National Officer Selection Process?

5. What do National Officer Candidates feel they gained from preparing for and participating in the National Officer Selection process?

6. What are candidates' opinions on the structure of the current process and recommendations for changes to the selection process?

\section{Limitations}

The National Officer Candidates being studied will consist of the candidates who competed for national office between the years of 2006-2010. The study was limited 
because of the challenge to obtain current contact information for all of the candidates that ran for a National Office over the designated time period.

\section{Definitions}

NOCs- NOCs is an abbreviation for National Officer Candidate

NOM COM- National FFA Officer Selection process nominating committee 


\section{CHAPTER II}

\section{Review of Literature}

The National FFA organization is dedicated to making a positive difference in the lives of young people by developing their potential for premier leadership, personal growth and career success through agricultural education (National FFA Organization, 2010). Since its establishment in 1928, the FFA, formerly known as the Future Farmers of America has strived to develop future leaders as, leadership is needed not only in agriculture, but in industry, business, government, education, finance, and international affairs (Moody \& Miller, 1974). From the local, to the state, and on to the national level, FFA members receive leadership training and skill development from a wide array of resources. Some of the most reported by members include but are not limited to; attending leadership conferences, serving as an officer, participating in contests, conducting service projects, membership recruitment activities, chapter activities, nominating committees, and team projects (Horstmeier \& Nall, 2007). All of these examples, in addition to many more undoubtedly aid in the leadership development of our FFA youth.

The National FFA Organization like many other youth organizations is designed not only to present leadership opportunities to the youth but to reward them for their success and achievements. Likewise the organization is based at the local, state, and national level. At each level, the leadership training received by members is intensified. Each state can submit only one candidate to run for an office each year. This candidate prepares weeks in advance for the intensive six day interview process held at the National FFA Convention. Candidates are evaluated by a student nominating committee. They are 
scored on whether or not they possess eight competencies which include; communication, team player, areas of knowledge, organization, character, passion for success, influence, and critical thinking. Candidates must prepare for a written exam, writing exercises, round robin interviews, stand and deliver, facilitation workshops and group interviews (National FFA Organization, 2006-2010).

Hoover \& Atwater (2005) found that, many states prepared their candidates by conducting interview training in the area of FFA issues, as well as writing activities that focused on the sentence structure and composition. Candidates would practice writing letters, requests for funds and responses to member questions. Thirty-one of the states said they used speech development workshops and mock interviews to help prepare for certain aspects of the process and 23 states said they had the candidates conduct business and industry visits. Between the years of 1994 and 2004 nine states have had three or more national officers elected. Of those states $57 \%$ used writing activities, $86 \%$ used FFA current events to prepare for the written exam, $71 \%$ provided print/non print media preparation and $86 \%$ provided knowledge of public school agricultural education. (Hoover \& Atwater, 2005)

The nominating committee members also receive training for this process. Prior to convention conference calls are held between Nominating Committee members, Adult Consultants and National FFA staff to discuss the process and answer questions. Members are also given study materials to help them understand the scoring process, behavioral interviewing and the written exam. Adult consultants are put in place to help guide the nominating committee, as the process for them is very tedious, time consuming and challenging. These members play a very important leadership role for the 
organization as they are selected by the retiring national officers to serve on the committee (Bruce \& Ricketts, 2007).

\section{Summary}

FFA members receive leadership training throughout their years of membership in the organization. Whether it is from attending leadership camps, serving as a chapter officer, performing community service, or meeting with agriculture industries and businesses, lifelong learning and career oriented skills are gained. There is no doubt that as students advance in the organization the training methods received become more relevant and more intense. The leadership development and training received by the National Officer Candidates as well as the National Officer Nominating Committee members is training that should be sought after by young FFA members. This select group of individuals could possibly receive the most one on one leadership training that the organization has to offer. These young adults may also certainly leave this intense process better prepared for their futures than many of their peers. 


\section{CHAPTER III}

\section{Methodology}

\section{Purpose of Study}

The purpose of this study was to analyze the training and preparation methods used to prepare National FFA Officer Candidates for a National Office. The training and preparation was examined from the perspective of the candidates as well as State Supervisors. The results examined methods used to prepare candidates for the National FFA Officer Selection Process.

\section{Objectives of the Study}

The objectives of this study were reflected in the following research questions:

1. What training processes and activities are utilized by candidates to prepare for the National Officer Selection Process?

2. What types of assistance and advice are provided to National Officer Candidates and by whom?

3. What are the perceptions of National Officer Candidates and State Supervisors on their state selection process and training techniques as compared to the national process and procedures?

4. What are the National Officer Candidates and State Supervisors perceptions of the eight character competencies used in the National Officer Selection Process? 
5. What do National Officer Candidates feel they gained from preparing for and participating in the National Officer Selection process?

6. What are candidates' opinions on the structure of the current process and recommendations for changes to the selection process?

\section{Research Design}

The research for this study was descriptive correlational. The study examined procedures used to prepare National FFA Officer Candidates from the perspective of the candidates as well as the perspectives of the State Supervisors. The target population was National FFA Officer Candidates that ran for a National Officer between the years of 2006-2010 $(N=150)$. The accessible population was all National Officer Candidates from 2006-2010 for which there were current email addresses available $(n=94)$. The responses from National Officer Candidates were compared to responses from State Supervisors for Agricultural Education. Equivalent surveys were used with both groups to compare training methods candidates say they have received versus the preparation methods states say candidates have been provided. Sample and selection errors were not relevant as a census was conducted and these individuals are the only ones who have the knowledge to complete the instrument. To avoid frame error official lists of past National Officer Candidates were requested from the National FFA, since they could not release their official lists, they contacted the National Officer Candidates from the past five years explaining the study and asking them to contact the researcher. An official list of the State Supervisors for 2011 was used to contact State Supervisors. Measurement error was controlled by making sure that the instrument was valid and reliable. 
Non-response error was evaluated by comparing early and late respondents. Three variables were used to compare the non-response bias. The first variable used the candidate's description of the process used to prepare them for the National Officer Selection Process. A Pearson chi-square test was performed to compare early and late respondents and it was determined to be not significant. The other two variables tested included the total hours of research conducted and the approximate hours spent per week in training preparing for the National Officer Selection Process. An independent T-test was conducted on both instruments and no significant differences were found so generalizations can be made about the entire population.

\section{Population}

The target population for this study was National FFA Officer Candidates from 2006-2010 and State Supervisors for Agricultural Education employed during the spring 2011. A census was conducted of the target population of approximately 150 past National Officer Candidates for the given time period. The researchers were able to obtain 115 email addresses from former candidates from 2006-2010. The email addresses were provided to the researcher from candidates in response to an invitation letter sent by National FFA staff and personal contacts made by the primary researcher. Twenty-one of those emails were no longer current which brought the accessible population to 94 past National Officer Candidates. Sixty-one of the accessible candidates responded to the survey, resulting in a response rate of $65 \%$. Fifty-two State Supervisors for Agricultural Education representing the 50 states and territories were also surveyed. Thirty-four State Supervisors responded to the survey for a response rate of $65.4 \%$. 


\section{Instrumentation}

A questionnaire consisting of a diverse array of questions was developed and compared with Hoover's instrument (Hoover, 2005). There were two separate but comparable instruments; one for past National Officer Candidates and one for State Supervisors of Agricultural Education. The survey began by seeking to answer the questions of what type of process was used to prepare candidates for the selection process, who provided assistance, and what types of activities were used to facilitate preparation.

Participants were asked to identify what types of interview situations candidates participated in, what types of information these candidates were seeking to gather, and what interview skills the candidates worked to improve. Participants were also asked to rank the level of interview training candidates received in given topic areas. The scale was a 1-5 scale where 1 represented no training and 5 represented extensive training. Finally candidates and State Supervisors were asked how closely the questions received during mock interviews related to the actual questions asked in the National Selection Process.

The second section of the survey related to public appearances and instructional workshops. Using open ended questions candidates and State Supervisors were asked to identify the most beneficial and least beneficial public appearances candidates made during preparation. Using a multiple choice question participants were asked to estimate the number of workshops candidates presented after being selected as their states respective candidate. With an open ended question candidates and State Supervisors were asked to list some of the topics candidates presented workshops on and finally with a 
multiple choice question participants were asked to identify how closely the topics presented during preparation corresponded with the topics given in the second round of the selection process.

The next section of the survey consisted of a series of questions which related to the eight character competencies which candidates were selected upon during the national selection process. Using a ranking scale of 1-8 candidates and State Supervisors were asked to rank each competency to determine which competencies were the hardest and the easiest to prepare for. Using the same scale participants were also asked to identify which competencies candidates exhibited the most after training was complete. Finally participants were asked to identify if the eight current character competencies were a good basis to select a National Officer upon.

Following this, the survey presented questions related to research. Candidates and State Supervisors were asked using a multiple choice question to identify the topics that candidates researched during training. After this, using open ended questions participants were asked to share the total hours or research that candidates conduct as well as the approximate amount of hours per week candidates spent in training. To wrap up this section, participants were asked to reflect on the process and share what topics are the most important to research.

At this point in the survey candidates and State Supervisors were asked a variety of questions regarding different resources and activities that may have assisted candidates in preparation. Candidates were asked if they were enrolled in post-secondary education during the fall semester in which they ran for an office. They were also asked if the university or college they attended provided any resources to assist them and if so what 
were some of the resources provided? National Officer Candidates and State Supervisors were then asked if candidates participated in an internship experience as part of their training, and if they consulted with past NOCs, past National Officers or past NOM COM members for additional advice or feedback. During the five year time span studied the guideline was made that members of NOM COM could not run for a National Office, but since some candidates ran prior to this guideline they were asked if they had been a previous member of NOM COM. Participants were asked to express how well they felt candidates were prepared for the selection process and how far in advance prior to the National FFA Convention were these individuals selected as their states candidate. Finally candidates were asked how closely the state selection process mirrored the national selection process.

The final section of the survey related to demographics and candidates personal thoughts about their experience as a National Officer Candidate. Using multiple choice questions candidates were asked what year or years they ran for a national office and what year or years they advanced to the second round of the selection process. Next candidates completed a series of open ended questions which covered, what state they represented, what was the most beneficial skill received from training and what training they may have liked to received that they did not. They were also asked to identify what most prepared them for the process and if there were training techniques that they spent too much time on or too little time on. They were asked to share what skills they expected to gain from the process and which sections of the selection process were the most and least challenging. The final questions of the survey asked candidates if they felt the 
national selection process was a good process that selected the best candidates and after going through the process if they had any suggestions for change.

\section{Reliability}

The reliability of the instrument was established by using the entire data set and the Statistical Package for Social Sciences' (SPSS). The Likert-type items were tested for reliability using the split-half statistic coefficient. The unequal-length Spearman-Brown value was found to be .85 for the National Officer Candidates instrument and .80 for the State Supervisor of Agriculture Education instrument making reliability of the instrument exemplary (Robinson, Shaver, \& Wrightsman, 1991).

\section{Validity}

The instrument was presented to a panel of experts to establish the content and face validity. The panel consisted of Agriculture Education professors from West Virginia University and Penn State University as well as five past National FFA Officer Candidates. Each one of these individuals has had extensive training, or experience with the National FFA organization. The panel concluded that the instrument had content and face validity.

\section{Data Collection Procedures}

Data was collected using an internet survey, located on Zoomerang. Candidates for whom email addresses were, available and State Supervisors for Agricultural Education were emailed an initial cover letter with a link to their respective surveys. 
National FFA agreed to forward the initial email to the list of candidates available to them. Approximately two weeks after initial contact was made follow up emails were sent every two weeks as needed for a six week period. After all efforts were made to contact the entire population of candidates and State Supervisors the results were analyzed and processed using SPSS software. Frequency tables were developed for all of data on both instruments.

\section{Analysis of Data}

Returned questionnaires were retrieved from the online system into an Excel spreadsheet. The data was transferred to the personal computer version of the Statistical Package for the Social Sciences (SPSS). The level of significance was set a priori at $\alpha$ $\leq .05$ for all statistical tests. Descriptive analyses were performed on the data. Frequency tables were used for Likert items.

\section{Use of Findings}

Findings will be used to provide states and the National FFA information on which methods are perceived to be most beneficial in preparing National Officer Candidates. The findings will be beneficial in developing training programs for chapter, state and national officers, as well as general leadership development for interested FFA members. 


\section{CHAPTER IV}

\section{Findings}

\section{Purpose of Study}

The purpose of this study was to analyze the training and preparation methods used to prepare National FFA Officer Candidates for a National Office. The training and preparation was examined from the perspective of the candidates as well as State Supervisors. The results examined methods used to prepare candidates for the National FFA Officer Selection Process.

\section{Specific Objectives}

The objectives of this study were reflected in the following research questions:

1. What training processes and activities are utilized by candidates to prepare for the National Officer Selection Process?

2. What types of assistance and advice are provided to National Officer Candidates and by whom?

3. What are the perceptions of Candidates and State Supervisors on their state selection process and training techniques as compared to the national process and procedures?

4. What are the National Officer Candidates and State Supervisors perceptions of the eight character competencies used in the National Officer Selection Process? 
5. What do National Officer Candidates feel they gained from preparing for and participating in the National Officer Selection process?

6. What are candidates' opinions on the structure of the current process and recommendations for changes to the selection process?

\section{Findings}

\section{Process Used to Prepare National Officer Candidates \\ Candidate Responses}

Candidates were asked to select which preparation method most closely described what they used to prepare for the National FFA Officer Selection Process. Of the 61 candidates who responded $51(83.6 \%)$ of them stated that they developed their own preparation process with assistance from others (see Table 1). Five respondents (8.2\%) stated that there was a structured process available for them to work through and another five $(8.2 \%)$ stated that they developed their own preparation process without assistance from others. None of the respondents indicated they did not have preparation for the process (see Table 1). 
Table 1

Process Used to Prepare for National FFA Office

\begin{tabular}{lll}
\hline & $\mathrm{N}$ & $\%$ \\
\hline $\begin{array}{l}\text { I developed my own process of preparation, } \\
\text { with assistance from others }\end{array}$ & 51 & 83.6 \\
$\begin{array}{l}\text { A structured process was available for me to } \\
\text { work through }\end{array}$ & 5 & 8.2 \\
$\begin{array}{l}\text { I developed my own process of preparation, } \\
\text { with no assistance from others }\end{array}$ & 5 & 8.2 \\
\begin{tabular}{l} 
I did not have preparation for the process \\
\hline
\end{tabular} & 0 & 0.0 \\
\hline
\end{tabular}

\section{State Supervisor Responses}

State FFA Supervisors were asked about the training process their respective states have in place for National Officer Candidates. Of the 34 states that responded eight $(23.5 \%)$ states reported they have a structured process available for candidates to work through, while $24(70.6 \%)$ indicated that the candidate develops their own process of preparation with assistance from others (see Table 2). None of the states reported the candidate developed a process of preparation with no assistance from others and two (5.9\%) states indicated that their candidates did not have preparation for the process (see Table 2). 
Table 2

Process Each State has to Prepare National Officer Candidates

\begin{tabular}{llc}
\hline & $\mathrm{N}$ & $\%$ \\
\hline $\begin{array}{l}\text { A structured process was available to work through } \\
\begin{array}{l}\text { The candidate developed a process of preparation, } \\
\text { with assistance from others }\end{array}\end{array}$ & 24 & 23.5 \\
$\begin{array}{l}\text { The candidate developed a process of preparation, } \\
\text { with no assistance from others }\end{array}$ & 0 & 70.6 \\
\begin{tabular}{l} 
The candidate did not have preparation for the process \\
\hline
\end{tabular} & 2 & 5.9 \\
\hline
\end{tabular}

\section{Assistance that was provided to Candidates}

\section{Candidate Responses}

Candidates were asked to identify who provided them with assistance during their preparation process. Forty-six (75.4\%) said the State Association, 43 (70.5\%) indicated a University or College professor, 24 (39.3\%) reported an FFA Chapter Advisor, while 27 (44.3\%) indicated a personal coach that they selected (see Table 3). Six (9.8\%) of the candidates reported a personal coach that was assigned by the state association, four $(6.6 \%)$ stated that the state association assigned a mentor, six $(9.8 \%)$ responded the State Ag Teacher's Association, and 18 (29.5\%) reported assistance from the FFA Alumni. Twenty (32.8\%) said they received assistance from past nominating committee members, $34(55.7 \%)$ reported past national officers, and $40(65.6 \%)$ indicated assistance from past National Officer Candidates. Only one candidate (1.6\%) stated that no assistance was provided to them (see Table 3). Candidates were also asked to identify what other sources, if any, provided assistance. Other sources reported included: the State FFA 
Foundation, agriculture industry representatives and university career services, parents, State FFA Officers, FFA board of directors, other current National Officer Candidates and any supporters of the FFA. One candidate noted that very little help was received from the state advisor.

Table 3

Individuals Candidates Indicate Provided Assistance to Candidates as they Prepared to Run for a National Office

\begin{tabular}{lcc}
\hline & $\mathrm{N}$ & $\%$ \\
\hline State FFA Association & 46 & 75.4 \\
University or College professor & 43 & 70.5 \\
FFA Chapter Advisor & 24 & 39.3 \\
Personal Coach - selected by you & 27 & 44.3 \\
Personal Coach - assigned by State & 6 & 9.8 \\
Association & 4 & 6.6 \\
State Association assigned mentor & 6 & 9.8 \\
State Ag Teacher's Association & 18 & 29.5 \\
FFA Alumni & 20 & 32.8 \\
Past Nominating Committee members & 34 & 55.7 \\
Past National Officer & 40 & 65.6 \\
Past National Officer Candidate & 1 & \\
No assistance provided & 6.6 & \\
\hline
\end{tabular}




\section{State Supervisor Responses}

When asked to identify who provided candidates with assistance during their preparation $32(94.1 \%)$ State Supervisors indicated the state FFA association, 24 (70.6\%) supervisors indicated a university or college professor, 24(70.6\%) said a chapter FFA advisor and $12(35.3 \%)$ said a personal coach selected by the candidate provided assistance (see Table 4). Four (11.8\%) State Supervisors indicated candidates received assistance from a personal coach assigned by the state, two (5.9\%) reported assistance from an assigned mentor, and nine (26.5\%) indicated the state agriculture teachers association provided assistance. Additionally 14 (41.2\%) State Supervisors said the FFA alumni provides the candidates with assistance, $12(35.3 \%)$ mentioned past nominating committee members, $19(55.9 \%)$ reported past national officers and $23(67.6 \%)$ responded that past National Officer Candidates assist candidates in their preparation (see Table 4). 
Table 4

Individuals who State Supervisors Believe Provide Candidates with Assistance During Preparation

\begin{tabular}{lcc}
\hline & $\mathrm{N}$ & $\%$ \\
\hline State FFA Association & 32 & 94.1 \\
University or College Professor & 24 & 70.6 \\
FFA Chapter Advisor & 24 & 70.6 \\
Personal Coach - selected by you & 12 & 35.3 \\
Personal Coach - assigned by State & 4 & 11.8 \\
Association & 2 & 5.9 \\
State Association Assigned Mentor & 9 & 26.5 \\
State Ag Teachers Association & 14 & 41.2 \\
FFA Alumni & 12 & 35.3 \\
Past Nominating Committee Members & 19 & 55.9 \\
Past National Officer & 23 & 67.6 \\
Past National Officer Candidate & & \\
\hline
\end{tabular}

\section{Training Activities in which Candidates Participated}

\section{Candidate Responses}

Candidates were asked to identify some of the training activities in which they participated. Fifty-six (91.8\%) of the candidates had participated in mock interviews, 45 (73.8\%) candidates had interviews with key agriculture leaders, 43 (70.5\%) candidates had made public appearances, and $50(80 \%)$ reported they had made presentations (see 
Table 5). Fifty-three (86.9\%) respondents indicated that they planned and coordinated workshops, while $50(82 \%)$ actually taught workshops. Forty $(65.6 \%)$ had assistance with the development of personal competencies, 46 (75.4\%) conducted research to improve their knowledge base, $53(86.9 \%)$ received pointers on improving interview and presentation skills and 32 (52.5\%) improved writing skills through the use of practice exercises. Other training activities that were listed included keeping a journal about the process and past experiences that taught life lessons, as well as being given past materials from previous state candidates, while some attended trainings hosted by past National Officer Candidates (see Table 5).

\section{State Supervisor Responses}

Supervisors were asked what types of training activities candidates from their state participated in during their preparation. Twenty-nine (85.3\%) supervisors reported their candidates used mock interviews, $31(91.2 \%)$ reported interviews with key agriculture leaders, $23(67.6 \%)$ reported participation in public appearances, and 28 $(82.4 \%)$ State Supervisors reported candidates gave presentations to enhance presentation skills (see Table 6). Twenty-nine State Supervisors (85.3\%) reported their candidates planned, coordinated, and taught workshops, 19 (55.9\%) said their candidates received assistance in the development of personal competencies and $21(61.8 \%)$ indicated that their candidates conducted research to improve their knowledge base. Twenty-seven (79.4\%) states responded that candidates received pointers on improving interview and presentation skills, and 17 (50\%) reported their candidates improved writing skills through the use of practice exercises (see Table 6). One state supervisor reported they did 
not have full information about what activities candidates participated in because candidate preparation in that state is self-directed.

Table 5

Training Activities in which Candidates Participated

\begin{tabular}{lcc}
\hline & $\mathrm{N}$ & $\%$ \\
\hline Participated in "mock" interviews & 56 & 91.8 \\
$\begin{array}{l}\text { Interviews with key Ag leaders } \\
\text { Public appearances (greetings or report) }\end{array}$ & 45 & 73.8 \\
$\begin{array}{l}\text { Presentations to enhance presentation skills } \\
\text { Planned and coordinated workshops }\end{array}$ & 50 & 70.5 \\
$\begin{array}{l}\text { Taught workshops } \\
\text { Assistance in the development of personal } \\
\text { competencies }\end{array}$ & 53 & 82.0 \\
$\begin{array}{l}\text { Conducted research to improve knowledge } \\
\text { base }\end{array}$ & 50 & 82.0 \\
$\begin{array}{l}\text { Pointers on improving interview and } \\
\text { presentation skills }\end{array}$ & 40 & 65.6 \\
$\begin{array}{l}\text { Improved writing skills through the use of } \\
\text { practice exercises }\end{array}$ & 32 & 76.9 \\
\hline
\end{tabular}


Table 6

Training Activities in which State Supervisors Report Candidates Participation

\begin{tabular}{lcc}
\hline & $\mathrm{N}$ & $\%$ \\
\hline Participated in "mock" interviews & 29 & 85.3 \\
$\begin{array}{l}\text { Interviews with key Ag leaders } \\
\text { Public appearances (greetings or report) }\end{array}$ & 31 & 91.2 \\
$\begin{array}{l}\text { Presentations to enhance presentation skills } \\
\text { Planned and coordinated workshops }\end{array}$ & 28 & 87.6 \\
$\begin{array}{l}\text { Taught workshops } \\
\text { Assistance in the development of personal } \\
\text { competencies }\end{array}$ & 29 & 85.3 \\
$\begin{array}{l}\text { Conducted research to improve knowledge } \\
\text { base }\end{array}$ & 29 & 85.3 \\
$\begin{array}{l}\text { Pointers on improving interview and } \\
\text { presentation skills }\end{array}$ & 21 & 55.9 \\
$\begin{array}{l}\text { Improved writing skills through the use of } \\
\text { practice exercises }\end{array}$ & 27 & 61.8 \\
\hline
\end{tabular}

\section{Interview situations in which Candidates Participate}

\section{Candidate Responses}

Candidates were asked to identify what interview situations they participated.

Thirty-three (54.1\%) reported they had participated in interviews with food, agriculture, and natural resource specialists, 34 (55.7\%) reported interviewing with past national officers, 35 (57.4\%) indicated work with past National Officer Candidates, and 20 
(32.8\%) reported they had interviewed with past nominating committee members (see Table 7). Forty-eight (78.7\%) indicated interviewing with fellow FFA members, 44 (72.1\%) reported individuals in ag and non ag business and industry while 30 (49.2\%) reported interviewing with FFA alumni or foundation members. Twenty-nine candidates (47.5\%) reported they interviewed Department of Agriculture staff, eight (13.1\%) mentioned legislatures, 38 (62.3\%) had interviewed personal coaches and 34 (55.7\%) reported they interviewed local individuals involved with agriculture (see Table7). One (1.6\%) individual did not participate in any mock interviews. Candidates listed other individuals they met with, which included agriculture teachers, college professors, state Farm Bureau members, Department of Education staff, FFA sponsors and international visitors in the US Department of State-Sponsored Programs (see Appendix C).

\section{State Supervisor Responses}

State Supervisors were asked to identify interview situations that they knew their National Officer Candidates participated in during preparation. Twenty-two (64.7\%) State Supervisors indicate that their candidates interview with food, agriculture and natural resource specialists, 18 (52.9\%) report interviews with past national officers, 21 (61.8\%) indicated past National Officer Candidates, and 12 (35.3\%) reported past nominating committee members (see Table 8). Nineteen (55.9\%) State Supervisors reported that candidates interviewed with fellow FFA members, while $26(76.5 \%)$ reported candidates interview with individuals involved with agriculture and nonagriculture related business and industry. Twenty-two (64.7\%) State Supervisors reported candidates interviewed with FFA alumni or foundation members and state or federal 
Department of Agriculture staff. Nine (26.5\%) supervisors reported candidates interviewed with legislators and 16 (47.1\%) indicated candidates interviewed with personal coaches and local individuals involved with agriculture (see Table 8). One state supervisor commented that who their candidates interview with changes every year.

Table 7

Interview Situations that Candidates Participated in While Preparing for a National Office

\begin{tabular}{|c|c|c|}
\hline & $\mathrm{N}$ & $\%$ \\
\hline \multicolumn{3}{|l|}{ Food, Agriculture \& Natural Resource } \\
\hline Specialists & 33 & 54.1 \\
\hline Past National Officers & 34 & 55.7 \\
\hline Past National Officer Candidates & 35 & 57.4 \\
\hline Past Nominating Committee members & 20 & 32.8 \\
\hline Fellow FFA members & 48 & 78.7 \\
\hline $\begin{array}{l}\text { Individuals in business and industry (A } \\
\text { non } \mathrm{Ag} \text { related) }\end{array}$ & 44 & 72.1 \\
\hline FFA Alumni or Foundation members & 30 & 49.2 \\
\hline $\begin{array}{l}\text { Department of Agriculture staff (state o } \\
\text { federal) }\end{array}$ & 29 & 47.5 \\
\hline Legislators & 8 & 13.1 \\
\hline Personal coaches & 38 & 62.3 \\
\hline Local individuals involved with Ag & 34 & 55.7 \\
\hline Did not participate in interviews & 1 & 1.6 \\
\hline
\end{tabular}


Table 8

Interview Situations of Candidates as Reported by State Supervisors

\begin{tabular}{lcc}
\hline & $\mathrm{N}$ & $\%$ \\
\hline $\begin{array}{l}\text { Food, Agriculture \& Natural Resource } \\
\text { Specialists }\end{array}$ & 22 & 64.7 \\
Past National Officers & 18 & 52.9 \\
Past National Officer Candidates & 21 & 61.8 \\
$\begin{array}{l}\text { Past Nominating Committee members } \\
\text { Fellow FFA members }\end{array}$ & 12 & 35.3 \\
$\begin{array}{l}\text { Individuals in business and industry (Ag and } \\
\text { non Ag related) }\end{array}$ & 19 & 55.9 \\
$\begin{array}{l}\text { FFA Alumni or Foundation members } \\
\text { Department of Agriculture staff (state or }\end{array}$ & 26 & 76.5 \\
federal) & 22 & 64.7 \\
Legislators & 16 & 47.1 \\
$\begin{array}{l}\text { Personal coaches } \\
\text { Did not participate in interviews }\end{array}$ & 22 & 6.0 \\
\hline
\end{tabular}

\section{Information that is Being Gathered from Interviews}

\section{Candidate Responses}

Candidates were asked to share what information they were seeking from mock interviews. Forty-one (67.2\%) reported FFA content knowledge and history, seven $(11.5 \%)$ were seeking relevant employment internships and 14 (23\%) reported utilization of print and non-print media sources (see Table 9). Thirty-two (52.5\%) wanted to gather 
information from industry and business, $50(82 \%)$ sought agriculture education knowledge and history and 55 (90.2\%) were seeking knowledge of agriculture issues. Forty-two candidates $(68.9 \%)$ wanted information about the farm bill, 35 (57.4\%) wanted information about communication techniques and $33(54.1 \%)$ were seeking information about leadership. Additionally, 40 (65.6\%) of the candidates wanted information about American education (see Table 9). Three candidates reported other types of information they sought to gather included information about comparative international agriculture and extension systems, specific agriculture issues as well as state agriculture issues, dynamics of agriculture education and interview styles (see Appendix C).

Table 9

Information Candidates were Seeking while Interviewing Others

\begin{tabular}{lcc}
\hline & $\mathrm{N}$ & $\%$ \\
\hline FFA content knowledge-history & 41 & 67.2 \\
Relevant employment internships & 7 & 11.5 \\
Utilization of print-non print media sources & 14 & 23.0 \\
Information from industry-business through & & \\
site visits & 32 & 52.5 \\
Agriculture Education knowledge-history & 50 & 82.0 \\
Knowledge of Agriculture Issues & 55 & 90.2 \\
Knowledge of Farm Bill & 42 & 68.9 \\
Communication Techniques & 35 & 57.4 \\
Leadership & 33 & 54.1 \\
American Education knowledge & 40 & 65.6 \\
\hline
\end{tabular}




\section{State Supervisor Responses}

State Supervisors were asked what information candidates were seeking from their mock interviews, 18 (52.9\%) of the State Supervisors reported FFA content knowledge and history, three (8.8\%) said relevant employment opportunities, $13(38.2 \%)$ said utilization of print-non print media sources, and $22(64.7 \%)$ reported candidates were looking for information from business and industry site visits (see Table 10). Twentyfour $(70.6 \%)$ State Supervisors reported candidates were gathering agriculture education knowledge and history, $28(82.4 \%)$ felt their candidates were gathering information on Agriculture issues and 22 (64.7\%) felt candidates were gathering information about the Farm Bill. Twenty-two (64.7\%) reported their candidates were gathering information about communication techniques, $16(47.1 \%)$ felt candidates were gathering information about leadership and 21(61.8\%) reported candidates wanted information regarding American education knowledge (see Table 10). 
Table 10

Information State Supervisors Report Candidates were Seeking from Mock Interviews

\begin{tabular}{lcc}
\hline & $\mathrm{N}$ & $\%$ \\
\hline FFA content knowledge-history & 18 & 52.9 \\
Relevant employment internships & 3 & 8.8 \\
Utilization of print-non print media sources & 13 & 38.2 \\
$\begin{array}{l}\text { Information from industry-business through } \\
\text { site visits }\end{array}$ & 22 & 64.7 \\
Agriculture Education knowledge-history & 24 & 70.6 \\
Knowledge of Agriculture Issues & 28 & 82.4 \\
Knowledge of Farm Bill & 22 & 64.7 \\
Communication Techniques & 22 & 64.7 \\
Leadership & 16 & 47.1 \\
American Education knowledge & 21 & 61.8 \\
\hline
\end{tabular}

\section{Interview Skills Candidates Worked to Improve During Preparation Candidate Responses}

Candidates were asked to identify what interview skills they worked to improve during preparation. Forty-three (70.5\%) said clear and concise speech, 23 (37.7\%) indicated the use of vocal variety, $22(36.1 \%)$ reported adequate eye contact and 48 (78.7\%) reported impromptu abilities were what they worked to improve during mock interviews (see Table 11). Forty candidates (65.6\%) reported situational adaptation, 30 (49.2\%) focused on relevant gestures, $40(65.6 \%)$ focused on time management and 19 
(31.1\%) sought to improve emergence of group goals. Of the candidates who responded $13(21.3 \%)$ wanted to work on task vs. relationship behaviors, $40(65.6 \%)$ sought to improve conversational ability and $42(68.9 \%)$ sought to improve memory and retention skills. Thirty-one (50.8\%) of candidates sought to improve language use, 37 (60.7\%) wanted to improve reading the audience, and 48 (78.7\%) hoped to improve the ability to organize thoughts. Additionally, 15 (24.6\%) candidates worked to improve rules governing interaction, $32(52.5 \%)$ worked on creativity while $26(42.6 \%)$ sought to create a personal vision (see Table 11).

Table 11

Interview Skills Candidates Worked to Improve During Preparation

\begin{tabular}{lll}
\hline & $\mathrm{N}$ & $\%$ \\
\hline Clear and concise speech & 43 & 70.5 \\
Use of vocal variety & 23 & 37.7 \\
Adequate eye contact & 22 & 36.1 \\
Impromptu abilities & 48 & 78.7 \\
Situational adaptation & 40 & 65.6 \\
Relevant gestures & 30 & 49.2 \\
Time management & 40 & 65.6 \\
Emergence of group roles & 19 & 31.1 \\
Task vs. Relationship behaviors & 13 & 21.3 \\
Conversational ability & 40 & 65.6 \\
Memory-retention skills & 42 & 68.9 \\
\hline
\end{tabular}


Table 11 (continued)

Interview Skills Candidates Worked to Improve During Preparation

\begin{tabular}{lll}
\hline & $\mathrm{N}$ & $\%$ \\
\hline Appropriate language use & 31 & 50.8 \\
Reading your audience & 37 & 60.7 \\
Ability to organize thoughts & 48 & 78.7 \\
Rules governing interaction & 15 & 24.6 \\
Creativity & 32 & 52.5 \\
Personal Vision & 26 & 42.6 \\
\hline
\end{tabular}

\section{State Supervisor Responses}

State Supervisors were asked to identify the skills they thought most of their candidates were working to improve during preparation. Twenty-two (64.7\%) reported candidates were working on clear and concise speech. Sixteen (47.1\%) supervisors reported candidates worked to improve the use of vocal variety, $17(50 \%)$ indicated adequate eye contact, 23 (67.6\%) felt candidates wanted to improve impromptu abilities, while $21(61.8 \%)$ felt candidates worked on improving situational adaptation (see Table 12). Thirteen (38.2\%) supervisors reported candidates worked to improve relevant gestures, $16(47.1 \%)$ believed candidates wanted better time management, and eight $(23.5 \%)$ reported candidates sought to improve the emergence of group roles. Eight (23.5\%) supervisors felt candidates worked to improve task vs. relationship behaviors, while $17(50 \%)$ reported conversational ability, $12(35.3 \%)$ believed candidates wanted to improve memory retention skills, and $16(47.1 \%)$ indicated candidates sought to improve use of appropriate language. Fourteen $(41.2 \%)$ supervisors reported candidates sought to 
improve skills on how to read an audience, while 22 (64.7\%) felt they worked on the ability to organize thoughts. While seven $(20.6 \%)$ supervisors reported their candidates worked to improve rules governing interaction, $14(41.2 \%)$ noted creativity, and 16 (47.1\%) supervisors indicated candidates wanted to improve their personal vision (see Table 12). Other areas supervisors reported candidates worked to improve depended on the student, and some candidates worked to improve the connection between FFA competencies and any given question or scenario (see Appendix D).

Table 12

Interview Skills State Supervisors Reported Candidates Worked to Improve During Preparation

\begin{tabular}{lcc}
\hline & $\mathrm{N}$ & $\%$ \\
\hline Clear and concise speech & 22 & 64.7 \\
Use of vocal variety & 16 & 47.1 \\
Adequate eye contact & 17 & 50.0 \\
Impromptu abilities & 23 & 67.6 \\
Situational adaptation & 21 & 61.8 \\
Relevant gestures & 13 & 38.2 \\
Time management & 16 & 47.1 \\
Emergence of group roles & 8 & 23.5 \\
Task vs. Relationship behaviors & 8 & 23.5 \\
Conversational ability & 17 & 50.0 \\
Memory-retention skills & 12 & 35.3 \\
\hline
\end{tabular}


Table 12 (Continued)

Interview Skills State Supervisors Reported Candidates Worked to Improve During Preparation

\begin{tabular}{lcc}
\hline & $\mathrm{N}$ & $\%$ \\
\hline Appropriate language use & 16 & 47.1 \\
Reading your audience & 14 & 41.2 \\
Ability to organize thoughts & 22 & 64.7 \\
Rules governing interaction & 7 & 20.6 \\
Creativity & 14 & 41.2 \\
Personal Vision & 16 & 47.1 \\
\hline
\end{tabular}

\section{Rating of the Level of Training Candidates Received in Given Topic Areas Candidate Responses}

Candidates were asked to rate the level of training they received for different topic areas. For the topic of personal skills three candidates $(4.9 \%)$ received no training, $16(26.2 \%)$ received little training, $20(32.8 \%)$ received some training, $15(24.6 \%)$ received moderate training and 7 candidates $(11.5 \%)$ received extensive training (see Table 13). On the topic of agriculture current events and issues one candidate $(1.6 \%)$ received no training, seven $(11.5 \%)$ received little training, $11(18 \%)$ received some training, $28(45.9 \%)$ received moderate training and $14(23 \%)$ received extensive training. In the area of group discussion and interaction six candidates or $9.8 \%$ received no training, $15(24.6 \%)$ received little training, $26(42.6 \%)$ received some training, 11 $(18 \%)$ received moderate training and three $(4.9 \%)$ received extensive training. The topic 
of involvement in conducting FFA activities two (3.3\%) candidates had no training, 12 (19.7\%) had little training, 15 (24.6\%) received some training, 22 (36.1) had moderate training and $10(16.4 \%)$ candidates received extensive training. When asked about the topic of American education current events and issues six (9.8) candidates stated they received no training, 12 (19.7) stated little training, 18 (29.5) candidates said they received some training, $14(23 \%)$ said moderate training and $11(18 \%)$ received extensive training (see Table 13). Agriculture education current events and issues was another topic in which two candidates $(3.3 \%)$ received no training in the area, $10(16.4 \%)$ of the candidates received little training, $14(23 \%)$ received some training, 18 (29.5\%) received a moderate level of training, and $17(27.9 \%)$ received extensive training. Candidates were also asked about FFA current events and issues. Of the candidates that responded all $(100 \%)$ of them received some training in this topic area. Ten of the candidates $(16.7 \%)$ received little training, $14(23.3 \%)$ received some training, 24 (40\%) received moderate training and $12(20 \%)$ of candidates received extensive training. For the topic of career and technical education two (3.3\%) candidates received no training, $11(18 \%)$ candidates received little training, $20(32.8 \%)$ received some training, 19 (31.1\%) received moderate training and nine (14.8\%) candidates received extensive training. When asked about No Child Left Behind legislation, nine (15\%) candidates received no training, 10 (16.7\%) received little training, $23(38.3 \%)$ received some training, 16 (26.7\%) received moderate training, and two (3.3\%) candidates received extensive training (see Table 13). Twentyfour (39.3\%) of candidates received no training in the area of 21 st century, while 23 (19.7\%) received little training, 14 (23\%) received some training, nine (14.8\%) received moderate training and two (3.3\%) candidates received extensive training. Two (3.3\%) 
candidates said they received no training with regard to the national officer selection process, $8(13.1 \%)$ said they received little training, $23(37.7 \%)$ received some training, $17(27.9 \%)$ stated they received moderate training and $11(18 \%)$ candidates said that extensive training was received in this topic area (see Table 13). 
Table 13

Level of Training Candidates Received

\begin{tabular}{|c|c|c|c|c|c|c|c|c|c|c|}
\hline & \multicolumn{2}{|c|}{ No Training } & \multicolumn{2}{|c|}{ Little Training } & \multicolumn{2}{|c|}{ Some Training } & \multicolumn{2}{|c|}{ Moderate Training } & \multicolumn{2}{|c|}{ Extensive Training } \\
\hline & $\mathrm{N}$ & $\%$ & $\mathrm{~N}$ & $\%$ & $\mathrm{~N}$ & $\%$ & $\mathrm{~N}$ & $\%$ & $\mathrm{~N}$ & $\%$ \\
\hline Personal Skills & 3 & 4.9 & 16 & 26.2 & 20 & 32.8 & 15 & 24.6 & 7 & 11.5 \\
\hline $\begin{array}{l}\text { Agriculture current } \\
\text { events and issues }\end{array}$ & 1 & 1.6 & 7 & 11.5 & 11 & 18.0 & 28 & 45.9 & 14 & 23.0 \\
\hline $\begin{array}{l}\text { Group discussion and } \\
\text { interaction }\end{array}$ & 6 & 9.8 & 15 & 24.6 & 26 & 42.6 & 11 & 18.0 & 3 & 4.9 \\
\hline $\begin{array}{l}\text { Involvement in- } \\
\text { conducting FFA } \\
\text { activities }\end{array}$ & 2 & 3.3 & 12 & 19.7 & 15 & 24.6 & 22 & 36.1 & 10 & 16.4 \\
\hline $\begin{array}{l}\text { American Education } \\
\text { current events and } \\
\text { issues }\end{array}$ & 6 & 9.8 & 12 & 19.7 & 18 & 29.5 & 14 & 23.0 & 11 & 18.0 \\
\hline
\end{tabular}


Table 13 (Continued)

Level of Training Candidates Received

\begin{tabular}{|c|c|c|c|c|c|c|c|c|c|c|}
\hline & \multicolumn{2}{|c|}{ No Training } & \multicolumn{2}{|c|}{ Little Training } & \multicolumn{2}{|c|}{ Some Training } & \multicolumn{2}{|c|}{ Moderate Training } & \multicolumn{2}{|c|}{ Extensive Training } \\
\hline & $\mathrm{N}$ & $\%$ & $\mathrm{~N}$ & $\%$ & $\mathrm{~N}$ & $\%$ & $\mathrm{~N}$ & $\%$ & $\mathrm{~N}$ & $\%$ \\
\hline \multicolumn{11}{|l|}{$\begin{array}{l}\text { Agricultural Education } \\
\text { current events and }\end{array}$} \\
\hline issues & 2 & 3.3 & 10 & 16.4 & 14 & 23.0 & 18 & 29.5 & 17 & 27.9 \\
\hline \multicolumn{11}{|l|}{ FFA current events and } \\
\hline issues & 0 & 0.0 & 10 & 16.7 & 14 & 23.3 & 24 & 40.0 & 12 & 20.0 \\
\hline \multicolumn{11}{|l|}{ Career and Technical } \\
\hline Education & 2 & 3.3 & 11 & 18.0 & 20 & 32.8 & 19 & 31.1 & 9 & 14.8 \\
\hline No Child Left Behind & 9 & 15.0 & 10 & 16.7 & 23 & 38.3 & 16 & 26.7 & 2 & 3.3 \\
\hline 21st Century Skills & 24 & 39.3 & 12 & 19.7 & 14 & 23.0 & 9 & 14.8 & 2 & 3.3 \\
\hline \multicolumn{11}{|l|}{ National Officer } \\
\hline Selection Process & 2 & 3.3 & 8 & 13.1 & 23 & 37.7 & 17 & 27.9 & 11 & 18.0 \\
\hline
\end{tabular}




\section{State Supervisor Responses}

State Supervisors were asked to identify the amount of training their candidates received in a variety of topic areas. The choices were no training, little training, some training, moderate training, or extensive training. In the area of personal skills one $(3.4 \%)$ supervisors stated their candidates received no training, five (17.2\%) supervisors indicated their candidates receive little training, 14 (48.3\%) reported their candidates receive some training, four $(13.8 \%)$ indicated their candidates receive moderate training and five (17.2\%) supervisors reported their candidates receive extensive training (see Table 14). In the topic area of agriculture current issues and events one (3.4\%) supervisor reported their candidates receive no training, six (20.7\%) reported their candidates receive some training, $18(62.1 \%)$ supervisors indicated their candidates receive moderate training and four $(13.8 \%)$ reported their candidates receive extensive training. In the area of group discussion and interaction one (3.4\%) supervisor reported their candidates receive no training, four $(13.8 \%)$ indicated their candidates receive little training, 13 $(44.8 \%)$ reported their candidates receive some training, nine $(31 \%)$ felt their candidates receive moderate training, and two (6.9\%) supervisors reported their candidates receive extensive training. When it came to involvement in and conducting FFA activities one (3.4\%) state supervisor reported they did not provide any training, two $(6.9 \%)$ supervisors reported they provided little training, two (20.7\%) supervisors indicated they provide some training, $12(41.4 \%)$ supervisors reported they provided moderate training and eight (27.6\%) supervisors indicated they provide extensive training. On the topic of American education current events and issues one (3.6\%) supervisor reported they provide no training, four (14.3\%) states provided little training, $12(42.9 \%)$ states 
provided some training, $10(35.7 \%)$ states provided moderate training, and one (3.6\%) state provided extensive training (see Table 14). Agriculture education current events and issues had one (3.4\%) state reported providing no training, one (3.4\%) state provides little training, $12(41.4 \%)$ states provide some training, nine $(31 \%)$ states provide moderate training, while six (20.7\%) states provide extensive training. When it came to FFA current events and issues one (3.6\%) state provided no training, one (3.6\%) state provided little training, six (21.4\%) states provided some training, 15 (53.6\%) provided moderate training and five (17.9\%) states provided extensive training. On the topic of career and technical education had two $(6.9 \%)$ states provided no training, three $(10.3 \%)$ states provided little training, $13(44.8 \%)$ states provided some training, eight (27.6\%) states provided moderate training, and three (10.3\%) states provided extensive training (see Table 14). On the topic of No Child Left Behind, four (14.3\%) states provided no training, eight (28.6\%) provided little training, $10(35.7 \%)$ provided some training, five (17.9\%) provided moderate training, and one (3.6\%) provided extensive training. Four (13.8\%) states provided no training with regard to $21^{\text {st }}$ century learning skills, six $(20.7 \%)$ states provided little training, nine (31\%) states provided some training, and nine (31\%) states provided moderate training, while one (3.4\%) state provided extensive training. Training about the national officer selection process was not provided in two $(6.9 \%)$ states, two (6.9\%) states provided little training, $10(34.5 \%)$ states provided some training, seven (24.1\%) states provided moderate training and eight (27.6\%) states provided extensive training on the national officer selection process (see Table 14). 
Table 14

Level of Training State Supervisors Believe is Provided to Candidates

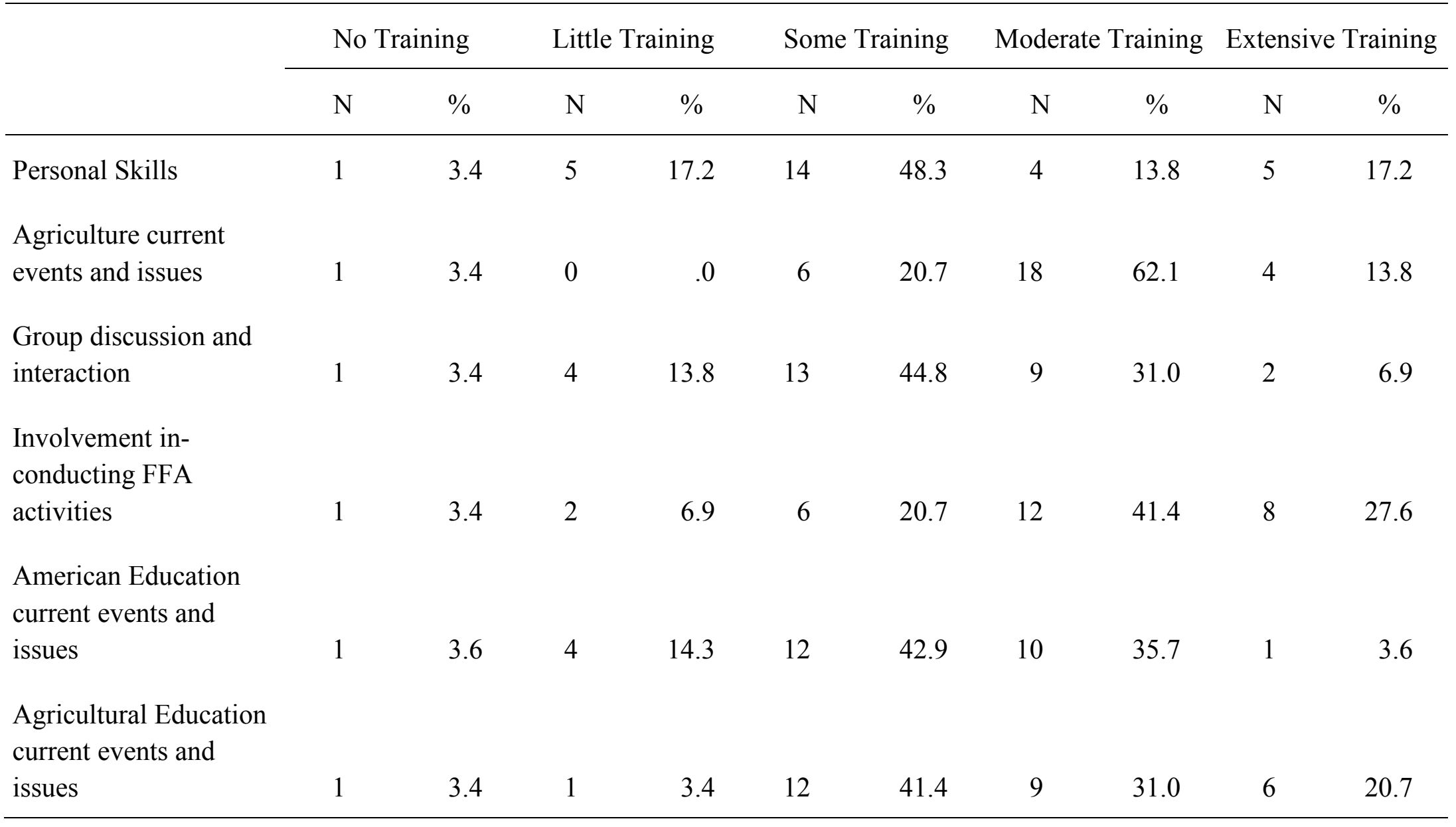


Table 14 (Continued)

Level of Training State Supervisors Believe is Provided to Candidates

\begin{tabular}{|c|c|c|c|c|c|c|c|c|c|c|}
\hline & \multicolumn{2}{|c|}{ No Training } & \multicolumn{2}{|c|}{ Little Training } & \multicolumn{2}{|c|}{ Some Training } & \multicolumn{2}{|c|}{ Moderate Training } & \multicolumn{2}{|c|}{ Extensive Training } \\
\hline & $\mathrm{N}$ & $\%$ & $\mathrm{~N}$ & $\%$ & $\mathrm{~N}$ & $\%$ & $\mathrm{~N}$ & $\%$ & $\mathrm{~N}$ & $\%$ \\
\hline $\begin{array}{l}\text { FFA current events and } \\
\text { issues }\end{array}$ & 1 & 3.6 & 1 & 3.6 & 6 & 21.4 & 15 & 53.6 & 5 & 17.9 \\
\hline Career and Technical & & & & & & & & & & \\
\hline Education & 2 & 6.9 & 3 & 10.3 & 13 & 44.8 & 8 & 27.6 & 3 & 10.3 \\
\hline No Child Left Behind & 4 & 14.3 & 8 & 28.6 & 10 & 35.7 & 5 & 17.9 & 1 & 3.6 \\
\hline 21st Century Skills & 4 & 13.8 & 6 & 20.7 & 9 & 31.0 & 9 & 31.0 & 1 & 3.4 \\
\hline National Officer & & & & & & & & & & \\
\hline Selection Process & 2 & 6.9 & 2 & 6.9 & 10 & 34.5 & 7 & 24.1 & 8 & 27.6 \\
\hline
\end{tabular}




\section{How Closely Mock Interview Questions Relate to Interview Questions asked During the National Selection Process}

\section{Candidate Responses}

Candidates were asked to share how closely they believed the questions they were asked in mock interviews related to the actual interview questions they were asked during the National Officer Selection process. None (100\%) of the candidates reported that the questions asked were exactly the same in both situations. Twenty-four (40.7\%) candidates felt that the questions were very similar, and $26(44.1 \%)$ candidates said that the questions were close. Seven $(11.9 \%)$ candidates felt that the questions between the two situations were not at all similar, and two (3.4\%) candidates said they did not participate in mock interviews (see Table 15).

\section{Table 15}

How Similar Candidates Felt Mock Interview Questions were to Questions Asked During the Selection Process

\begin{tabular}{lcc}
\hline & $\mathrm{N}$ & $\%$ \\
\hline Exactly the same & 0 & 0.0 \\
Very similar & 24 & 40.7 \\
Close & 26 & 44.1 \\
Not at all & 7 & 11.9 \\
Did not do mock interviews & 2 & 3.4 \\
\hline
\end{tabular}




\section{Public Appearances that were the Most Beneficial}

\section{Candidate Responses}

In an open ended question candidates were asked to list the top three public appearances that they felt were the most beneficial in preparing them to run for a national office. There were a wide array of answers given; responses were sorted and similar responses were grouped together. Eighteen candidates responded that chapter visits, local chapter activities such as high school workshops, banquets, fundraisers and other local FFA events were most beneficial. Seventeen candidates reported that FFA member workshops, camps and recruitment activities were beneficial public appearances to make. While 12 candidates reported that presenting at State FFA conventions, leadership conferences and other state FFA functions were of benefit to their training. Eleven candidates stated that public appearances such as presentations, workshops, and attending meetings with agriculture business and industry leaders were beneficial. Eight candidates reported that they had met with government agencies, public officials or attended political events in which they made presentations or had discussions with these individuals which were beneficial to them. Seven candidates stated that public appearances made through college visits with professors and students assisted in their preparation. Five candidates reported they gave presentations at FFA alumni and foundation events meetings and conferences, while four lead presentations and speeches to State Department of Education staff as well as to local boards of education that were not aware of the benefits of FFA and agriculture education. Three candidates felt that mock interviews in general and impromptu speaking events were a great help, and two reported public appearances with Farm Bureaus and civic groups to be beneficial. A few 
candidates made very unique public appearances that they felt were a great benefit which included a State Fair, Agriculture field day, TV \& radio spots, and a presentation at a teach agriculture orientation class (see Appendix C).

\section{State Supervisors Responses}

In an open ended question State Supervisors were asked to identify what types of public appearances they felt were the most beneficial for their candidates to make. Eleven supervisors felt that having their candidates present workshops to FFA members, or at FFA functions were the most beneficial. Nine State Supervisors reported delivering keynote speeches to outside groups, students and business leaders was beneficial while five supervisors reported meetings and interaction with agriculture and non-agriculture business and industry leaders were beneficial to their candidates. Three State Supervisors felt having their candidates work with representatives from government agencies, or political officials were very beneficial. Two states reported working with sponsors, key stakeholders, experienced teachers, and interviews proved to be beneficial public appearances for their candidates. Other recommended appearances included, meeting with a national officer from the past five years, interaction with college level agriculture students, small group discussions, appearances with the media and a greenhand conference all were reported to have been beneficial public appearances (see Appendix D). 


\section{Public Appearances made that were the Least Beneficial \\ Candidate Responses}

Candidates were asked to identify public appearances they felt were the least beneficial during their preparation. Sixteen candidates reported that all of the appearances they made were beneficial in some way. Ten candidates reported that events such as agriculture educator meetings, in-services, banquets and other events where they were present but not speaking or presenting were not beneficial. Other examples of public appearances candidates shared that were not very beneficial consisted of phone interviews, practice with college peers, representing FFA at CDE meetings and prepared speeches where there was limited interaction with group members before and/or after the speech (see Appendix C).

\section{State Supervisor Responses}

State Supervisors were asked to identify any of the public appearances they felt were not very beneficial for the candidates. Seven State Supervisors stated that all appearances made can be beneficial to the candidate. Other responses from State Supervisors included, hanging out with members, visiting with a past national officer who was elected more than five years prior to each individual candidate running for an office, meetings with family and friends, simple chapter visits or work with their home chapter, county fairs, very short speeches, and presentations made to groups where the candidate is completely comfortable (see Appendix D). 


\section{Approximate Amount of Workshops Candidates Presented \\ Candidate Responses}

Candidates were asked to identify approximately how many workshops they facilitated prior to the national officer selection process. One candidate (1.8\%) did not facilitate any workshops. Twenty-one candidates $(36.8 \%)$ had facilitated between one and five workshops, while 19 (33.3\%) candidates facilitated between six and 10 workshops. Five candidates $(8.8 \%)$ reported they facilitated 11 to 15 workshops and six $(10.5 \%)$ reported facilitating between 15 and 20 workshops. Five $(8.8 \%)$ of the candidates reported they had conducted more than 20 workshops prior to the National Selection Process (see Table 16).

Table 16 Amount of Workshops Candidates Facilitated Prior to the National Selection Process

\begin{tabular}{lcc}
\hline & $\mathrm{N}$ & $\%$ \\
\hline None & 1 & 1.8 \\
$1-5$ & 21 & 36.8 \\
$6-10$ & 19 & 33.3 \\
$11-15$ & 5 & 8.8 \\
$15-20$ & 6 & 10.5 \\
20 plus & 5 & 8.8 \\
\hline
\end{tabular}




\section{State Supervisor Responses}

State Supervisors were asked to give the approximate number of workshops their candidates present after they are selected as the states National Officer Candidate. Two (6.9\%) State Supervisors reported their candidates do not present any workshops, 14 (48.3\%) reported their candidates present between one and five workshops, and 10 (34.5\%) State Supervisors indicated their candidates present between six and 10 workshops. Two (6.0\%) supervisors reported their candidates present between 11 and 15 workshops prior to the selection process and one (3.4\%) state supervisor said their candidates present more than 20 workshops (see Table 17).

Table 17

Number of Workshops State Supervisors Report Candidates Present after Selection as a National Officer Candidate

\begin{tabular}{lcc}
\hline & $\mathrm{N}$ & $\%$ \\
\hline None & 2 & 6.9 \\
$1-5$ & 14 & 48.3 \\
$6-10$ & 10 & 34.5 \\
$11-15$ & 2 & 6.9 \\
$15-20$ & 0 & .0 \\
20 plus & 1 & 3.4 \\
\hline
\end{tabular}




\section{Topics of Workshops Candidates Presented During Preparation \\ Candidate Responses}

Candidates were asked to identify what workshop topics they presented during their preparation. Twenty-six candidates reported presenting a workshop related to leadership. Fourteen candidates presented workshops related to FFA knowledge, history, involvement and opportunities. Ten candidates presented topics related to agriculture facts and issues as well as agriculture education issues. Ten candidates reported that they presented workshops related to goal setting and developing plans. Nine candidates presented workshops related to teamwork and team building and another nine presented workshops related to chapter officer development. Topics for chapter officer development included officer responsibilities, parliamentary procedure, etiquette, and chapter officer selection processes. Nine candidates presented workshops related to character, with topics ranging from basic character building, finding strengths, values, making good choices, self-worth, and mentoring. Seven candidates presented communication workshops, seven presented workshops related to personal growth and development and seven stated that all of the workshops they presented were recommended by the hot topics given by National FFA. Six candidates conducted workshops about time management and prioritizing and five presented workshops that could be used as agricultural teaching tools with topics such as developing successful programs of activities, resources of the Team Ag Ed Learning Center, National Quality Program Standards and implementing accountability, "New Media" as a chapter resource, and 10 X 15 Agricultural Education Strategic Goal. Four candidates presented workshops on healthy lifestyles and two presented workshops on FFA Alumni in chapters. Two 
candidates presented workshops on building relationships, two on vision and another two on facilitation and teaching techniques. Other workshop topics consisted of advocacy and building awareness, chapter visit curriculum, influence, greenhand involvement, conflict resolution, social media, mission statements, organization, 4-H, civic engagement, middle school involvement, and recordkeeping (see Appendix C).

\section{State Supervisor Responses}

State Supervisors were asked to indicate topics of the workshops candidates presented. Eleven states reported their candidates presented workshops about FFA opportunities, knowledge, recruitment or general activities. Ten states reported candidates presented leadership workshops, five states had candidates that presented workshops related to team building and team work, while four State Supervisors reported that all of the workshops candidates presented were directly related to the hot topics of that particular year. Three State Supervisors reported that candidates presented workshops related to facilitation and workshop techniques, and three supervisors had candidates conduct workshops on goal setting. Two supervisors reported candidate workshops on communication and career development. Other topics reported included: personal mission statements, motivation, attitudes, resources for state officers, taking risks, committee work, chapter visits, general agriculture knowledge, personal development, and building relationships (see Appendix D). 


\section{Similarity Between Workshops Presented During Preparation and Workshop Topics Given During the Selection Process \\ Candidate Responses}

Candidates were asked if the topics of their preparation workshops were similar to the topics given to candidates in the second round of the selection process. Twenty-four of the candidates $(40.7 \%)$ did not advance to the second round of the process however 35 $(59.4 \%)$ of the candidates did advance. Of the 35 candidates who advanced $27(45.8 \%)$ said that the topics of their workshops during training were similar to the topics given during the selection process. Eight (13.6\%) candidates stated that they topics they presented during training were not similar to the topics given in the second round of the process (see Table 18).

Table 18

Were Workshops Presented Similar to the Topics Given in the $2^{\text {nd }}$ Round of the National Selection Process?

\begin{tabular}{lcc}
\hline & N & $\%$ \\
\hline Yes & 27 & 45.8 \\
No & 8 & 13.6 \\
Did not present workshops & 0 & 0.0 \\
Did not advance to the second round & 24 & 40.7 \\
\hline
\end{tabular}




\section{Competencies that were the Most Difficult and Easiest to Prepare for Candidate Responses}

Candidates were asked to think about the current eight competencies and rank them on a scale of one through eight with one being the hardest to prepare for and eight being the easiest the prepare for. These answers were then averaged to determine the ranking for competencies. Candidates felt that the competency of influence was the hardest to prepare for with a mean of $3.43(\mathrm{SD}=1.97)($ see Table 19). This was followed by critical thinking with a mean of $3.62(\mathrm{SD}=1.76)$, and areas of knowledge with a mean of $4.33(\mathrm{SD}=2.8)$. Candidates felt that Team player and Passion for success was in the middle. Team player had a mean of $4.57(\mathrm{SD}=2.16)$ followed by Passion for success with a mean of $4.60(\mathrm{SD}=2.21)$. The next competency was character with a mean of $4.96(\mathrm{SD}=2.56)$ and organization with a mean of $5.18(\mathrm{SD}=1.82)$. The competency that candidates felt was the easiest to prepare for was communication with a mean of 5.42 $(\mathrm{SD}=2.20)$ 
Table 19

Competencies that were the Hardest and Easiest in which to Prepare Mean on a scale of1-8 scale with 1being the hardest

\begin{tabular}{lcccccc}
\hline & \multicolumn{3}{c}{ Hardest to Prepare } & \multicolumn{3}{c}{ Easiest to Prepare } \\
\cline { 2 - 7 } & Rank & $\mathrm{M}$ & $\mathrm{SD}$ & Rank & $\mathrm{M}$ & $\mathrm{SD}$ \\
\hline Influence & 1 & 3.43 & 1.97 & 8 & 5.76 & 1.85 \\
Critical Thinking & 2 & 3.62 & 1.76 & 7 & 5.31 & 1.88 \\
Areas of Knowledge & 3 & 4.33 & 2.80 & 6 & 4.73 & 2.65 \\
Team Player & 4 & 4.57 & 2.16 & 4 & 4.54 & 2.24 \\
Passion for Success & 5 & 4.60 & 2.21 & 4 & 4.54 & 2.18 \\
Character & 6 & 4.96 & 2.56 & 2 & 3.98 & 2.52 \\
Organization & 7 & 5.18 & 1.82 & 3 & 4.05 & 1.90 \\
Communication & 8 & 5.42 & 2.20 & 1 & 2.77 & 1.93 \\
\hline
\end{tabular}

\section{State Supervisor Responses}

State Supervisors were asked to rank the competencies on a 1-8 scales that they felt were the hardest and easiest in which to prepare candidates. Influence was the hardest to prepare for with a mean of $3.36(\mathrm{SD}=1.73)$, critical thinking was second with a mean of $3.50(\mathrm{SD}=1.67)$ and third was character with a mean of $3.95(\mathrm{SD}=2.70)($ see Table 20). Team player fell to the middle where it was perceived to be the fourth hardest to prepare for with a mean of $4.70(\mathrm{SD}=1.63)$ and the third easiest to prepare for with a mean of $4.05(\mathrm{SD}=1.39)$. Passion for success was ranked the fifth hardest $4.81(\mathrm{SD}=$ $2.42)$ and the fifth easiest to prepare for $4.22(\mathrm{SD}=2.76)$. Supervisors felt that 
organization was relatively easy to prepare for as it was ranked with a mean of 4.21 (SD $=2.10)$. The easiest competencies to train for were communication with a mean of 2.84 $(\mathrm{SD}=1.42)$ and areas of knowledge with a mean of $3.95(\mathrm{SD}=2.78)$.

Table 20

Competencies that were the Hardest and Easiest in which to Prepare Candidates Mean of on a scale of 1-8 scale with 1being the hardest

\begin{tabular}{lcccccc}
\hline & Hardest to Prepare for & \multicolumn{5}{c}{ Easiest to Prepare for } \\
& Rank & SD & Mean & Rank & SD & Mean \\
\hline $\begin{array}{l}\text { Influence } \\
\text { Critical Thinking }\end{array}$ & 1 & 1.73 & 3.36 & 8 & 1.60 & 5.81 \\
Character & 3 & 1.67 & 3.50 & 7 & 1.75 & 5.48 \\
Team Player & 4 & 1.63 & 4.70 & 3 & 1.39 & 4.05 \\
$\begin{array}{l}\text { Passion for } \\
\text { Success }\end{array}$ & 5 & 2.42 & 4.81 & 5 & 2.76 & 4.22 \\
Organization & 6 & 1.87 & 4.91 & 4 & 2.10 & 4.21 \\
$\begin{array}{l}\text { Areas of } \\
\text { Knowledge }\end{array}$ & 7 & 2.66 & 5.15 & 2 & 2.78 & 3.95 \\
Communication & 8 & 2.03 & 6.00 & 1 & 1.42 & 2.84 \\
\hline
\end{tabular}

\section{Competencies that were Exhibited the Most After Training was Complete}

\section{Candidate Responses}

Candidates were asked to reflect back on their training and identify which competencies they thought they exhibited the most once training was complete. 
Candidates were asked to rank the competencies from 1-8 with one being the competency they felt they exhibited the most and eight being the competency they felt they exhibited the least. A mean and standard deviation was calculated for each competency. Candidates felt that once training was complete they exhibited character the most with a mean of $2.57(\mathrm{SD}=1.96)($ see Table 21$)$. Communication followed with a mean of $3.80(\mathrm{SD}=$ 2.30) and then Passion for success with a mean of $4.31(\mathrm{SD}=2.17)$. Followed by organization and team player, with organization having a mean of $4.41(\mathrm{SD}=1.96)$ and team player having a mean of $4.96(\mathrm{SD}=2.05)$. Influence followed with a mean of 5 $(\mathrm{SD}=2.06)$ and then areas of knowledge with a mean of $5.10(\mathrm{SD}=2.48)$. The competency that candidates felt they exhibited the least after their training was complete was critical thinking with a mean of $5.40(\mathrm{SD}=2.13)$.

Table 21

Competencies Most Exhibited After Training was Complete. Rank 1-8 with 1 being Exhibited the Most

\begin{tabular}{lcc}
\hline & $\mathrm{M}$ & $\mathrm{SD}$ \\
\hline Communication & 3.80 & 2.30 \\
Team Player & 4.96 & 2.05 \\
Areas of Knowledge & 5.10 & 2.48 \\
Organization & 4.41 & 1.96 \\
Character & 2.57 & 1.96 \\
Passion for Success & 4.31 & 2.17 \\
Influence & 5.00 & 2.06 \\
Critical Thinking & 5.40 & 2.13 \\
\hline
\end{tabular}




\section{State Supervisor Responses}

State Supervisors were asked to evaluate and rank on a scale of 1-8 which of the competencies the candidates display the most once training was completed, with one being the competency displayed the most and eight being the competency displayed to least. Supervisors believe that their candidates display the competency of communication the most with a mean of $3.06(\mathrm{SD}=2.57)$, followed by passion for success with a mean of $3.11(\mathrm{SD}=2.49)$; character with a mean off $4.06(\mathrm{SD}=1.73)$ and area of knowledge with a mean of $4.06(\mathrm{SD}=2.10)$ followed by organization with a mean of $4.23(\mathrm{SD}=$ 1.60). The competencies that states feel candidates exhibit the least after training in this order were critical thinking with a mean of $5.48(\mathrm{SD}=2.40)$, influence with a mean score of $5.40(\mathrm{SD}=1.88)$ and team player with a mean of $4.93(\mathrm{SD}=1.94)($ see Table 22$)$.

Table 22

Competencies State Supervisors Believe Candidates Display Most After Training is Complete.

\begin{tabular}{lcc}
\hline & SD & Mean \\
\hline Communication & 2.57 & 3.06 \\
Team Player & 1.94 & 4.93 \\
Areas of Knowledge & 2.10 & 4.06 \\
Organization & 1.60 & 4.23 \\
Character & 1.73 & 4.06 \\
Passion for Success & 2.49 & 3.11 \\
Influence & 1.88 & 5.40 \\
Critical Thinking & 2.40 & 5.48 \\
\hline
\end{tabular}




\section{Are the Competencies a Good Basis to be Selected Upon? \\ Candidate Responses}

Candidates were asked whether or not they agreed that the eight competencies are a good basis to use in selecting a national officer. Seventeen (30.9) of the responding candidates strongly agreed the eight competencies are a good basis for selecting a national officer, and $26(47.3 \%)$ candidates agree. While nine (16.4\%) candidates disagree, and three (5.5\%) candidates strongly disagree that the eight competencies are a good basis for selecting a national officer (see Table 23).

Table 23

Are the 8 Competencies a Good Basis to use in Selecting a National FFA Officer

\begin{tabular}{lcc}
\hline & $\mathrm{N}$ & $\%$ \\
\hline Strongly Agree & 17 & 30.9 \\
Agree & 26 & 47.3 \\
Disagree & 9 & 16.4 \\
Strongly Disagree & 3 & 5.5 \\
\hline
\end{tabular}

\section{State Supervisor Responses}

State Supervisors were asked if they felt that the eight competencies are a good basis to use in selecting a National Officer. Six (25\%) supervisors indicated they strongly agreed, 15 (62.5\%) agreed, two (8.3\%) supervisors disagree and one (4.2\%) state supervisor strongly disagreed that the eight competencies were a good basis to use in selecting a National Officer (see Table 24). 
Table 24

Do States feel Competencies are Good Basis to Select a National Officer?

\begin{tabular}{lcc}
\hline & $\mathrm{N}$ & $\%$ \\
\hline Strongly Agree & 6 & 25.0 \\
Agree & 15 & 62.5 \\
Disagree & 2 & 8.3 \\
Strongly Disagree & 1 & 4.2 \\
\hline
\end{tabular}

\section{Topics Candidates Researched During Preparation}

\section{Candidate Responses}

Candidates were asked to share the topics they researched during their training and preparation. Fifty candidates (82\%) reported they researched the topic of FFA content knowledge and history, seven (11.5\%) indicated relevant employment internships, 30 (49.2\%) reported utilization of print and non-print media sources, and 34 (55.7\%) indicated they researched information from industry and business through site visits (see Table 25). Fifty-one candidates (83.6\%) reported researching agriculture education knowledge and history, and $50(82 \%)$ researched knowledge of agriculture issues. Forty- two (68.9\%) sought to gain more knowledge on the farm bill, and 40 (65.6\%) researched communication techniques. Of the candidates who responded 41 (67.2\%) reported they researched leadership, and 46 (75.4\%) indicated they researched American education (see Table 25). Other responses included international agriculture and extension systems, personal faith, the selection process, and teaching styles (see Appendix C). 
Table 25

Topics Candidates Researched During Preparation

\begin{tabular}{lcc}
\hline & $\mathrm{N}$ & $\%$ \\
\hline FFA content knowledge-history & 50 & 82.0 \\
Relevant employment internships & 7 & 11.5 \\
Utilization of print-non print media sources & 30 & 49.2 \\
Information from industry-business through & & \\
site visits & 34 & 55.7 \\
Agriculture Education knowledge-history & 51 & 83.6 \\
Knowledge of Agriculture Issues & 50 & 82.0 \\
Knowledge of Farm Bill & 42 & 68.9 \\
Communication Techniques & 40 & 65.6 \\
Leadership & 41 & 67.2 \\
American Education knowledge & 46 & 75.4 \\
\hline
\end{tabular}

\section{State Supervisor Responses}

State Supervisors were asked to identify the topics their candidates researched during their preparation, $22(64.7 \%)$ supervisors reported FFA content knowledge and history. Two (5.9\%) mentioned relevant employment internships, 12 (35.3\%) indicated utilization of print and non-print media sources, 17 (50\%) supervisors reported information from business and industry visits and 22 (64.7\%) State Supervisors said agriculture education knowledge and history (see Table 26). Twenty-two (64.7\%) supervisors also said candidates researched agriculture issues, $20(58.8 \%)$ reported that candidates researched the Farm Bill and 16 (47.1\%) supervisors said candidates 
researched communication techniques. Finally 14 (41.2\%) State Supervisors felt candidates researched leadership, while 17 (50\%) State Supervisors believed their candidates researched American education.

Table 26

Topics that State Supervisors felt Candidates Research During Preparation

\begin{tabular}{lcc}
\hline & $\mathrm{N}$ & $\%$ \\
\hline FFA content knowledge-history & 22 & 64.7 \\
Relevant employment internships & 2 & 5.9 \\
Utilization of print-non print media sources & 12 & 35.3 \\
Information from industry-business through & 17 & 50.0 \\
site visits & 22 & 64.7 \\
Agriculture Education knowledge-history & 22 & 64.7 \\
Knowledge of Agriculture Issues & 20 & 58.8 \\
Knowledge of Farm Bill & 16 & 47.1 \\
Communication Techniques & 14 & 41.2 \\
Leadership & 17 & 50.0 \\
American Education knowledge & 0 & 0.0 \\
Do Not Know & & \\
\hline
\end{tabular}




\section{Total Hours of Research Conducted and Approximate Number of Hours Per Week Spent in Training}

\section{Candidate Responses}

When candidates were asked about how many hours of total research they conducted over the course of their preparation many answers were received. The minimum number of hours spent conducting research was 19 hours with the maximum being 2000 hours. On average candidates spent 210.47 hours $(\mathrm{SD}=334.03)$ conducting research. They were also asked to share the approximate number of hours spent per week in training. This would include any training activity in which the candidate may have participated. The minimum was 2 hours per week and the maximum was 45 hours per week. On average however, candidates spent about 14.12 hours $(\mathrm{SD}=10.74)$ per week in training (see Table 27).

Table 27

Total Number Hours of Research Conducted as well as Approximate Number of Hours Spent Per Week in Training

\begin{tabular}{lcccc}
\hline & Min & Max & SD & M \\
\hline $\begin{array}{l}\text { Total hours of research } \\
\text { conducted during preparation }\end{array}$ & 19 & 2000 & 334.03 & 210.47 \\
$\begin{array}{l}\text { Approximate number of hours } \\
\text { spent per week in training }\end{array}$ & 2 & 45 & 10.74 & 14.12 \\
\hline
\end{tabular}




\section{State Supervisor Responses}

State Supervisors were asked to estimate the total number of hours of research they think their candidates conduct along with the approximate hours per week each candidate spends in training. The average number of hours spent conducting research was $139.72(\mathrm{SD}=155.40)$ with approximately $10.53(\mathrm{SD}=8.99)$ hours spent per week in training (see Table 28).

Table 28

Hours State Supervisors say Candidates spend in Training and Conducting Research

\begin{tabular}{lrc}
\hline & SD & Mean \\
\hline $\begin{array}{l}\text { Total hours of research conducted during } \\
\text { preparation }\end{array}$ & 155.40 & 139.72 \\
$\begin{array}{l}\text { Approximate number of hours spent per week } \\
\text { in training }\end{array}$ & 8.99 & 10.53 \\
\hline
\end{tabular}

\section{Topics Candidates feel are the Most Important to Research after Completing the}

\section{Process}

\section{Candidate Responses}

Candidates were asked to think back and indicate the topics they now feel are the most important to research after the preparation and selection processes have been completed. Forty-four $(72.1 \%)$ candidates reported that FFA content knowledge and history is a topic that should be researched and $8(13.1 \%)$ felt relevant employment internships (see Table 29). Ten candidates (16.4\%) felt utilization of print and non-print media sources should be researched, as well as 25 (41\%) think that information from 
business and industry visits is useful. Forty-three candidates (70.5\%) indicated agriculture education knowledge and history should be researched, 45 (73.8\%) think agriculture issues is a relevant topic to research, and $19(31.1 \%)$ believe the farm bill is also worth researching. Forty $(65.6 \%)$ candidates felt that communication techniques should be studied, and 34 (55.7\%) believed future candidates should research leadership. Lastly 37 (60.7\%) think that researching American education could be an asset. Other answers included researching the psychology of education, the selection process, and knowledge about yourself and your strengths. One candidate stated that "being able to answer questions with personal experiences is very important to the process." Another candidate said that "understanding and manipulating the process is to your advantage.'(see Appendix C).

\section{State Supervisor Responses}

After reflecting back on the training given to candidates, State Supervisors were asked to identify which topics they now feel are the most important for their candidates to research while preparing to run for a national office. Fifteen $(44.1 \%)$ supervisors said FFA content knowledge and history, five (14.7\%) mentioned utilization of print and nonprint media sources, $12(35.3 \%)$ indicated information from business and industry visits, while 20 (58.8\%) State Supervisors reported agriculture education knowledge and history (see Table 30). Twenty-one (61.8\%) State Supervisors mentioned candidates needed to research agricultural issues, $14(41.2 \%)$ believed candidates should research the Farm Bill, 15 (44.1\%) supervisors felt candidates should research communication techniques, $11(32.4 \%)$ states reported leadership and 13 (38.2\%) State Supervisors felt candidates 
should research American education knowledge. One state supervisor reported that it depends on the year and the hot topics listed.

Table 29

Topics Candidates feel are the Most Important to Research after Having Completed the National Selection Process

\begin{tabular}{lcc}
\hline & $\mathrm{N}$ & $\%$ \\
\hline FFA content knowledge-history & 44 & 72.1 \\
Relevant employment internships & 8 & 13.1 \\
Utilization of print-non print media sources & 10 & 16.4 \\
Information from industry-business through & & \\
site visits & 25 & 41.0 \\
Agriculture Education knowledge-history & 43 & 70.5 \\
Knowledge of Agriculture Issues & 45 & 73.8 \\
Knowledge of Farm Bill & 19 & 31.1 \\
Communication Techniques & 40 & 65.6 \\
Leadership & 34 & 55.7 \\
American Education knowledge & 37 & 60.7 \\
\hline
\end{tabular}


Table 30

Topics States feel are the Most Important for Candidates to Research after Having Candidates Compete in the Process

\begin{tabular}{lcc}
\hline & $\mathrm{N}$ & $\%$ \\
\hline FFA content knowledge-history & 15 & 44.1 \\
Relevant employment internships & 0 & 0.0 \\
Utilization of print-non print media sources & 5 & 14.7 \\
Information from industry-business through & 12 & 35.3 \\
site visits & 20 & 58.8 \\
Agriculture Education knowledge-history & 21 & 61.8 \\
Knowledge of Agriculture Issues & 14 & 41.2 \\
Knowledge of Farm Bill & 15 & 44.1 \\
Communication Techniques & 11 & 32.4 \\
Leadership & 13 & 38.2 \\
\hline American Education knowledge & & \\
\hline
\end{tabular}

Post-Secondary Enrollment Status of Candidates and College or University Assistance with Preparation.

\section{Candidate Responses}

When asked about the type of secondary education candidates were enrolled in during the semester in which they ran for a national office, $51(92.7 \%)$ of candidates were enrolled as full time students. Only two candidates (3.6\%) were enrolled as part time students and another two (3.6\%) took the semester off (see Table 31). Of the candidates that were enrolled in postsecondary education, $32(58.2 \%)$ indicated that their college or 
university provided assistance in preparing them to run for a national office. Twentythree $(41.8 \%)$ candidates reported that their respective college or university did not provide assistance in preparing them to run for a national office (see Table 32).

Table 31

Where Candidates Enrolled in Post-Secondary Education During the Semester they ran for a National Office?

\begin{tabular}{lcc}
\hline & $\mathrm{N}$ & $\%$ \\
\hline Part-time student & 2 & 3.6 \\
Full-time student & 51 & 92.7 \\
Never enrolled in post-secondary program & 0 & .0 \\
Took semester off & 2 & 3.6 \\
\hline
\end{tabular}

Table 32

Did Candidates College or University Provide any Resources to Assist in Preparation?

\begin{tabular}{lcc}
\hline & $\mathrm{N}$ & $\%$ \\
\hline Yes & 32 & 58.2 \\
No & 23 & 41.8 \\
\hline
\end{tabular}

\section{State Supervisor Responses}

When asked about the post-secondary status of the candidates, $21(87.5 \%)$ State Supervisors reported that their candidates were full-time students while two $(8.3 \%)$ 
indicated their candidates were part-time students (see Table 33). Only one state supervisor reported that their candidates took the semester off. Of the State Supervisors that responded to this question all of their candidates $(100 \%)$ were enrolled in some sort of secondary education. When asked if any colleges or universities in their state provided assistance in training the candidates $11(45.8 \%)$ of the supervisors reported that these institutions did provide assistance and 13 (54.2\%) supervisors indicated that educational institutions did not provide assistance to the candidates (see Table 34).

Table 33

Post-Secondary Education State Supervisors Indicated Candidates are Enrolled in During the Semester they run for a National Office

\begin{tabular}{lcc}
\hline & $\mathrm{N}$ & $\%$ \\
\hline Part-time student & 2 & 8.3 \\
Full-time student & 21 & 87.5 \\
Never enrolled in post-secondary program & 0 & 0.0 \\
Took semester off & 1 & 4.2 \\
\hline
\end{tabular}

Table 34

Do Colleges or Universities in the State Provide Assistance in Training Candidates?

\begin{tabular}{lcc}
\hline & $\mathrm{N}$ & $\%$ \\
\hline Yes & 11 & 45.8 \\
No & 13 & 54.2 \\
\hline
\end{tabular}




\section{Resources Provided to Candidates by their College or University Candidate Responses}

Candidates were asked to identify resources that may have been provided to them by their college or university during the time of their preparation. Many colleges grant independent study credit to National Officer Candidates during their semester of preparation. Credit ranged from 2-4 credit hours. Many candidates said that they received assistance from professors and /or past National Officer Candidates that helped them with writing skills, interviewing, American education, agriculture education and FFA knowledge, as well as parliamentary procedure and stand and deliver practice. Others also mentioned that schedules were made more flexible to compensate for the National FFA convention, leadership conferences and other training activities. Some professors also provided coaching and financial support to the candidates. Research documents, Power Points, and FFA board minutes were other resources made available to candidates (see Appendix C).

\section{State Supervisor Responses}

Of the states that reported assistance was provided from colleges or universities, most indicated that agriculture education professors provide agriculture education resources and materials. In addition they assisted with conducting mock interviews and setting candidates up with other expert interviews. 


\section{Internships Candidates Participates in During Candidacy \\ Candidate Responses}

When asked whether or not candidates participated in an internship as part of their training, $31(56.4 \%)$ did not participate in an internship. Twenty-four (43.6\%) candidates participated in an internship they arranged on their own, and none of the candidates participated in a state required internship (see Table 35).

Table 35

Type of Internship Participated in by Candidates

\begin{tabular}{lcc}
\hline & $\mathrm{N}$ & $\%$ \\
\hline $\begin{array}{lc}\text { Did not participate in an internship } \\
\text { Participated in a State required internship }\end{array}$ & 31 & 56.4 \\
$\begin{array}{l}\text { Participated in an internship I arranged on my } \\
\text { own }\end{array}$ & 24 & 0.0 \\
\hline
\end{tabular}

\section{State Supervisor Responses}

When asked if any of their candidates participated in internships during the time of preparation, $16(69.6 \%)$ State Supervisors reported their candidates did not participate in an internship. Six (26.1\%) indicated candidates participated in internships they arranged on their own and one (4.3\%) supervisor had no way of knowing (see Table 36 ). 
Table 36

Internships State Supervisors say Candidates Participated in during Preparation

\begin{tabular}{lcc}
\hline & $\mathrm{N}$ & $\%$ \\
\hline Did not participate in an internship & 16 & 69.6 \\
$\begin{array}{l}\text { Participated in a State required internship } \\
\begin{array}{l}\text { Participated in an internship I arranged on my } \\
\text { own }\end{array}\end{array}$ & 0 & 0.0 \\
Have no way of knowing & 6 & 26.1 \\
\hline
\end{tabular}

Who Candidates Consulted with for Advice or Feedback about the Selection Process Candidate Responses

Candidates were asked to identify if they consulted with National Officer Candidates, National Officers, or nominating committee members, for advice about the process, and feedback. Fifty ( $82 \%$ ) candidates consulted with National Officer Candidates past or present, $40(65.6 \%)$ consulted with National Officers past or present, and $26(42.6 \%)$ consulted with nominating committee members past or present for advice about the selection process (see Table 37). When it came to receiving feedback on areas of improvement, all of the individuals that gave advice about the process also gave feedback to the candidates (see Table 38). Other individuals that candidates sought advice and received feedback from included past and present board of director members, national and state staff, and other past or present state officers (see Appendix C). 
Table 37

Individuals from which Candidates Sought Advice about the Process

\begin{tabular}{lcc}
\hline & $\mathrm{N}$ & $\%$ \\
\hline National Officer Candidates (past or present) & 50 & 82.0 \\
$\begin{array}{l}\text { National Officers (past or present) } \\
\begin{array}{l}\text { Nominating Committee members (past or } \\
\text { present) }\end{array}\end{array}$ & 40 & 65.6 \\
\hline
\end{tabular}

Table 38

Individuals from which Candidates Received Feedback about the National Selection

Process

\begin{tabular}{lcc}
\hline & $\mathrm{N}$ & $\%$ \\
\hline National Officer Candidates (past or present) & 50 & 82.0 \\
$\begin{array}{l}\text { National Officers (past or present) } \\
\begin{array}{l}\text { Nominating Committee members (past or } \\
\text { present) }\end{array}\end{array}$ & 40 & 65.6 \\
\hline
\end{tabular}

\section{State Supervisor Responses}

State Supervisors were asked to share who they recommend their candidates consult with about the national selection process. Twenty (58.8\%) supervisors reported past or present National Officer Candidates, 17 (50\%) supervisors indicated past or present National Officers, and $13(38.2 \%)$ supervisors recommended past or present 
Nominating Committee members (see Table 39). Other responses included individuals from the agriculture industry, professors and professional associations. State Supervisors were also asked to identify which individuals provide candidates with feedback on areas of improvement and $16(47.1 \%)$ indicated past or present National Officer Candidates. Fifteen $(44.1 \%)$ supervisors indicated past or present National Officers, nine $(26.5 \%)$ mentioned past or present nominating committee members and four (11.8\%) State Supervisors had no way of knowing (see Table 40).

Table 39

Individuals State Supervisors Recommend Candidates Consult with about the National Selection Process

\begin{tabular}{lcc}
\hline & $\mathrm{N}$ & $\%$ \\
\hline $\begin{array}{l}\text { National Officer Candidates (past or present) } \\
\text { National Officers (past or present) }\end{array}$ & 20 & 58.8 \\
$\begin{array}{l}\text { Nominating Committee members (past or } \\
\text { present) }\end{array}$ & 17 & 50.0 \\
\hline
\end{tabular}


Table 40

Individuals that State Supervisors Indicate Provide Candidates Feedback on Areas of Improvement

\begin{tabular}{lcc}
\hline & $\mathrm{N}$ & $\%$ \\
\hline National Officer Candidates (past or present) & 16 & 47.1 \\
$\begin{array}{l}\text { National Officers (past or present) } \\
\begin{array}{l}\text { Nominating Committee members (past or } \\
\text { present) }\end{array}\end{array}$ & 15 & 44.1 \\
\begin{tabular}{l} 
Have no way of knowing \\
\hline
\end{tabular} & 4 & 26.5 \\
\hline
\end{tabular}

\section{Candidates that were Past Nominating Committee Members \\ Candidate Responses}

Candidates were asked if they served as a member of the nominating committee prior to running for a national office. This question was asked because during the time period studied some candidates could have been previous members of the nominating committee. Effective after October 1, 2006 any FFA member serving on the National FFA Nominating Committee became ineligible to run for a National FFA Office (National FFA Organization, 2006-2010). Of the candidates who responded none of them had served as a member of the nominating committee (see Table 41). 
Table 41

Candidates that were a Past Member of the National Nominating Committee

\begin{tabular}{lcc}
\hline & $\mathrm{N}$ & $\%$ \\
\hline Yes & 0 & 0.0 \\
No & 55 & 100.0 \\
\hline
\end{tabular}

\section{State Supervisor Responses}

Of the State Supervisors that responded 22 (95.7\%) supervisors reported that their candidates were not members of the National Nominating Committee prior to running for a National Office. Only one (4.3\%) supervisor indicated they had candidates that were a member of the National Nominating Committee (see Table 42).

Table 42

States that had Candidates that were Past Members of the Nominating Committee

\begin{tabular}{lcc}
\hline & $\mathrm{N}$ & $\%$ \\
\hline Yes & 1 & 4.3 \\
No & 22 & 95.7 \\
\hline
\end{tabular}




\section{Rating of How Well Candidates Feel they were Prepared for the Process after Looking Back and Reflecting \\ Candidate Responses}

Candidates were asked to rate how well they felt they were prepared for the national selection process. Seven $(12.7 \%)$ felt they were poorly prepared, eight $(14.5 \%)$ thought they were fairly prepared and $13(23.6 \%)$ believed to be prepared on an average level. Another $13(23.6 \%)$ rated their preparation as good and $14(25.5 \%)$ believed their preparation was excellent (see Table 43).

Table 43

How Well Candidates Felt they were Prepared for the National Selection Process

\begin{tabular}{lcc}
\hline & $\mathrm{N}$ & $\%$ \\
\hline Poor & 7 & 12.7 \\
Fair & 8 & 14.5 \\
Average & 13 & 23.6 \\
Good & 13 & 23.6 \\
Excellent & 14 & 25.5 \\
\hline
\end{tabular}

\section{State Supervisor Responses}

When asked how prepared they felt their candidates were for the national selection process, One (4.3\%) state supervisor indicated their candidate was poorly prepared, two $(8.7 \%)$ supervisors reported their candidates preparation as fair, three $(13 \%)$ felt their candidates were prepared on an average level, $13(56.5 \%)$ State 
Supervisors reported their candidates' preparation as good and four (17.4\%) State Supervisors believed their candidates were excellently prepared (see Table 44).

Table 44

How Well State Supervisors Feel their Candidates are Prepared for the Process

\begin{tabular}{lcc}
\hline & $\mathrm{N}$ & $\%$ \\
\hline Poor & 1 & 4.3 \\
Fair & 2 & 8.7 \\
Average & 3 & 13.0 \\
Good & 13 & 56.5 \\
Excellent & 4 & 17.4 \\
\hline
\end{tabular}

\section{Length of Time Between when Candidates were Selected to Represent their State and the National Selection Process}

\section{Candidate Responses}

When asked how far in advance candidates were selected as their states respective candidate, $44(80 \%)$ said they were selected between four and seven months in advance. One $(1.8 \%)$ candidate was selected more than 18 months in advance, one $(1.8 \%)$ candidate was selected 12 to 15 months in advance and four (7.3\%) candidates were selected eight to 11 months in advance. Five candidates $(9.1 \%)$ were selected less than three months in advance (see Table 45). 
Table 45

Length of Time Prior to Selection Process that Candidates were Selected

\begin{tabular}{lcc}
\hline & $\mathrm{N}$ & $\%$ \\
\hline More than 18 months in advance & 1 & 1.8 \\
$16-18$ months in advance & 0 & .0 \\
$12-15$ months in advance & 1 & 1.8 \\
$8-11$ months in advance & 4 & 7.3 \\
$4-7$ months in advance & 44 & 80.0 \\
3 months or less in advance & 5 & 9.1 \\
\hline
\end{tabular}

\section{State Supervisor Responses}

The length of time prior to the National Selection Process that candidates are selected varies from state to state. One (4.3\%) state selects their candidates between 16 and 18 months in advance, three (13\%) states select candidates eight to 11 months in advance, $16(69.6 \%)$ states select candidates four to seven months in advance, and three (13\%)states select their candidates less than three months in advance (see Table 46). 
Table 46

Length of time Prior to the National Selection Process that Candidates are Selected by States

\begin{tabular}{lcc}
\hline & $\mathrm{N}$ & $\%$ \\
\hline More than 18 months in advance & 0 & 0.0 \\
$16-18$ months in advance & 1 & 4.3 \\
$12-15$ months in advance & 0 & .0 \\
$8-11$ months in advance & 3 & 13.0 \\
$4-7$ months in advance & 16 & 69.6 \\
3 months or less in advance & 3 & 13.0 \\
\hline
\end{tabular}

\section{How Closely State Nominating Committee Processes Mirror the National Nominating Committee Process \\ Candidate Responses}

Candidates were asked to compare their state selection process with the national selection process and identify how similar the two are. Three candidates $(5.5 \%)$ reported that both processes were exactly the same (see Table 47$)$. Thirty-one (56.4\%) candidates indicated that some segments are similar and $16(29.1 \%)$ candidates indicated that the selection processes were not at all similar. One candidate $(1.8 \%)$ was elected by popular vote with a state nominating committee. Of the four candidates $(7.3 \%)$ that indicated their state selection process was not similar to any of the above; two stated they were the only one who was interested in running for an office so there was no selection process, one was selected by a State FFA advisory board, and another stated that when they ran the 
process was not at all similar however now it mirrors the national selection process very closely (see Appendix C).

Table 47

Candidates Opinions of the Similarity Between State and National Selection Processes

\begin{tabular}{lcc}
\hline & $\mathrm{N}$ & $\%$ \\
\hline Exactly the same & 3 & 5.5 \\
Some segments are similar & 31 & 56.4 \\
Not at all similar & 16 & 29.1 \\
$\begin{array}{l}\text { Elected by popular vote without a nominating } \\
\text { committee }\end{array}$ & 1 & 1.8 \\
None of the above, please explain & 4 & 7.3 \\
\hline
\end{tabular}

\section{State Supervisor Responses}

When asked to compare their state selection process with the national selection process, five (21.7\%) State Supervisors indicated that their state selection process was exactly the same as nationals, $13(56.5 \%)$ reported that some of the segments were similar, and four (17.4\%) supervisors indicated their state selection process is not at all similar (see Table 48). One state supervisor reported that their nominating committee is made up of agriculture, education, and FFA leaders with one student. It is a one day process with written assignments and tests happening before the selection, and competency weights are utilized (see Appendix D). 
Table 48

State Supervisors Opinion of the Similarity Between State and National Selection Processes

\begin{tabular}{lcc}
\hline & $\mathrm{N}$ & $\%$ \\
\hline None of the above, please explain & 1 & 4.3 \\
Exactly the same & 5 & 21.7 \\
Some segments are similar & 13 & 56.5 \\
Not at all similar & 4 & 17.4 \\
$\begin{array}{l}\text { Elected by popular vote without a nominating } \\
\text { committee }\end{array}$ & 0 & 0.0 \\
\hline
\end{tabular}

Year or Years Candidates Ran for a National Office and Advanced to the $\mathbf{2}^{\text {nd }}$ Round of the Process

\section{Candidate Responses}

Of the candidates that responded, eight $(13.1 \%)$ ran in $2010,10(16.4 \%)$ ran in 2009, $19(31.1 \%)$ ran in 2008, $20(32.8 \%)$ ran in 2007 and $10(16.4 \%)$ ran in 2006 (see Table 49). Of these former candidates three (4.9\%) advanced to the second round in 2010, five (8.2\%) advanced in 2009 , nine (14.8\%) in 2008, and 2007 , and seven $(11.5 \%)$ advanced in 2006 (see Table 50). 
Table 49

Year in which Candidates Ran for a National Office

\begin{tabular}{lcc}
\hline & $\mathrm{N}$ & $\%$ \\
\hline 2010 & 8 & 13.1 \\
2009 & 10 & 16.4 \\
2008 & 19 & 31.1 \\
2007 & 20 & 32.8 \\
2006 & 10 & 16.4 \\
\hline
\end{tabular}

Table 50

Year Candidates Advanced to the Second Round of Selection Process

\begin{tabular}{lcc}
\hline & $\mathrm{N}$ & $\%$ \\
\hline 2010 & 3 & 4.9 \\
2009 & 5 & 8.2 \\
2008 & 9 & 14.8 \\
2007 & 9 & 14.8 \\
2006 & 7 & 11.5 \\
\hline
\end{tabular}

State Supervisor Responses

State Supervisors were asked what year(s) their state association sent candidates to the national level. Eighteen (52.9\%) of the states had candidates in 2010, $20(58.8 \%)$ states had candidates in 2009, 2008 and 2006, and 17 (50\%) states had candidates in 
2007(see Table 51). Of the state associations that sent candidates $12(35.3 \%)$ of them had candidates advance to the second round of the process in 2010 . Eleven $(32.4 \%)$ had candidates advance in 2009, and 10 (29.4\%) states had candidates advance in 2008, 2007 and 2006 . Three $(8.8 \%)$ states did not have any candidates advance to the second round of the process (see Table 52).

Table 51

Years State Associations had Candidates for National Office

\begin{tabular}{lcc}
\hline & $\mathrm{N}$ & $\%$ \\
\hline 2010 & 18 & 52.9 \\
2009 & 20 & 58.8 \\
2008 & 20 & 58.8 \\
2007 & 17 & 50.0 \\
2006 & 20 & 58.8 \\
\hline
\end{tabular}


Table 52

Years State Supervisors Indicated Candidates Advanced to the Second Round of the National Selection Process

\begin{tabular}{lcc}
\hline & $\mathrm{N}$ & $\%$ \\
\hline 2010 & 12 & 35.3 \\
2009 & 11 & 32.4 \\
2008 & 10 & 29.4 \\
2007 & 10 & 29.4 \\
2006 & 10 & 29.4 \\
Candidate did not advance to the second round & 3 & 8.8 \\
\hline
\end{tabular}

\section{States Represented}

\section{Candidate Responses}

Candidates were asked to voluntarily identify what state they represented when they ran for a national office. Candidates represented 31 different states including: Alabama, Alaska, Arizona, Arkansas, California, Colorado, Idaho, Indiana, Iowa, Kansas, Kentucky, Maryland, Massachusetts, Michigan, Nebraska, Nevada, New Jersey, North Carolina, North Dakota, Ohio, Oklahoma, Oregon, Pennsylvania, South Dakota, Tennessee, Texas, Utah, Virginia, Washington, West Virginia, and Wyoming (see Appendix C). 


\section{State Supervisor Responses}

The State Supervisors that responded to this survey represented the states of: Alabama, California, Colorado, Connecticut, Idaho, Illinois, Indiana, Kansas, Kentucky, Maine, Maryland, Massachusetts, Michigan, Montana, New Hampshire, New Jersey, New Mexico, New York, North Carolina, Pennsylvania, South Carolina, Virginia, West Virginia, and Wyoming (see Appendix D).

\section{Most Beneficial Skill Received from Preparations as a Candidate \\ Candidate Responses}

In an open ended question candidates were asked to share what they thought the most beneficial skills were that they received from running for a national office. Many candidates stated that they learned more about themselves. Their strengths, weaknesses, likes and dislikes, values and standards as well as what type of leader they are. Candidates also felt that their agriculture, education, agriculture education and FFA knowledge base was enhanced. Skills such as communication, confidence, critical thinking, impromptu speaking, discipline and determination were either gained or greatly improved from the experience. Collectively the candidates mentioned interview skills and techniques as well. Some of them felt better prepared for future interviews and many stated they now have stronger interview skills than before. One candidate said they "realize the foundation of why we run... growth in students, the organization and ourselves." Another stated the most beneficial skill they received was "understanding that I can fail and be strong throughout my failure" (see Appendix C). 


\section{State Supervisor Responses}

State Supervisors were asked to share what they thought the most beneficial skills their candidates received were. Four supervisors mentioned candidates develop into great communicators that have the ability to communicate agriculture and agriculture education to any individual. Three State Supervisors indicated their candidates personally grow and learn who they really are as individuals. Another three supervisors reported that their candidates develop the skill of discipline, while two supervisors felt their candidates enhance presentation skills and another two supervisors believe their candidates learn critical thinking skills. Other skills states felt their candidates acquired were interview skills, the ability to conduct research, leadership, time management, character development, study habits, and knowledge of agriculture and agriculture education (see Appendix D).

\section{Training Candidates Would have Liked to Received But Did Not Get Candidate Responses}

Of the 42 candidates that responded to this question, 11 mentioned that they wish they would have known and understood more about the selection process, what the nominating committee was looking for and how the nominating committee evaluates the candidates. Six candidates felt they needed more practice with interviews in general, and specifically behavioral interviewing, and interviews that would have helped them with the process. Five candidates would like to have had more support from their home state. Four candidates mentioned that they would have liked to been informed about or have been able to attend some of the National Officer Candidate workshops and retreats held 
in various locations across the country. Three would have liked more practice with their writing skills and the written exam. Another three said they would have liked to have had more practice developing and facilitating workshops. Two candidates would have liked to receive competency training and how to apply it to the process, while two others said they needed more work on public appearances and speeches. One candidate still does not understand the Farm Bill, while another would have liked training on how to focus on yourself at the interviews instead of other candidates and finally one would have liked to receive training on how to respond and cope if not selected (see Appendix C).

\section{What Most Prepared Candidates for Process}

\section{Candidate Responses}

Candidates were asked to identify what they thought most prepared them for the selection process. Many candidates felt general conversations with state staff, teachers, professors, state officers and other mentors prepared them the most. Others believed interviewing prepared them the most while others felt meeting with industry professionals and others who had worked with the process were the most beneficial (see Appendix C).

\section{Preparation Methods Candidates Believe they Spent too Much Time On Candidate Responses}

When asked to reflect back and identify what preparation methods or topics they may have spent too much time on 17 of the 37 candidates that responded to this question said there was nothing for which they spent too much time preparing. Sixteen of these 
candidates felt that they spent too much time preparing for the knowledge areas on the written exam. These knowledge areas included state and national agriculture issues, agriculture knowledge, FFA knowledge and history, the Farm Bill, and commodity prices. One candidate felt they practiced too many mock interviews, because it caused them to over think the one on one interview round. Another candidate just felt they needed more time studying for the process as a whole (see Appendix C).

\section{Preparation Methods Candidates would have Liked More Time On Candidate Responses}

Candidates were also asked to identify preparation methods that they wish they would have spent more time working on. Of the 38 candidates that responded to this question nine mentioned that they wish they would have spent more time practicing mock interviews and behavioral interviewing for the one on one interview rounds. Another nine felt they needed more work developing, and facilitating workshops. Eight mentioned wanting more work in practicing writing skills for the SAE writing activity, and the written exam. Seven candidates would have liked more preparation on the competencies and the selection process, while five wanted more time with prepared and extemporaneous speaking skills. Another five candidates would have liked more time learning about agriculture issues, education issues, and agriculture education issues. Three candidates believed there was nothing that they wished they had spent more time preparing for while two candidates would have liked more preparation time for every topic. Finally two candidates wish they would have spent more personal time getting to know themselves (see Appendix C). 


\section{What Candidates Wanted to Gain from the Process other than Being Selected as a National Officer}

Candidate Responses

Other than being selected as a National Officer, candidates were asked to share what they expected to gain from going through the process. Twenty-five of the 42 candidates that answered this question expected to gain some sort of personal development. Whether it was developing a better understanding of who they were, gaining more self-confidence, or achieving personal growth $60 \%$ of the candidates felt this way. Nineteen (45\%) wanted to build relationships, develop friendships and network with other candidates as well as business and industry leaders. Nine candidates wanted to enhance their knowledge base of agriculture, agriculture education, FFA or American education. Six expected to develop their interview skills and another six felt this would give them the chance to become a better leader. Four of the candidates gained stronger communication and speaking skills, while three wanted to enjoy the experience the most. Another three candidates expected to gain professional development and job preparation skills. One candidate wanted to gain lifelong skills, while another wanted social skills and one candidate wanted to build character (see Appendix C).

\section{State Supervisor Responses}

States were also asked to share what they would like their candidates to gain from this experience other than being selected as a national officer. Nine State Supervisors want their candidates to gain pride, self-satisfaction, and personal growth from the experience. Four supervisors want their candidates to use the experience to network, and 
build connections. Four supervisors hoped that each candidate's knowledge base increases and three supervisors wanted interview skills to improve. Other responses included increased communication and leadership skills, maturity, and possible employment potential. Still yet some supervisors want their candidates to become advocates for agriculture, develop into well rounded individuals, and to be an influence for future agriculture leaders (see Appendix D).

\section{Part of National Selection Process that was the Most Challenging Candidate Responses}

Candidates were asked to identify the portion of the selection process they found to be the most difficult. Eight (13.1\%) candidates thought the application process was most challenging, $13(21.3 \%)$ candidates mentioned the written test, $11(18 \%)$ candidates believed the one on one interview and nine (14.8\%) candidates indicated the SAE writing exercise was the most challenging (see Table 53). Another 22 (36.1\%) candidates reported that the stand and deliver practicum was the most challenging, while $10(16.4 \%)$ felt the facilitation practicum, seven $(11.5 \%)$ believed the round robin issues conversation was the most challenging, and seven (11.5\%) candidates indicated they felt the personal interview round was the most challenging. 
Table 53

Part of Selection Process that was the Most Challenging for Candidates

\begin{tabular}{lcc}
\hline & $\mathrm{N}$ & $\%$ \\
\hline Application process & 8 & 13.1 \\
Written test & 13 & 21.3 \\
One-on-One interview round & 11 & 18.0 \\
SAE Writing Exercise & 9 & 14.8 \\
Stand and Deliver Practicum & 22 & 36.1 \\
Facilitation Practicum & 10 & 16.4 \\
Round Robin Issues Conversation & 7 & 11.5 \\
Personal Interview Round & 7 & 11.5 \\
\hline
\end{tabular}

\section{State Supervisor Responses}

After reflecting on the selection process and the training candidates receive State Supervisors were asked to identify which portion of the process they felt to be the most challenging for their candidates. One (2.9\%) supervisor mentioned the application process, six (17.6\%) supervisors thought the written test, four $(11.8 \%)$ supervisors indicate the one on one interview round was the most challenging and five (14.7\%) supervisors believed the SAE writing exercise to be the most difficult (see Table 54). One (2.9\%) state supervisor felt the stand and deliver practicum was the most challenging, while three $(8.8 \%)$ supervisors felt the facilitation practicum and round robin issues conversation was the most challenging. 
Table 54

Part of Process State Supervisors Believe to be the Most Challenging for Candidates

\begin{tabular}{llc}
\hline & $\mathrm{N}$ & $\%$ \\
\hline Application process & 1 & 2.9 \\
Written test & 6 & 17.6 \\
One-on-One interview round & 4 & 11.8 \\
SAE Writing Exercise & 5 & 14.7 \\
Stand and Deliver Practicum & 1 & 2.9 \\
Facilitation Practicum & 3 & 8.8 \\
Round Robin Issues Conversation & 3 & 8.8 \\
Personal Interview Round & 0 & 0.0 \\
\hline
\end{tabular}

\section{Part of National Selection Process that was the Least Challenging Candidate Responses}

Candidates were also asked to identify the least challenging part of the selection process. Seven (11.5\%) mentioned the application process, $16(26.2 \%)$ candidates believed it was the written test, $22(36.1 \%)$ candidates indicated the one on one interview round, and $14(23 \%)$ candidates reported the SAE writing exercise to be the least challenging. Four candidates $(6.6 \%)$ believed the stand and deliver practicum was the least challenging, while three (4.9\%) felt the facilitation practicum, two $(3.3 \%)$ indicated the round robin issues conversation, and nine (14.8\%) believed the personal interview round was the least challenging (see Table 55). 
Table 55

Part of Process that Candidates felt was the Least Challenging

\begin{tabular}{lcc}
\hline & $\mathrm{N}$ & $\%$ \\
\hline Application process & 7 & 11.5 \\
Written test & 16 & 26.2 \\
One-on-One interview round & 22 & 36.1 \\
SAE Writing Exercise & 14 & 23.0 \\
Stand and Deliver Practicum & 4 & 6.6 \\
Facilitation Practicum & 3 & 4.9 \\
Round Robin Issues Conversation & 2 & 3.3 \\
Personal Interview Round & 9 & 14.8 \\
\hline
\end{tabular}

\section{State Supervisor Responses}

State Supervisors were also asked to share which part of the process their candidates found to be the least challenging. Six (17.6\%) State Supervisors reported the application process was the least challenging, two (5.9\%)State Supervisors mentioned the written test, seven (20.6\%) supervisors felt the one on one interview round, and one (2.9) supervisor thought both the SAE writing exercise and stand and deliver practicum was the least challenging. Three $(8.8 \%)$ State Supervisors reported that the facilitation practicum was the least challenging, one $(2.9 \%)$ believed the round robin issues conversation, and four (11.8) supervisors felt the personal interview round was the least challenging (see Table 56). 
Table 56

Part of Process State Supervisors Believe to be the Least Challenging for Candidates

\begin{tabular}{llc}
\hline & $\mathrm{N}$ & $\%$ \\
\hline Application process & 6 & 17.6 \\
Written test & 2 & 5.9 \\
One-on-One interview round & 7 & 20.6 \\
SAE Writing Exercise & 1 & 2.9 \\
Stand and Deliver Practicum & 1 & 2.9 \\
Facilitation Practicum & 3 & 8.8 \\
Round Robin Issues Conversation & 1 & 2.9 \\
Personal Interview Round & 4 & 11.8 \\
\hline
\end{tabular}

Do Candidates feel the Current Selection Process is a Good Process that Assists the Nominating Committee in selecting the Best Candidates?

Candidate Responses

When candidates were asked if they felt the current selection process was a good process to select a National Officer, $39(72.2 \%)$ believed it was a good process and 15 $(27.8 \%)$ did not think it was a good process. When asked if candidates believed that the process assisted the nominating committee in selecting the best candidates $37(68.5 \%)$ felt it did, and 17 (31.5\%) believed it did not (see Table 57). 
Table 57

Is the Current Selection Process a Good Process for Selecting National Officers and Does it Assist the Nominating Committee Selecting the Best Candidates

\begin{tabular}{lcccc}
\hline & \multicolumn{3}{c}{ Yes } & \multicolumn{2}{c}{ No } \\
\cline { 2 - 5 } & $\mathrm{N}$ & $\%$ & $\mathrm{~N}$ & $\%$ \\
\hline $\begin{array}{l}\text { Is current selection process a } \\
\text { good process for selecting a } \\
\text { National FFA Officer? }\end{array}$ & 39 & 72.2 & 15 & 27.8 \\
$\begin{array}{l}\text { Is National FFA officer } \\
\text { selection process structured to } \\
\begin{array}{l}\text { assist the nominating committee } \\
\text { in selecting the best? }\end{array}\end{array}$ & & & & \\
\hline
\end{tabular}

\section{State Supervisor Responses}

When asked if the State Supervisors felt the current selection process was a good process to select a national officer, $16(69.6 \%)$ supervisors reported that yes it was. Seven (30.4\%) supervisors however felt that the process was not a good process to select a national officer. State Supervisors were also asked if they felt that the process was structured to assist the nominating committee in selecting the best candidates. Fifteen (65.6\%) of them felt that it was while eight (34.8\%) felt it was not (see Table 58). 
Table 58

States Supervisors Opinion on Whether or Not the National Selection Process is a Good Process, which Assists the Nominating Committee to Select the Best Candidates

\begin{tabular}{lcccc}
\hline & \multicolumn{2}{c}{ Yes } & \multicolumn{2}{c}{ No } \\
\cline { 2 - 5 } & $\mathrm{N}$ & $\%$ & $\mathrm{~N}$ & $\%$ \\
\hline $\begin{array}{l}\text { Is current selection process a } \\
\text { good process for selecting a } \\
\text { National FFA Officer? }\end{array}$ & 16 & 69.6 & 7 & 30.4 \\
$\begin{array}{l}\text { Is National FFA officer } \\
\text { selection process structured to } \\
\text { assist the nominating committee } \\
\text { in selecting the best candidates? }\end{array}$ & 15 & & & \\
\hline
\end{tabular}

\section{Suggestions for Change to the Process}

\section{Candidate Responses}

After going through the process candidates were asked to make recommendations for change. Some of the suggestions were:

- Add a round or group interview to evaluate group interaction and team dynamics to determine compatibility of candidates.

- Add one more round of interviews after the cut

- Allow more time for all rounds

- Allow more one on one time with the nominating committee

- Place a workshop or facilitation round in the $1^{\text {st }}$ section as well as a personal interview to allow for more interaction with the Nom Com prior to the cut. 
- Add an activity where candidates and nominating committee members can speak freely and restructure the fun activity. It lead to dancing and flirting between nom com members and NOCs

- Don't make the written exam just a few days before the process because the FFA website changes right before national convention

- Make the application process easier and focus less on the competencies

- Eliminate the cuts as they are not fair when regions are different sizes.

- The number of candidates allowed to move on from each region should not be limited, the process should select the best 6 no matter what region they are from

- Allow candidates more than 15 minutes in the $1^{\text {st }}$ round with nom com members

- Create a portion that focuses on donor relations because national officers need to be able to garner financial support

- Nom com is made of up individuals with valued and trusted opinions. They should be allowed to give more personal input. The process is to objective and doesn't allow them to give their opinion

- Too much emphasis is based upon the test in early rounds and too much of the pre-cut score was based on rounds that did not involve interaction with the nominating committee.

- There should be no affiliation between Nom Com members and NOCs

- No trainers should be allowed to coach candidates a standardized preparation process could be developed

- Re-look at the round robin interviews 
- Nom Com members should be trained to listen to the answer instead of for key "buzz" words. Just because a candidate does not use a certain word does not mean they do not possess a competency.

- The process is not always about the response but the words in the response

- The process is based upon the person they want you to be and the process leans towards those who have the best prepared answers based upon the competencies.

- The questions in the one on one interview should be made less predictable so that the answers candidates give are genuine and not rehearsed.

- As it is the questions are designed to measure competencies and you can answer a question well but in the wrong direction receiving bad scores in that competency area because you do not know which competency each member is looking for.

- Add a portion that exposes underlying character because many candidates are trained to play the part.

- Questions in the one on one interview round were too specific to the state officer year. Every state is run differently all questions may not apply to all states.

- Nom Com exhibits difficulty identifying the difference between NOC potential and current candidate ability.

- The Star Battery should not be used to determine the amount of agriculture and FFA knowledge a person possesses because every individual SAE is unique and different. How can one be compared to another to determine which candidate possesses the most knowledge?

- There should be a formation of a candidate network prior to convention so that candidates can share resources if they choose too. 


\section{State Supervisor Responses}

States were asked to share any recommendations they may have for the National Selection Process. In open ended responses a variety of answers were received. Some of the recommendations were:

- Re-evaluate the regions as they are slightly skewed and unequal

- The behavioral interviewing process has been watered down and needs to be strengthened

- Eliminate the cut

- "Competencies are in some ways a detriment to the process

- $\quad$ Pick the best 6

- Needs to be a committee for each round to eliminate bias

- There is not enough time with the committee prior to the cut

- Additional samples of training plans should be provided

- Candidates selected need to be more down to earth

- All candidates should be allowed to complete all parts of process 


\section{CHAPTER V}

\section{Summary, Conclusions, and Recommendations}

\section{Purpose of Study}

The purpose of this study was to analyze the training and preparation methods used to prepare National FFA Officer Candidates for a National Office. The training and preparation was examined from the perspective of the candidates as well as State Supervisors. The results examined methods used to prepare candidates for the National FFA Officer Selection Process.

\section{Specific Objectives}

The objectives of this study were reflected in the following research questions:

1. What training processes and activities are utilized by candidates to prepare for the National Officer Selection Process?

2. What types of assistance and advice are provided to National Officer Candidates and by whom?

3. What are the perceptions of Candidates and State Supervisors on their state selection process and training techniques as compared to the national process and procedures?

4. What are the National Officer Candidates and State Supervisors perceptions of the eight character competencies used in the National Officer Selection Process? 
5. What do National Officer Candidates feel they gained from preparing for and participating in the National Officer Selection process?

6. What are candidates' opinions on the structure of the current process and recommendations for changes to the selection process?

\section{Summary}

\section{What training processes and activities are utilized by candidates to prepare for the National Officer Selection process?}

The type of process that the majority of candidates (83.6\%) use to prepare for a National Office was a process they developed on their own with assistance from others. Less than a quarter of the candidates $(16.4 \%)$ have a structured process to work through, or develop their own preparation process with no help from others. All of the candidates that responded said they had some type of preparation process. State Supervisors responses to the same questions indicated that a majority $(70.6 \%)$ of their candidates develop a process on their own with assistance from others. Eight (23.5\%) states however said they have a structured process available for candidates to work through while two $(5.9 \%)$ states said that their candidate did not have preparation for the process.

When asked about the training activities candidates participates in, over half of the candidates said they participated in all of the training activities listed, and over half of the states also said that candidates participated in all activities. These training activities included, participated in "mock" interviews, interviews with key ag leaders, public appearances (greetings or report), presentations to enhance presentation skills, planned and coordinated workshops, taught workshops, assistance in the development of personal 
competencies, conducted research to improve knowledge base, received pointers on improving interview and presentation skills, and improved writing skills through the use of practice exercises. Other training activities that candidates mentioned using included keeping a journal about the process and past experiences that taught life lessons, as well as being given past materials from previous state candidates.

Interview training was a major preparation method used by many candidates. Candidates participated in mock interviews with many individuals but the most common, as stated by both the candidates and state staff were interviews with food, agriculture, and natural resource specialists, past national officers, past National Officer Candidates, fellow FFA members, and individuals in agriculture and non-agriculture business and industry. Only one candidate did not participate in any mock interviews. One discrepancy between the candidate and State Supervisors' responses was that, $62.3 \%$ of the candidates said they conducted interviews with personal coaches, while $64.7 \%$ of the states said candidates interviewed with FFA alumni or foundation members and state or federal Department of Agriculture Staff. Unique individuals that candidates stated they met with included agriculture teachers, college professors, state Farm Bureau members, department of education staff, FFA sponsors and international visitors in the US Department of State Sponsored Programs (IVLPs).

What information were candidates seeking to gather from these individuals? The majority of the candidates and state staff said candidates were seeking to gather information regarding FFA content knowledge and history, industry and business, agriculture education knowledge and history, agriculture issues, the farm bill, communication techniques, leadership, and American education. 
As students participated in these mock interviews, they were not only meeting with influential people, and gathering valuable information; they were also working to improve their interview skills through the process of practice. The interview skills that the majority (over 50\%) of candidates and State Supervisors both said they were improving included, clear and concise speech, impromptu abilities, situational adaptation, conversational ability, and the ability to organize thoughts. Some of the answers between the State Supervisors and candidates did differ slightly. The majority of the candidates also wanted to improve time management skills, memory and retention skills, language use, creativity, and reading an audience. While a majority of the State Supervisors said candidates were also working to improve adequate eye contact, and rules governing interaction.

A majority of the candidates and State Supervisors report that the candidates had moderate to extensive training in the areas of: current events and issues in agriculture and agricultural education, involvement in conducting FFA activities, and FFA current events and activities. Both groups agree that candidates received no training or only some training in the areas of personal skill, group discussion and interaction, American education current events and issues, career and technical education, No Child Left Behind, and $21^{\text {st }}$ Century skills. The area where there seems to be more disparity in the responses is in the area of the National Officer Selection Process, where candidates and State Supervisors have nearly a 50/50 split between no training or some training and moderate to extensive training. This is an area with the greatest amount of discrepancy across all topic areas. 
In addition to mock interviews, candidates often conduct many public appearances. Three most beneficial public appearances candidates felt they made were chapter visits, and local chapter activities such as high school workshops, banquets, fundraisers and other local FFA events. Secondly, candidates said that FFA member workshops, camps and recruitment activities were beneficial public appearances to make. Additionally they reported presenting at State FFA conventions, leadership conferences and any other state FFA functions as beneficial to their training. The State Supervisors felt that having their candidates present workshops to FFA members, or at FFA functions were the most beneficial, which was followed by delivering keynote speeches to outside groups, students and business leaders. State Supervisors also reported meetings and interaction with agriculture and non-agriculture business and industry leaders as beneficial.

Events or appearances that individuals felt were not very beneficial to their training and preparation included Agriculture educator meetings, in-services, banquets and other events where they were present but not speaking or presenting. Several candidates and State Supervisors agreed that all appearances can be some sort of benefit to the candidate. Other non-beneficial activities included, hanging out with members, visiting with a past national officer who were elected more than five years prior to each individual candidate running for an office, meetings with family and friends, simple chapter visits or work with their home chapter, county fairs, very short speeches, and presentations made to groups with which the candidate is completely comfortable. Workshop facilitation is a part of the selection process so many candidates prepare for this by conducting workshops throughout their training. A majority of the 
candidates and State Supervisors reported candidates conducted between one and 10 workshops, with more than a third of the candidates and about half of the State Supervisors reporting that candidates facilitated between one and five workshops. A third of the candidates and State Supervisors report candidates facilitated between six and 10 workshops. The most common topic of workshops reported by candidates and State Supervisors was leadership. Other common topics included workshops related to FFA knowledge, history, involvement and opportunities, as well as topics related to agriculture facts and issues, agriculture education issues and goal setting and developing plans. Other topics that states said their candidates presented workshops about included, FFA opportunities, knowledge, recruitment or general activities.

Candidates spend many hours preparing and training for a national office. On average candidates reported they spent about 14 hours per week in training, while State Supervisors estimated their candidates spent about 10 hours per week in training. Candidates reported they spent about 210 hours over the course of training conducting research, while State Supervisors estimated the amount of time candidates spent conducting research wasabout140 hours.

The main topics that the majority of candidates reported and the State Supervisors reported candidates spent time researching were FFA content knowledge and history information from industry and business through site visits agriculture education knowledge and history knowledge of agriculture issues knowledge on the farm bill , and American education While candidates reported researching communication techniques and leadership, a majority of State Supervisors did not feel these two topics were ones that candidates spent a lot of time researching. 
Internships could be a great learning and preparation tool for National Officer Candidates. When asked whether or not they participated in an internship as part of their preparation over half of candidates reported they did not participate in an internship. However, less than half of the candidates did participate in some sort of internship that they arranged on their own. A majority of the states agreed that their candidates did not participate in an internship, with less than a fourth reporting their candidates participated in an internship they arranged on their own.

\section{What types of assistance and advice are provided to National Officer} Candidates and by whom?

An overwhelming majority of the candidates developed their own preparation process with the assistance of others. Which raises the questions, who were the individuals that candidates sought assistance and advice from? A majority of the candidates received assistance from the state association, a university or college professor, past national officers, and past National Officer Candidates. Only one candidate indicated that no assistance was provided to them. A majority of the State Supervisors listed the individuals with the addition of a chapter FFA advisor. A third of the candidates said their chapter advisor provided them with assistance.

Knowing and understanding the selection process and its procedures would be a benefit to any candidate and one way to learn this information would be to seek advice from individuals who have some prior knowledge of the process. An overwhelming majority of the candidates had consulted with present or past National Officer Candidates for advice and feedback about the process. About two-thirds of the candidates met with 
past or present national officers and less than half consulted with past or present nominating committee members.

All of the candidates where enrolled in postsecondary education during the time they ran for a national office. Nearly $100 \%$ of the candidates were enrolled as full time students, with only a few who were enrolled part time and or took the semester off. Of the candidates that were enrolled in postsecondary education the semester they ran for an office a little over half said that their college or university provided assistance in preparing them to run for a national office. However this does not mean that candidates did not receive assistance from other colleges or universities. They may have received assistance from professors in other majors of study other than their own; as three-fourths of the candidates said that a college or university professor provided them with assistance. State Supervisors reported that about fifty percent of the colleges and universities in their state did not provide assistance to the candidates.

Resources provided to candidates by their college or university included independent study credit to National Officer Candidates during their semester of preparation as well as assistance from professors and /or past National Officer Candidates. Others assistance noted included that schedules were made more flexible to compensate for the National FFA convention, leadership conferences and other training activities. Some professors also provided coaching and financial support to the candidates, as well as research documents, PowerPoint, and FFA board minutes were other resources made available to candidates. 


\section{What are the perceptions of candidates and state staff on their state selection process and training techniques as compared to the national process and procedures?}

This research not only sought to discover the training techniques used and assistance received, but how closely state selection processes reflect the national process and candidates perceptions of both processes. None of processes were reported to be exactly the same in both situations. However a majority indicated the state process was very similar. Candidates indicated their preparation workshop topics were similar to those given in the second round of the process. Three fourths of the candidates who indicated the topics of their workshops during training were similar to the topics given during the selection process advanced to the second round of the national process.

The major topics that a majority of candidates feel are the most important to research after completing the process include FFA content knowledge and history, agriculture education knowledge and history, agriculture issues, communication techniques, leadership, and American education .A majority of the State Supervisors felt that candidates should research agriculture education knowledge and history, and agricultural issues.

While reflecting on the process candidates shared their perceptions of the most challenging and the least challenging parts of the National process. The results were scattered across the board for all parts of the process, however the two portions of the process that candidates felt to be the most challenging were the stand and deliver practicum and the written test. The parts that they found to be the least challenging were the interview round and the written test. There was no distinct section of the process that 
candidates felt to be overly easy or hard. Since the answers varied based upon candidates personal strengths, weaknesses, and training background it cannot be determined which part of the process is the most or least challenging for them.

Along with identifying the most and least challenging portion of the process candidates when asked to rate how well they felt they were prepared for the process, slightly less than half of the candidates felt their preparation was either good or excellent. However, three-fourths of the State Supervisors felt their candidates were prepared good or excellent. This leads the researchers to question how much preparation states think they are providing compared to how much candidates feel they are receiving.

Many candidates felt that general conversations with state staff, teachers, professors, state officers and other mentors was the most beneficial in preparing candidates for the process. Other beneficial activities included: interviewing, meeting with industry professionals and others who had worked with the process.

Candidates indicated they would like to have known and understood more about the selection process, what the nominating committee was looking for and how the nominating committee evaluates the candidates. Other candidates felt they needed more practice with interviews in general, and specifically behavioral interviewing, and interviews that would have helped them with the process. A number of candidates reported they would have liked to had more support from their home state, and been informed about or have been able to attend some of the National Officer Candidate workshops and retreats held in various locations across the country. While others would have liked more practice with their writing skills and the written exam, more practice developing and facilitating workshops,. Some felt competency training and how to apply 
it to the process, as well as training on how to respond and cope if not selected as a national officer would have been beneficial.

Candidates reported they spent too much time preparing for the knowledge areas on the written exam. These knowledge areas included state and national agriculture issues, agriculture knowledge, FFA knowledge and history, the Farm Bill, and commodity prices. Many candidates however said there was nothing that they spent too much time preparing.

Preparation methods candidates would have liked more time on consisted of more time practicing mock interviews and behavioral interviewing for the one on one interview rounds. Others needed more work developing, and facilitating workshops, work in practicing writing skills for the SAE writing activity, and the written exam. Several candidates would have liked more preparation on the competencies and the selection process, while others wanted more time with prepared and extemporaneous speaking skills.

Over the five year period that was studied, candidates from earlier years could have been previous members of the nominating committee as the rule prohibiting nom com members from running for a national office was enacted during this time period. As a result candidates were asked if they were previous members of the nominating committee. Of the candidates that responded none of them had served as a member of the nominating committee. Only one state staff response said they had a candidate(s) that had previously served as a member of the nominating committee.

The length of time between when candidates are selected to represent their state and the National Selection Process could make a difference on the amount of preparation 
and training received. However, $80 \%$ of the candidates and almost $70 \%$ of the states said that candidates were selected between four and seven months in advance of the national selection process.

Only three candidates indicated that their state nominating committee processes was exactly the same as the national nominating committee process. Over half indicated some segments are similar, while less than a third indicated that the selection processes were not at all similar. One candidate was elected by popular vote with a state nominating committee. Of the State Supervisors that responded one-fifth of the state process are exactly the same as nationals, over half of the states have some of the segments that are similar, and one fifth who state their state selection process is not at all similar to national.

\section{What are the National Officer Candidates and State Staff perceptions of the eight character competencies used in the National Officer Selection process?}

A majority of the candidates and the State Supervisors agree that the competencies are a good basis for selection. Candidates and State Supervisors felt that the competency of influence was the hardest to prepare for, followed by critical thinking. Candidates and State Supervisors felt the competency easiest to prepare for was communication. State Supervisors felt areas of knowledge was the second easiest for candidates, while candidates indicated areas of knowledge was the third hardest to prepare for.

Candidates felt that once training was complete they exhibited character the most followed by communication. Candidates felt they exhibited the competency critical 
thinking least after their training was complete followed by areas of knowledge. State Supervisors believed that their candidates display the competency of communication the most followed by passion for success. The competencies that State Supervisors feel candidates exhibit the least after training were critical thinking, influence, and team player.

\section{What do National Officer Candidates feel they gained from preparing for and participating in the National Officer Selection process?}

Many candidates felt they learned more about themselves, their strengths, weaknesses, likes and dislikes, values and standards as well as what type of leader they are through their preparation and participation in the National Officer selection process. Candidates also felt that their agriculture, education, agriculture education and FFA knowledge base was enhanced. Skills such as communication, confidence, critical thinking, impromptu speaking, discipline and determination were either gained or greatly improved from the experience. Collectively the candidates mentioned interview skills and techniques as well. Some of them feel better prepared for future interviews and many stated they now have stronger interview skills than before. One candidate said they "realize the foundation of why we run... growth in students, the organization and ourselves." Another stated the most beneficial skill they received was "understanding that I can fail and be strong throughout my failure."

State Supervisors said candidates develop into great communicators that have the ability to communicate agriculture and agriculture education to any individual as a result of the process. Their candidates personally grow and learn who they really are as 
individuals. They develop the skill of discipline, enhance their presentation skills, and learn critical thinking skills. Other skills states feel their candidates acquire are interview skills, the ability to conduct research, leadership, time management, character development, study habits, and knowledge of agriculture and agriculture education.

Other than being selected as a National Officer over half of the candidates said they expected to gain some sort of personal development. Whether it was developing a better understanding of who they were, gaining more self-confidence, or achieving personal growth. Nearly half of the candidates wanted to build relationships, develop friendships and network with other candidates as well as business and industry leaders. Other candidates wanted to enhance their knowledge base of agriculture, agriculture education, FFA or American education, and expected to develop their interview skills. A handful of the candidates felt participation in the process would give them the chance to become a better leader, gain stronger communication and speaking skills, and professional development and job preparation skills. Some candidates just wanted to enjoy the experience, gain lifelong skills or to build character.

State Supervisors want their candidates to gain pride, self-satisfaction, and personal growth from the experience. They want their candidates to use the experience to network, build connections, and they hope that each candidate's knowledge base increases, and interview skills improve. Other responses included increased communication and leadership skills, maturity, and possible employment potential. Some State Supervisors want their candidates to become advocates for agriculture, develop into well rounded individuals, and to be an influence for future agriculture leaders. 


\section{What are candidates' opinions on the structure of the current process and recommendations for changes to the selection process?}

Over two-thirds of the candidates and State Supervisors feel the current selection process is a good process for selecting a National Officer and is it structured to assist the nominating committee in selecting the best candidate Although a majority of the respondents feel that the process is a good process that is structured to assist the nominating committee in selecting the best candidates there are however some suggestions for change. Candidate suggestions included but were not limited to: add a round or group interview to evaluate group interaction and team dynamics to determine compatibility of candidates, allow more time for all rounds as well as more time with the nominating committee prior to the cut, place a workshop or facilitation round in the $1 \mathrm{st}$ section, and eliminate the cuts altogether or do not limit the number of candidates from each region that can advance to the second round of the process as regions are different sizes and the best six candidates should be selected no matter what region they are from. Other suggestions included: allowing the nom com members to give more personal input, train nom com to listen for genuine answers instead of key words during the interview rounds, and make interview questions less predictable so candidates cannot rehearse answers. State Supervisors identified some of the same changes and also suggested to reevaluate the regions as they are slightly skewed and unequal; competencies are in some ways a detriment to the process, pick the best 6 , there is not enough time with the committee prior to the cut, and candidates selected need to be more down to earth. 


\section{Demographics of the candidates}

Respondents represented candidates who ran for National FFA Officer in 2010 (8), 2009 (10), 2008 (19), 2007 (20) and 2006 (10). Of those three advanced to the second round in 2010, five advanced in 2009, nine in 2008 and 2007, and seven advanced in 2006.Candidate respondents represented 31 different states, while State Supervisors responded from 24 different states.

State Supervisors indicated they sent candidates to the national level, 18states had candidates in 2010, 20had candidates in 2009, 2008 and 2006, and 17states had candidates in 2007. Of the states that sent candidates 12 states had candidates advance to the second round of the process in 2010. Eleven had candidates advance in 2009, and 10states had candidates advance in 2008, 2007 and 2006. Three states did not have any candidates advance to the second round of the process in any of the five years.

\section{Conclusions}

It can be concluded from this research that an overwhelming number of the candidates develop their own preparation and training process with assistance from others. The majority of candidates participate in "mock" interviews, interviews with key Ag leaders, public appearances (greetings or report), and presentations to enhance presentation skills. They also plan, coordinate and teach workshops, as well as receive assistance in the development of personal competencies. Candidates conduct research to improve knowledge base, receive pointers on improving interview and presentation skills, and improve their writing skills through the use of practice exercises. 
The individuals that candidates most often seek to conduct interviews with are food, agriculture, and natural resource specialists, past national officers, past National Officer Candidates, fellow FFA members, and individuals in agriculture and nonagriculture business and industry. One discrepancy to note between the candidate and state supervisor responses was that, $60 \%$ of the candidates said they conducted interviews with personal coaches as compared to $47 \%$ of the State Supervisors. Is there a reason why the majority of candidates say they conducted interviews with personal coaches when the State Supervisors say they do not? Since an overwhelming number of candidates develop their own preparation process, it is possible State Supervisors are unaware that candidates have personal coaches. It could also be that states do not want researchers to know personal coaches are used to prepare candidates. It could also be a reflection that some State Supervisors and candidates from states represented may not have responded to the survey. Another discrepancy was that nearly $70 \%$ of the states said candidates interviewed with FFA alumni or foundation members and state or federal Department of Agriculture Staff as compared to $49 \%$ of the candidates. It is possible that candidates are recommended by states to meet with these individuals and for whatever reason candidates cannot or do not meet with them.

The most frequently noted information that candidates seek to gather from their interviews is information regarding FFA content knowledge and history, industry and business, agriculture education knowledge and history, agriculture issues, the farm bill, communication techniques, leadership, and American education.

The topic areas that most candidates receive moderate to extensive training in include agriculture current events and issues, involvement in conducting FFA activities, 
agriculture education current events and issues, and the national officer selection process. There are however some discrepancies between what the candidates say they receive and what the State Supervisors say is provided. Involvement in conducting FFA activities for example was pretty evenly split between candidates that received not very much training and candidates that received moderate to extensive amounts of training. However, almost $70 \%$ of the states say the candidates received moderate to extensive training in that topic area. The other topic area was FFA current events and issues. About $60 \%$ of the candidates said they received moderate to extensive training when about $72 \%$ of the states said candidates received moderate to extensive training. Where does the discrepancy lie? Do states feel they are heavily preparing candidates in this topic area when in reality they are not? Or do candidates feel they could receive more than what is provided which is why only about half of the candidates feel they received enough training? It is obvious that some differences of opinions exist between candidates and State Supervisors on the amount of training received in these given topic areas. Out of the 11 given topic areas candidates report receiving moderate to extensive training in four of those topic areas. This means candidates are getting moderate to extensive levels of training in only about a third of the topic areas. The remaining seven topics areas that candidates receive no training to some training in are personal skills, group discussion and interaction, American education current events and issues, career and technical education, no child left behind, and $21^{\text {st }}$ century skills.

The public appearances that candidates perceive as the most beneficial include, chapter visits, and local chapter activities such as high school workshops, and other local FFA events. FFA member workshops, camps and recruitment activities, state FFA 
conventions, leadership conferences and any other state FFA function are a benefit to any candidates training. Most candidates and State Supervisors said that all of the appearances they made were beneficial in some way. A few appearances however that were not beneficial included: agriculture educator meetings, in-services, banquets, county fairs, very short speeches, presentations made to groups that the candidate is completely comfortable in front of and other events where they were present but not speaking or presenting.

The majority of candidates presented between one and 10 workshops during their time of preparation prior to the national selection process. The most common topic presented was leadership followed by FFA knowledge, history, involvement and opportunities. On average candidates said they spent about 14 hours per week in training. Candidates felt they spent on average about 210 hours over the course of their training conducting research. The estimates state staff provided were lower than the amounts candidates provided, which is not surprising as state staff can only base their estimates off of what they witness and are told by candidates.

The main topics that the majority of candidates spent time researching were FFA content knowledge and history, information from industry and business through site visits, agriculture education knowledge and history, knowledge of agriculture issues, knowledge on the farm bill, communication techniques, leadership, and American education .The majority of State Supervisors did not feel that candidates spent a lot of time researching communication techniques and leadership. One reason for this could be that state staff already believes candidates are great communicators and leaders before beginning the process as they have already lead their respective state successfully. 
Candidates however realize that this process is still a competition where they are competing against other great communicators and leaders, so brushing up on these topic areas will not hinder them in anyway.

The majority of candidates did not participate in an internship as part of their preparation process. However, just slightly less than half of the candidates did participate in some sort of internship that they arranged on their own. A majority of the State Supervisors however said that their candidates did not participate in an internship. A fourth of the State Supervisors reported their candidates participated in an internship they arranged on their own. The differences in the responses leads the researcher to questions how much the state supervisor is aware of the types of preparation in which their National Officer Candidates are involved. The majority of the candidates received assistance from the state association, a university or college professor, past national officers, and past National Officer Candidates. A majority of the State Supervisors listed these individuals while $70 \%$ also indicated candidates were getting assistance from their chapter FFA advisor. However, less than $40 \%$ of the candidates said their chapter advisor provided them with assistance. The researcher questions why so many State Supervisors feel that chapter advisors are providing assistance to candidates when candidate responses do not support that claim..

During the time that they ran for a national office nearly all of the candidates were enrolled as full time students. A little over half said that their college or university provided assistance in preparing them to run for a national office. In contrast, a little over half of the State Supervisors that responded reported that colleges and universities in their state did not provide assistance to candidates. 
When comparing state and national selection processes an overwhelming majority of the candidates indicated that the questions they were asked during mock interviews were either very similar or close to the interview questions asked during the national selection process. Of the candidates that advanced to the second round of the process and were eligible to participate in the workshop facilitation round about three fourths said the topics of the workshops they presented during preparation were similar to the topics given during the selection process. As a whole a little over half of the candidates said their state selection processes have segments that are similar to the national selection process.

The major topics that the majority of candidates feel are the most important to research after completing the process include FFA content knowledge and history, agriculture education knowledge and history, agriculture issues, communication techniques, leadership, and American education. There was no distinct section of the process that candidates felt to be overly easy or hard. Since the answers varied based upon candidates personal strengths, weaknesses, and training background it cannot be determined which part of the process is the most and/or least challenging for them.

Close to half of the candidates felt their preparation was good or excellent and almost three fourths of the State Supervisors said their candidates were prepared good or excellent. This leads the researcher to question how much preparation states think they are providing as compared to how much candidates feel they are receiving. Many candidates said the most beneficial preparation techniques were general conversations with state staff, teachers, professors, state officers and other mentors. Others said 
interviewing prepared them the most while others felt meeting with industry professionals and others who had worked with the process were the most beneficial.

The most common training candidates would have liked to received but did not get was more training about the selection process, what the nominating committee was looking for and how the nominating committee evaluates the candidates. The major preparation method candidates believed they spent too much time on was preparing for the knowledge areas on the written exam. Preparation methods candidates would have liked more time on consisted of more time practicing mock interviews and behavioral interviewing for the one on one interview rounds. Others said they needed more work developing, and facilitating workshops and some mentioned wanting more work in practicing writing skills for the SAE writing activity, and the written exam.

The preparation time that candidates have to prepare probably does not make a difference in whether or not they get selected as a national officer. Over three fourths of the candidates are selected as a candidate between four and seven months in advance of the national selection process. Candidates felt that the competency of influence was the hardest to prepare for followed by critical thinking. The competency that was the easiest to prepare for was communication. Character was the competency that candidates felt they exhibited the most after training was complete followed by communication. The competency that candidates felt they exhibited the least after their training was complete was critical thinking, followed by areas of knowledge. State Supervisors believe that their candidates display the competency of communication the most which is followed by passion for success. The competencies that states feel candidates exhibit the least after training in this order are critical thinking, influence, and team player. Around $80 \%$ of the 
candidates and State Supervisors feel that the competencies are a good basis for selecting a national officer.

Candidates feel they learn more about themselves, enhance their knowledge base and improve many skills such as communication and interviewing techniques. Other than getting selected as a national officer, candidates want to personally develop, network and build relationships and friendships from the process. In addition to this State Supervisors want their candidates to become advocates for agriculture, develop into well rounded individuals, and be an influence for future agriculture leaders. Even though the majority of the respondents feel that the process is a good process that is structured to assist the nominating committee in selecting the best candidates there were however some suggestions for change.

It is clear that some state associations do take an active role in preparing their candidates however, it is also clear that many state associations do not. This is reflected in the fact that throughout the study state staff answers do not reflect the answers of the candidates.

\section{Recommendations}

The researcher offers the following recommendations based on the results of the study.

1. It is recommended that State Supervisors who do not provide assistance develop a process to assist state candidates to prepare for the National Officer Selection process. 
2. Throughout the study state supervisor answers do not reflect the answers of the candidates. It is recommended that communication and support provided to the candidates by the state supervisor/FFA advisor throughout the entire preparation process be increased.

3. To achieve the most accurate data, all candidates should be surveyed at the completion of the national selection process each year while preparation and training is still fresh in the candidates' minds. As a result $100 \%$ of the population could be reached, and National FFA staff would then have very realistic and accurate data of the process from the individuals that have participated in it.

4. In addition to the materials located on FFA.org, training and insight from the National FFA regarding the national selection process and its components needs to be provided to all State Supervisors and National Officer Candidates. This would equal the playing field for all candidates and could be provided on a national or regional level.

5. It is strongly recommended that National FFA Staff review all of the recommendations and changes candidates and State Supervisors have suggested be made to the process to improve the process for future years. 


\section{REFERENCES}

Bruce, J., \& Ricketts, K. (2007). Evaluation of the National FFA Nominating Commitee Training. Journal of Leadership Education, 6 (1), 59-72.

Hoover, T. S., \& Atwater, D. F. (2005). National FFA Officer Candidate Preparation: Developing Future Leaders for Society. Journal of Agriculture Education, 46 (1), 79-89.

Horstmeier, R. P., \& Nall, M. A. (2007). Rural FFA Leadership: Understanding Members' Role and the Context of Chapter Activities. Journal of Leadership Education, 6 (1), 127-140.

Moody, S. B., \& Miller, L. E. (1974). FFA Leadership Handbook. National FFA Organization. (2005). American FFA Degree Handbook 2006-2012

National FFA Organization. (2010). Agriculture Education-The National FFA

Organization. Retrieved 2010, from http://www.ffa.org/

National FFA Organization. (2006-2010). National Officer Selection Process Handbook. National FFA Organization. (2009). Official FFA Manual 2009-2010. 
APPENDICES 


\section{APPENDIX A}

\section{Cover Letters}

June 20, 2011

Dear Former National FFA Officer Candidate:

Thank you for agreeing to participate in our study about training provided to National FFA Officer candidates. As a former National FFA Officer candidate, you excelled to the highest point in the organization by earning your American FFA Degree and being selected as the candidate from your home state. Because you are among a select group of individuals who have participated in the National Officer Selection process, your perspectives on preparation and training methods used to prepare you for the process are crucial to the development of future FFA members.

I am Becky Berkebile, a graduate student in Agricultural and Extension Education, and under the direction of my advisor, Dr. Deborah Boone, we are conducting a research study to determine the types of training and preparation methods used to help develop National FFA officer candidates. The results of this study will be used to prepare a thesis to partially fulfill the requirements for a Master of Science Degree in Agricultural and Extension Education. By determining the most beneficial preparation methods, individuals can begin to use these same methods for state and chapter officer training. West Virginia University's IRB acknowledgement of this research is on file.

We welcome your particpation in this very important study. You may access the link to the online survey at http://www.zoomerang.com/Survey/WEB22CBRKJ39RL/ Participation in this research study is completely voluntary, will take about 20 minutes to complete and all information you provide will be held as confidential as possible. For questions, you may contact Dr. Debby Boone at debby.boone@mail.wvu.edu or by phone at 304-293-5450 or Becky at bberkebi@mix.wvu.edu.

Your participation in this research project is crucial to its success; we hope you will participate in this study. Thank you in advance for your assistance with this research effort. We sincerely appreciate your time and effort.

Sincerely,

Becky Berkebile

Graduate Student
Deborah A. Boone, Ph.D. Associate Professor 
June 20, 2011

Dear Former National FFA Officer Candidate:

As a former National FFA Officer candidate, you excelled to the highest point in the organization by earning your American FFA Degree and being selected as the candidate from your home state. Because you are among a select group of individuals who have participated in the National Officer Selection process, your perspectives on preparation and training methods used to prepare you for the process are crucial to the development of future FFA members.

I am Becky Berkebile, a graduate student in Agricultural and Extension Education, and under the direction of my advisor, Dr. Deborah Boone, we are conducting a research study to determine the types of training and preparation methods used to help develop National FFA officer candidates. The results of this study will be used to prepare a thesis to partially fulfill the requirements for a Master of Science Degree in Agricultural and Extension Education. By determining the most beneficial preparation methods, individuals can begin to use these same methods for state and chapter officer training. West Virginia University's IRB acknowledgement of this research is on file.

We welcome your particpation in this very important study. You may access the link to the online survey at http://www.zoomerang.com/Survey/WEB22CBRKJ39RL/ Participation in this research study is completely voluntary, it will take about 20 minutes to complete and all information you provide will be held as confidential as possible. For questions, you may contact Dr. Debby Boone at debby.boone@mail.wvu.edu or by phone at 304-293-5450 or Becky at bberkebi@mix.wvu.edu.

Your participation in this research project is crucial to its success; we hope you will participate in this study. Thank you in advance for your assistance with this research effort. We sincerely appreciate your time and effort.

Sincerely,

Becky Berkebile

Graduate Student
Deborah A. Boone, Ph.D. Associate Professor 
May 24, 2011

Dear State FFA Supervisor:

As a State Supervisor,with FFA responsibilities you work with FFA members who are selected as National FFA Officer candidates from your state. Because you are among a select group of individuals who work withNational Officer Candidates, your perspectives on preparation and training methods used to prepare candidates for the process are crucial to the development of future FFA members.

I am Becky Berkebile, a graduate student in Agricultural and Extension Education, and under the direction of my advisor, Dr. Deborah Boone, we are conducting a research study to determine the types of training and preparation methods used to help develop National FFA officer candidates. The results of this study will be used to prepare a thesis to partially fulfill the requirements for a Master of Science Degree in Agricultural and Extension Education. By determining the most beneficial preparation methods, individuals can begin to use these same methods for state and chapter officer training. West Virginia University's IRB acknowledgement of this research is on file.

We would like to invite you to participate in this very important study. This is an online survey about how your state preparations FFA members to run as a National FFA Officer candidate. Participation in this research study is completely voluntary, will take about 20 minutes to complete and all information you provide will be held as confidential as possible. You may access the survey at:http://www.zoomerang.com/Survey/WEB22CBRT23EC5/

Your participation is crusical to the success of our study, we hope you will ocnsider participating. For questions, you may contact Dr. Debby Boone at debby.boone@mail.wvu.edu or by phone at 304-293-5450 or Becky at bberkebi@mix.wvu.edu.Thank you in advance for your assistance with this research effort. We sincerely appreciate your time and effort.

Sincerely,

Becky Berkebile

Graduate Student
Deborah A. Boone, Ph.D.

Associate Professor 
July 5,2011

\section{Dear State FFA Supervisor:}

On May 24, June 6, and June 20 we sent you a letter requesting your participation in our online survey about the preparation of National Officer Candidates. Your participation is critial to the success of our study, if you have not completed the survey, please consider doing so.

As a State Supervisor,with FFA responsibilities you work with FFA members who are selected as National FFA Officer candidates from your state. Because you are among a select group of individuals who work withNational Officer Candidates, your perspectives on preparation and training methods used to prepare candidates for the process are crucial to the development of future FFA members.

I am Becky Berkebile, a graduate student in Agricultural and Extension Education, and under the direction of my advisor, Dr. Deborah Boone, we are conducting a research study to determine the types of training and preparation methods used to help develop National FFA officer candidates. The results of this study will be used to prepare a thesis to partially fulfill the requirements for a Master of Science Degree in Agricultural and Extension Education. By determining the most beneficial preparation methods, individuals can begin to use these same methods for state and chapter officer training. West Virginia University's IRB acknowledgement of this research is on file.

We would like to invite you to participate in this very important study. This is an online survey about how your state preparations FFA members to run as a National FFA Officer candidate. Participation in this research study is completely voluntary, will take about 20 minutes to complete and all information you provide will be held as confidential as possible. You may access the survey at:http://www.zoomerang.com/Survey/WEB22CBRT23EC5/

Your participation is crucical to the success of our study, we hope you will consider participating. For questions, you may contact Dr. Debby Boone at debby.boone@mail.wvu.edu or by phone at 304-293-5450 or Becky at bberkebi@mix.wvu.edu.Thank you in advance for your assistance with this research effort. We sincerely appreciate your time and effort.

Sincerely,

Becky Berkebile

Graduate Student
Deborah A. Boone, Ph.D. Associate Professor 


\section{APPENDIX B}

\section{Questionnaire}

Training Methods Used to Prepare National FFA Officer Candidates for the National FFA Officer Selection Process

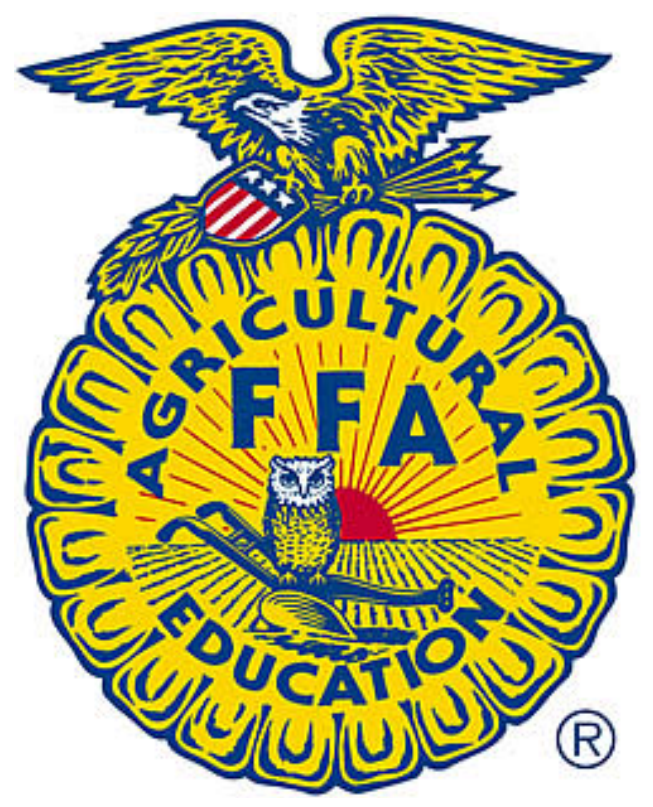

Becky Berkebile

Graduate Student

Agricultural and Extension Education

Davis College of Agriculture, Natural Resources, and Design

West Virginia University

Morgantown, WV 26506 


\section{Training Methods Used to Prepare National FFA Officer Candidates for the National FFA Officer Selection Process}

Instructions: Reflect back on your National FFA Officer candidacy and answer the following questions to the best of your ability.

1. Which best describes the process you used while preparing to run for a National FFA Office?

a. A structured process was available for me to work through.

b. I developed my own process of preparation, with assistance from others.

c. I developed my own process of preparation, with no assistance from others.

d. I did not have preparation for the process.

2. As you prepared to run for a National FFA Office, who provided you with assistance? ( check all that apply)

a. State FFA Association

b. University or College professor

c. FFA Chapter Advisor

d. Personal Coach - selected by you

e. Personal Coach - assigned by State Association

f. State Association assigned mentor

g. State Ag Teacher's Association

h. FFA Alumni

i. Past Nominating Committee members

j. Past National Officer

k. Past National Officer candidate

1. No assistance provided

m. Other (please

specify)

3. In what types of training activities did you participate?(check all that apply)

a. Participated in "mock" personal interviews

b. Conducted interviews with key Ag leaders for gathering information

c. Made public appearances (greetings or report)

d. Gave presentations to enhance presentation skills

e. Planned and coordinated workshops

f. Taught workshops

g. Received assistance in the development of personal competencies

h. Conducted research to improve knowledge base

i. Received pointers on improving interview and presentation skills

j. Improved writing skills through the use of practice exercises

k. Other (please

specify) 


\section{Interviewing Skills}

4. Which interview situations did you participate in while preparing to be a National Officer Candidate? ( Check all that apply)

Interviews with:

a. Food, Agriculture \& Natural Resource Specialists

b. Past National Officers

c. Past National Officer Candidates

d. Past Nominating Committee members

e. Fellow FFA members

f. Individuals in business and industry (Ag and non Ag related)

g. FFA Alumni or Foundation members

h. Department of Agriculture staff (state or federal)

i. Legislators

j. Personal coaches

k. Local individuals involved with $\mathrm{Ag}$

1. Did not participate in interviews

m. Other (please

specify)

5. When interviewing others, what types of information were you seeking to gather?
a. FFA content knowledge/history
b. Relevant employment internships
c. Utilization of print/non print media sources
d. Information from industry/business through site visits
e. Agriculture Education knowledge/history
f. Knowledge of Agriculture Issues
g. Knowledge of Farm Bill
h. Communication Techniques
i. Leadership
j. American Education knowledge
k. Other (please specify)

6. What types of interview skills did you work to improve during your preparation? (check all that apply)
a. Clear and concise speech
b. Use of vocal variety
c. Adequate eye contact
d. Impromptu abilities
e. Situational adaptation 
f. Relevant gestures

g. Time management

h. Emergence of group roles

i. Task vs. Relationship behaviors

j. Conversational ability

k. Memory/retention skills

1. Appropriate language use

$\mathrm{m}$. Reading your audience

n. Ability to organize thoughts

o. Rules governing interaction

p. Creativity

q. Personal Vision

r. Other (please list)

7. Level of Interview Training-For each area below, please indicate the level of training you received as a national officer candidate $(1=$ No training, $2=$ little training, $3=$ some training, $4=$ moderate training, $5=$ extensive training).

\begin{tabular}{|c|c|c|c|c|c|}
\hline Area & 之葛 & 邑怘 & 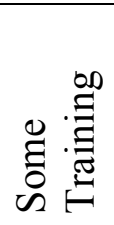 & 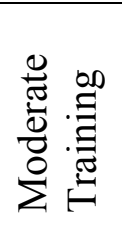 & 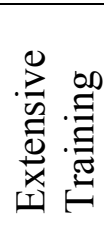 \\
\hline Personal Skills & 1 & 2 & 3 & 4 & 5 \\
\hline $\begin{array}{l}\text { Agriculture current events and } \\
\text { issues }\end{array}$ & 1 & 2 & 3 & 4 & 5 \\
\hline Group discussion and interaction & 1 & 2 & 3 & 4 & 5 \\
\hline $\begin{array}{l}\text { Involvement in/conducting FFA } \\
\text { activities }\end{array}$ & 1 & 2 & 3 & 4 & 5 \\
\hline $\begin{array}{l}\text { American Education current events } \\
\text { and issues }\end{array}$ & 1 & 2 & 3 & 4 & 5 \\
\hline $\begin{array}{l}\text { Agricultural Education current } \\
\text { events and issues }\end{array}$ & 1 & 2 & 3 & 4 & 5 \\
\hline FFA current events and issues & 1 & 2 & 3 & 4 & 5 \\
\hline Career and Technical Education & 1 & 2 & 3 & 4 & 5 \\
\hline No Child Left Behind & 1 & 2 & 3 & 4 & 5 \\
\hline $21^{\text {st }}$ Century Skills & 1 & 2 & 3 & 4 & 5 \\
\hline National Officer Selection Process & 1 & 2 & 3 & 4 & 5 \\
\hline
\end{tabular}

8. How similar were the questions you were given during your mock interviews to the types of questions you were asked during the actual process?

a. Exactly the same 

b. Very similar
c. Close
d. Not at all
e. Did not do mock interviews

9. What types of public appearances do you feel were most beneficial in preparing you to run for National Office? (Please list your top 3)

10. What types of public appearances do you feel were least beneficial in preparing you to run for National Office? (Please list 3)

11. After you were selected as a National Officer Candidate how many workshops did you facilitate prior to the selection process?
a. None
b. $\quad 1-5$
c. $\quad 6-10$
d. $\quad 11-15$
e. $\quad 15-20$
f. $\quad 20$ plus

12. If you presented workshop(s), what were the general topics of your workshop(s)? (List all you can recall, if you did not conduct workshops, put N/A)

13. Of the workshops you presented, were the workshop topics similar to that of the topics given in the $2^{\text {nd }}$ round of the selection process?
a. Yes
b. $\quad$ No
c. Did not present workshops
d. Did not advance to the second round

Please check all that apply

14. Of the eight competencies currently included in the process which ones were the most difficult for you to prepare for? (Rank in order of difficulty to prepare for. Rank 1-8 with 1 being the hardest) 
a. Communication

b. Team Player

c. Areas of Knowledge

d. Organization

e. Character

f. Passion for Success

g. Influence

h. Critical Thinking

15. Which competencies were the easiest for you to prepare for?( Rank 1-8 with 1 being the easiest)
a. Communication
b. Team Player
c. Areas of Knowledge
d. Organization
e. Character
f. Passion for Success
g. Influence
h. Critical Thinking

16. After your training was complete which competencies do you think you exhibited the most? (Rank the competencies based upon your perception with 1 being the highest and 8 being the lowest)

a. Communication

b. Team Player

c. Areas of Knowledge

d. Organization

e. Character

f. Passion for Success

g. Influence

h. Critical Thinking

17. Do you feel that the set of 8 competencies are a good basis to select a National FFA Officer?

Strongly Agree $\quad$ Agree Disagree Strongly Disagree

18. What topics did you research during your candidacy preparation? (Check all that apply) 

a. FFA content knowledge/history
b. Relevant employment internships
c. Utilization of print/non print media sources
d. Information from industry/business through site visits
e. Agriculture Education knowledge/history
f. Knowledge of Agriculture Issues
g. Knowledge of Farm Bill
h. Communication Techniques
i. Leadership
j. American Education knowledge
k. Other (please specify)

19. Over the course of your preparation about how many hours of research did you conduct total?

20. Approximately how many hours did you spend in training per week?

21. Now that you have been through the process, what topics do you think are the most important to research?
a. FFA content knowledge/history
b. Relevant employment internships
c. Utilization of print/non print media sources
d. Information from industry/business through site visits
e. Agriculture Education knowledge/history
f. Knowledge of Agriculture Issues
g. Knowledge of Farm Bill
h. Communication Techniques
i. Leadership
j. American Education knowledge
k. Other (please specify)

22. During the fall semester you were running for national office were you enrolled in a post-secondary education program as a...
a. Part-time student
b. Full-time student
c. Never enrolled in a post-secondary education program
d. Took semester off from post-secondary education program 
23. Did your university/college provide any resources to assist you in preparing as a National Officer Candidate?
a. Yes
b. No

24. If you answered yes to question 23, what were the resources provided? (please list)

25. As a National Officer Candidate what type of internship did you participate in during the summer or fall prior to your run?

a. Did not participate in an internship

b. Participated in a State required internship

c. Participated in an internship I arranged on my own

26. As a candidate did you consult with any of the following for advice about the selection process?(check all that apply)

a. National Officer Candidates (past or present)

b. National Officers (past or present)

c. Nominating Committee members (past or present)

d. Other (please specify)

27. Did any of the following provide you with feedback on areas of improvement? (check all that apply)
a. National Officer Candidates (past or present)
b. National Officers (past or present)
c. Nominating Committee members (past or present)
d. Other (please specify)

28. Were you a member of the Nominating Committee prior to running for National Office?
a. Yes
b. No

29. How well do you feel you were prepared for the process?
a. Poor
b. Fair
c. Average
d. Good 

e. Excellent

30. How long before you actually ran were you selected as a National Officer candidate?
a. More than 18 months in advance
b. 16-18 months in advance
c. $12-15$ months in advance
d. 11- 8 months in advance
e. 7-4 months in advance
f. 3 months or less in advance

31. How closely does your state nominating committee process mirror the national nominating committee process?
a. Exactly the same
b. Some segments are similar
c. Not at all similar
d. Elected by popular vote without a nominating committee
e. None of the above (please explain)

32. What year(s) did you run for a national office? (check all that apply)
a. 2010
b. 2009
c. 2008
d. 2007
e. 2006

33. What year(s) did you advance to the second round?
a. 2010
b. 2009
c. 2008
d. $\quad 2007$
e. 2006
f. I did not advance to the second round

34. What state are you from?

35. What do you think was the most beneficial skill you received from your preparations as a National Officer Candidate? 
36. What training would you have liked to have received that you did not get?

37. What most prepared you for the process?

38. As you reflect back on your training program were there preparation methods or topics that you felt you spent too much time on? (Please list)

39. As you reflect back on your training program were there preparation methods or topics that you wish you had spent more time on? (Please list)

40. Other than being elected to National Office what did you expect to gain by going through the National Officer Selection process?

41. Which part of the process was the most challenging? (only select from the parts you participated in)
a. Application process
b. Written test
c. One-on-One interview round
d. SAE Writing Exercise
e. Stand and Deliver Practicum
f. Facilitation Practicum
g. Round Robin Issues Conversation
h. Personal Interview Round 
42. Which part of the process was the least challenging?

a. Application process

b. Written test

c. One-on-One interview round

d. SAE Writing Exercise

e. Stand and Deliver Practicum

f. Facilitation Practicum

g. Round Robin Issues Conversation

h. Personal Interview Round

43. Do you think the current selection process is a good process for selecting a National FFA Officer?

a. Yes

b. No

44. In your opinion do you feel that the current National FFA officer selection process is structured to assist the nominating committee in selecting the best candidates?

a. Yes

b. No

45. After being a member of the process, what recommendations would you suggest for change?

Thank you for taking the time and effort to complete this survey. We appreciate your input.

If you have questions regarding the questionnaire, please contact me at:

bberkebi@mix.wvu.edu 
Training Methods Used to Prepare National FFA Officer Candidates for the National FFA Officer Selection Process (State Staff Survey)

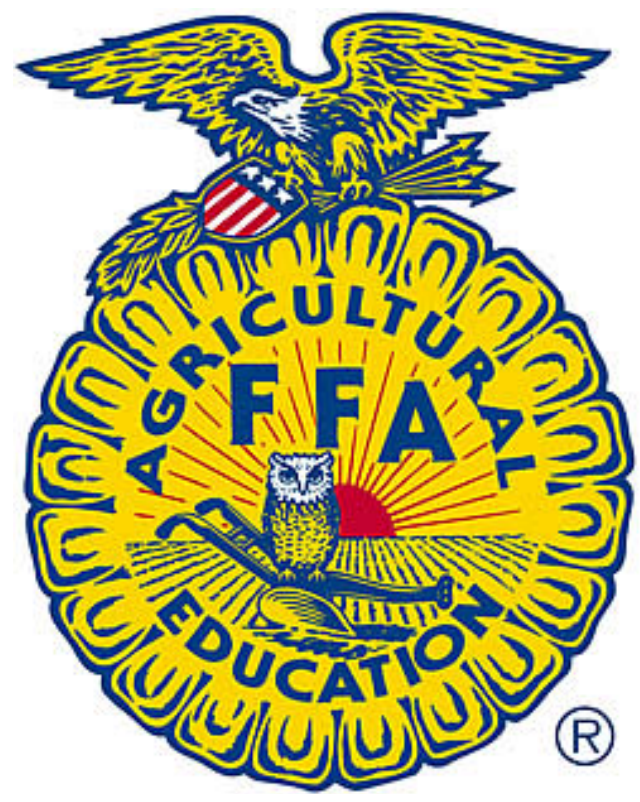

Becky Berkebile

Graduate Student

Agricultural and Extension Education

Davis College of Agriculture, Natural Resources, and Design

West Virginia University

Morgantown, WV 26506 


\section{Training Methods Used to Prepare National FFA Officer Candidates for the National FFA Officer Selection Process}

1. Which best describes the process your state has to prepare National Officer Candidates?

a. A structured process that is available for candidates to work through.

b. The candidate develops their own process of preparation, with assistance from others.

c. The candidate develops their own process of preparation, with no assistance from others.

d. There is not a preparation process in place.

2. As your candidate prepares to run for a National FFA Office, who provides them assistance? ( check all that apply)

a. State FFA Association

b. University or College professor

c. FFA Chapter Advisor

d. Personal Coach - selected by you

e. Personal Coach - assigned by State Association

f. State Association assigned mentor

g. State Ag Teacher's Association

h. FFA Alumni

i. Past Nominating Committee members

j. Past National Officer

k. Past National Officer Candidate

1. No assistance provided

m. Do Not Know

n. Other(please

specify)

3. In what types of training activities does your candidate participate?(check all that apply)

a. Participated in "mock" personal interviews

b. Conducted interviews with key Ag leaders for gathering information

c. Made public appearances (greetings or report)

d. Gave presentations to enhance presentation skills

e. Planned and coordinated workshops

f. Taught workshops

g. Received assistance in the development of personal competencies

h. Conducted research to improve knowledge base

i. Received pointers on improving interview and presentation skills

j. Improved writing skills through the use of practice exercises

k. None 
1. Other (please

specify)

\section{Interviewing Skills}

4. Which interview situations does your candidate participate in while preparing to be a National Officer Candidate? ( Check all that apply)

Interviews with:

a. Food, Agriculture \& Natural Resource Specialists

b. Past National Officers

c. Past National Officer Candidates

d. Past Nominating Committee members

e. Fellow FFA members

f. Individuals in business and industry (Ag and non Ag related)

g. FFA Alumni or Foundation members

h. Department of Agriculture staff (state or federal)

i. Legislators

j. Personal coaches

k. Local individuals involved with Ag

1. Did not participate in interviews

m. Other (please

specify)

5. When interviewing others, what types of information are your candidates seeking to gather?
a. FFA content knowledge/history
b. Relevant employment internships
c. Utilization of print/non print media sources
d. Information from industry/business through site visits
e. Agriculture Education knowledge/history
f. Knowledge of Agriculture Issues
g. Knowledge of Farm Bill
h. Communication Techniques
i. Leadership
j. American Education knowledge
k. Other (please specify)

6. What types of interview skills did your candidates work to improve during their preparation? (check all that apply)

a. Clear and concise speech

b. Use of vocal variety 

c. Adequate eye contact
d. Impromptu abilities
e. Situational adaptation
f. Relevant gestures
g. Time management
h. Emergence of group roles
i. Task vs. Relationship behaviors
j. Conversational ability
k. Memory/retention skills
1. Appropriate language use
$\mathrm{m}$. Reading your audience
n. Ability to organize thoughts
o. Rules governing interaction
p. Creativity
q. Personal Vision
r. Other (please list)

7. Level of Interview Training-For each area below, please indicate the level of training that you provided to your National Officer Candidates ( 1 = No training, $2=$ little training, $3=$ some training, $4=$ moderate training, $5=$ extensive training).

\begin{tabular}{|c|c|c|c|c|c|}
\hline Area & 乙冓 & 邑 & 苛 & 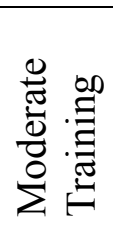 & 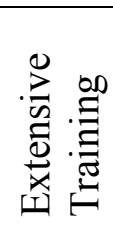 \\
\hline Personal Skills & 1 & 2 & 3 & 4 & 5 \\
\hline $\begin{array}{l}\text { Agriculture current events and } \\
\text { issues }\end{array}$ & 1 & 2 & 3 & 4 & 5 \\
\hline Group discussion and interaction & 1 & 2 & 3 & 4 & 5 \\
\hline $\begin{array}{l}\text { Involvement in/conducting FFA } \\
\text { activities }\end{array}$ & 1 & 2 & 3 & 4 & 5 \\
\hline $\begin{array}{l}\text { American Education current events } \\
\text { and issues }\end{array}$ & 1 & 2 & 3 & 4 & 5 \\
\hline $\begin{array}{l}\text { Agricultural Education current } \\
\text { events and issues }\end{array}$ & 1 & 2 & 3 & 4 & 5 \\
\hline FFA current events and issues & 1 & 2 & 3 & 4 & 5 \\
\hline Career and Technical Education & 1 & 2 & 3 & 4 & 5 \\
\hline No Child Left Behind & 1 & 2 & 3 & 4 & 5 \\
\hline $21^{\text {st }}$ Century Skills & 1 & 2 & 3 & 4 & 5 \\
\hline National Officer Selection Process & 1 & 2 & 3 & 4 & 5 \\
\hline
\end{tabular}


8. What types of public appearances do you feel are most beneficial in preparing your candidate to run for National Office? (Please list your top 3)

9. What types of public appearances do you feel are least beneficial in preparing your candidate to run for National Office? (Please list 3)

10. After your candidates are selected as a National Officer Candidate how many workshops do they facilitate prior to the selection process?
a. None
b. $\quad 1-5$
c. $6-10$
d. $11-15$
e. $\quad 15-20$
f. 20 plus

11. If they presented workshop(s), what were the general topics of the workshop(s)? (List all you can recall, if you did not conduct workshops, put N/A)

Please check all that apply

12. Of the eight competencies currently included in the process which ones were the most difficult to prepare your candidate for? (Rank in order of difficulty to prepare for. Rank $1-8$ with 1 being the hardest)

a. Communication

b. Team Player

c. Areas of Knowledge

d. Organization

e. Character

f. Passion for Success

g. Influence

h. Critical Thinking 
13. Which competencies were the easiest for you to prepare your candidate for?( Rank 18 with 1 being the easiest)

a. Communication

b. Team Player

c. Areas of Knowledge

d. Organization

e. Character

f. Passion for Success

g. Influence

h. Critical Thinking

14. After your training is complete which competencies do you think your candidates exhibit the most? (Rank the competencies based upon your perception with 1 being the highest and 8 being the lowest)
a. Communication
b. Team Player
c. Areas of Knowledge
d. Organization
e. Character
f. Passion for Success
g. Influence
h. Critical Thinking

15. Do you feel that the set of 8 competencies are a good basis to select a National FFA Officer?

Strongly Agree Agree $\quad$ Disagree Strongly Disagree

16. What topics do your candidates research during their candidacy preparation? (Check all that apply)
a. FFA content knowledge/history
b. Relevant employment internships
c. Utilization of print/non print media sources
d. Information from industry/business through site visits
e. Agriculture Education knowledge/history
f. Knowledge of Agriculture Issues
g. Knowledge of Farm Bill
h. Communication Techniques
i. Leadership
j. American Education knowledge 
k. Do not know

1. Other (please specify)

17. Over the course of their preparation about how many hours of research did you think your candidates conduct total?

18. Approximately how many hours do your candidates spend in training per week?

19. After having candidates that have been through the process, what topics do you think are the most important for a candidate to research?
a. FFA content knowledge/history
b. Relevant employment internships
c. Utilization of print/non print media sources
d. Information from industry/business through site visits
e. Agriculture Education knowledge/history
f. Knowledge of Agriculture Issues
g. Knowledge of Farm Bill
h. Communication Techniques
i. Leadership
j. American Education knowledge
k. Other (please specify)

20. During the fall semester your candidates were running for national office they were enrolled in a post-secondary education program as a...

a. Part-time student

b. Full-time student

c. Never enrolled in a post-secondary education program

d. Took semester off from post-secondary education program

21. Did your university/college provide any resources to assist your candidates in preparing as a National Officer Candidate?
a. Yes
b. No

22. If you answered yes to question 21 , what were the resources provided? (please list) 
23. What type of internships do your candidates participate in during the summer or fall prior to the selection process?

a. Did not participate in an internship

b. Participated in a State required internship

c. Participated in an internship the candidate arranged on their own

d. Have no way of knowing

24. Did your candidates consult with any of the following for advice about the selection process?(check all that apply)

a. National Officer Candidates (past or present)

b. National Officers (past or present)

c. Nominating Committee members (past or present)

d. Other (please specify)

25. Did any of the following provide your candidates with feedback on areas of improvement? (check all that apply)

a. National Officer Candidates (past or present)

b. National Officers (past or present)

c. Nominating Committee members (past or present)

d. Have no way of knowing

e. Other (please specify)

26. Were any of your candidates a member of the Nominating Committee prior to running for National Office?
a. Yes
b. No

27. How well do you feel your candidates are prepared for the process?
a. Poor
b. Fair
c. Average
d. Good
e. Excellent

28. How far in advance prior to the national selection process does your state select its National Officer Candidate?
a. More than 18 months in advance
b. $16-18$ months in advance
c. $12-15$ months in advance
d. 11- 8 months in advance 
e. 7-4 months in advance

f. 3 months or less in advance

29. How closely does your state nominating committee process mirror the national nominating committee process?

a. Exactly the same

b. Some segments are similar

c. Not at all similar

d. Elected by popular vote without a nominating committee

e. None of the above (please explain)

30. What year(s) did you have candidates run for a national office? (check all that apply)

a. 2010

b. 2009

c. 2008

d. 2007

e. 2006

31. What year(s) did your candidates advance to the second round?
a. 2010
b. $\quad 2009$
c. $\quad 2008$
d. $\quad 2007$
e. $\quad 2006$
f. I did not advance to the second round

32. What state are you from?

33. What do you think was the most beneficial skill your candidates received from their preparations as a National Officer Candidate?

34. Other than being elected to National Office what would you like your candidates to gain by going through the National Officer Selection process? 
35. Which part of the process was the most challenging for your candidates?

a. Application process

b. Written test

c. One-on-One interview round

d. SAE Writing Exercise

e. Stand and Deliver Practicum

f. Facilitation Practicum

g. Round Robin Issues Conversation

h. Personal Interview Round

36. Which part of the process was the least challenging for your candidates?

a. Application process

b. Written test

c. One-on-One interview round

d. SAE Writing Exercise

e. Stand and Deliver Practicum

f. Facilitation Practicum

g. Round Robin Issues Conversation

h. Personal Interview Round

37. Do you think the current selection process is a good process for selecting a National FFA Officer?

a. Yes

b. No

38. In your opinion do you feel that the current National FFA officer selection process is structured to assist the nominating committee in selecting the best candidates?

a. Yes

b. No

39. After being involved in preparing candidates for the process, what recommendations would you suggest for change? 
Thank you for taking the time and effort to complete this survey. We appreciate your input.

If you have questions regarding the questionnaire, please contact me at:

bberkebi@mix.wvu.edu 


\section{APPENDIX C}

\section{Candidate Open Ended Responses}

Question 2-As you prepared to run for a National FFA Office, who provided you with assistance? ( check all that apply)

Active members of the Board of Directors were available for personal interviews (noncoaching, informational and opinion only)

Agricultural Industry Representatives/University Career Services

FFA Foundation and other sponsors

I sought help from anyone I could and found people were more than willing to help- all I had to do was ask.

My parents and State Agricultural industry representatives and supporters of FFA

No one "provided assistance" willingly, but I sought assistance from a variety of people (past national officers, chapter advisors, leaders in the agriculture industry, state association, etc.

Non-FFA mentors

Other current National Officer Candidates

Parents, my state officer team, church family

Past State FFA Officers

State FFA Foundation

State officer team members, other candidates

Very little help from state Advisor 
Question 3-In what types of training activities did you participate?(check all that apply) Attended training event in MN put on by past National Officer Candidate Journaled process through a blog. Journaled/recorded past experiences that taught significant life lessons Spent one with some upper Midwest officers in a training but didn't do much Was just given past materials printed out by past candidates.

Question 4-Which interview situations did you participate in while preparing to be a National Officer Candidate? ( Check all that apply)

Ag teachers

college leaders

College professor

College Professors

International visitors in US Department of State-sponsored programs (IVLPs)

State Department of Education staff

State Farm Bureau

State Supervisor of Education, FFA Sponsors

Question 5-When interviewing others, what types of information were you seeking to gather?

Comparative international ag and extension systems; Personal experiences with FFA

I focused on gathering all information possible about the specified ag issues to be interviewed on as well as state specific issues. Also to understand the dynamics surrounding aged at all levels.

Interview Style 
Question 9-What types of public appearances do you feel were most beneficial in preparing you to run for National Office? (Please list your top 3)

- Didn't really make any as a "Candidate" felt that was inappropriate. Any meetings I held with individuals was to gather information.

- Chapter Visits State Leadership Conference presentations College Banquets

- speeches, workshops, events where I mingled with agricultural professionals

- Did not do public appearances aside from state officer appearances

- Any appearances with FFA member

- My state association did not help prepare candidates at the time of my candidacy. My university allowed me to have opportunities to present and practice but my state did not really foster appearances.

- No one in my state association helped me to prepare in any way. Once the selection was over they gave me a timeline and suggestions and other than that all trainings were done on my own.

- National FFA Alumni Development Conference, Capital Visits, Round table discussion with State Commissioner of Agriculture

- FFA Camp Workshops

- Workshop presentations Meetings with State Education Officials

Meetings with State/University Agriculture stakeholders

- Presenting to government, presenting to students, presenting to community members. 
- Alaska FFA State Convention

Chapter Visits

Presentations before the Soil and Water Conservation Districts

- State 4-H and FFA winter leadership conference

State Convention

Talking with Business people

- Visiting chapters (local and out-of-state) to conduct workshops and interact with students

Meetings with US State Department guests travelling in international visitor leadership programmes $\{$ SIC $\}$

Events where asked to provide comments without prior notice (impromptu)

- Real time workshops that were preplanned; impromptu workshops; meetings with public officials

- Those that were impromptu

- Workshops with students, visits with ag leaders, visits with school boards not $100 \%$ clear on the value of FFA and ag education

- Civic Groups

Local FFA Chapter

College Students

- Chapter Visits

- Speaking Engagements

Workshops

- Civic groups

FFA Chapters

Political functions

- The only public appearance I participated in was workshop facilitation which was very beneficial. 
- Working with actual students to present workshops

Making comments about Agricultural Education to a Board of Education

- Interaction with FFA Members at conferences

- Conducting the State Greenhand Workshop

Meeting with Business Leaders

- Conducting camp workshops

Conducting mock interviews with aged professors

Conducting mock interviews with past national officers

- Farm Bureau Visit

Leadership Conference Workshop Facilitator

Alumni Visit

- Foundation sponsor recognition events.

State Fair

School Visits

- Presented recruitment workshop to new FFA chapter--150 students present Mock interviews

Agricultural field day

- Workshops to FFA members

Visiting a high school and giving a speech

Doing a speech to State Staff

- -Mock interviews with a variety of groups, even though they were not structured as 'behavioral based interviews'

-Presenting a few workshops to a variety of groups

- Workshops with FFA members, industry interactions.

- Classroom

Business meetings

Political events 
- Spending time with people my age

Time spent with high school FFA members

Greenhand conferences

- Chapter visits

Visiting home chapter

- Presenting workshops

Meeting with ag industry leaders in my state.

- TV, radio and representing at FFA events

- Greeting the State Farm Bureau, preparing workshops for FFA members and speaking with other CTE Associations

- Participation in ND Chapter Officer Training workshops.

Attended District Leadership Conferences with current State FFA Officers. Numerous interviews and sponsor visits with industry leaders, agricultural professionals, and sponsors.

- Local Workshops

State Activities

College Visits

- Bringing greetings at state FFA foundation dinner, presentations to high school student groups, Introduction on stage at state convention

- Participating in an FFA leadership camp, giving greetings at a formal banquet

- FFA Banquets

University Visits

FFA Fundraisers

- Speaking at FFA events. Practicing Workshops in local Ag classrooms. Preparing a leadership conference. 
- Stand and deliver, workshops, ag industry presentations

- Workshops in high schools

- speaking to agriculture industry representatives, staying active in the FFA through workshops and other appearances, and meeting with college professors to increase knowledge.

- National FFA Alumni,

- Workshops for FFA Members Teaching Ag Orientation Class 
Question 10-What types of public appearances do you feel were least beneficial in preparing you to run for National Office? (Please list 3)

- (Can't think of any--I did very few appearances)

- + Large-audience addresses

+ Meetings with state ag educator's association bodies

+ Prepared speeches to industry organizations with limited interaction time pre- or post-address

- Conducting mock interviews with CTE individuals Speaking at a banquet Chapter visit workshop

- Some meetings with ag industry leaders were not beneficial.

- All appearances were beneficial.

- All events were beneficial. I know it sounds cheesy, but it's true. Every opportunity to speak to people or meet people was a growing experience.

- All prep was beneficial

- All were helpful.

- Anything that just involved "being present" instead of actually testing yourself. (public appearances where you are just there...instead of having to visit with people, answer or ask questions, and practice your ability to think on your feet).

I don't really feel that are any appearances that don't benefit you in some way or form- you can always learn something from every situation.

- Banquets

Camp

State Convention

- Can't recall if any were not beneficial

- Did not have more than three public appearances

- general introductions and appearances 
- I did not participate in much more than the above, but I think any time you practice presenting to others is good preparation.

- I was able to gain something from every public event I attended during my preparation.

- learned skills from everything

- meeting with ag leaders, ag teachers, etc. due to the fact that a majority of knowledge came from print or internet. It was difficult to find a national perspective in our state.

- N/A

- $\mathrm{n} / \mathrm{a}$

- $\mathrm{n} / \mathrm{a}$

- No such thing.

- None

- None.

- Representing FFA at CDE meetings

- State Ag Teachers Meeting Phone Interviews

Practice with college peers

- State Agriculture Teacher In-service State Leadership Banquets

- Talking with other candidates Training put on by the University of \{STATE\} Not Really knowing the correct areas of study

- Writing exercises, everything else was beneficial in some way 
Question 12-If you presented workshop(s), what were the general topics of your workshop(s)? (List all you can recall, if you did not conduct workshops, put N/A)

- Leadership

Time management

FFA history

Communication

- "New media" as a chapter resource

Principles of TEAM for chapter officers

Get with the program- Developing a POA

Personal growth series: Acceptance and tolerance

Personal growth series: Emotional IQ

Personal growth series: The leader in you

Personal growth series: Image the Potential...Habitudes

Making the message: advocacy and building awareness

Resources of the Team Ag Ed Learning Center

Communicating the benefits of FFA membership

Alumni in the local chapter

National Quality Program Standards: implementing to build local program success and accountability

Addressing the Ag Teacher shortage : inspiring today's student to be tomorrow's educators

Developing a chapter officer selection process

Collegiate membership/programs

FFA in the 10X15 Agricultural Education Strategic Goal

- Alumni

Ag Issues

Ag Education Issues

FFA

Leadership

- Careers/College Opportunities in Agriculture, facilitation techniques, basic leadership

- Chapter Office Team Development

Personal Growth

- Chapter officer responsibilities, teamwork, goal setting

- Chapter visit curriculum, chapter officer training, Greenhand involvement

- Communication skills, leadership, teamwork 
- Communication, Teamwork

- Did workshops on all of the topics that were provided to candidates

- Etiquette

- FFA knowledge Farm Facts

Ag Issues

- General leadership (all the workshops I facilitated were for younger students)

- Goal setting and Goal Preparation

- Goal Setting, Time Management, Vision

- Goal-setting, developing plans, building relationships, developing a servant-mind for leadership, conflict resolution, parli-pro skills and knowledge, and others

- Hot Topics for the year. Most were randomly selected and I would present them.

- I only did one and I can't remember. Something to do with general leadership. It was very basic and general.

- I used the "hot facilitation topics" provided by nationals

- Involvement in FFA

Character Development

- Leadership

Accountability

Natural Resources

Influence

- Leadership

FFA Involvement

Setting Goals

- Leadership

Healthy Lifestyles

- Leadership

Personal Growth

- Leadership, Character, Goal Setting, Team Building

- Leadership, Communication, Agriculture Issues, Relationships, Social Media, Vision and Mission Statements, and Organization

- Leadership, FFA Knowledge, Communication

- Leadership, FFA, 4-H, Dairy subjects, Agriculture \& other things I got asked too 
- Leadership, Group Interaction

- Leadership, Mentoring, Civic Engagement, Happiness

- Leadership, middle school level

- leadership, records, communication, teamwork, and job information (writing)

- Leadership, Teamwork, Character, Chapter Development, Health,

- Leadership. Involvement in FFA. Chapter Officer Relationships/Responsibilities. Communication.

- Misconceptions of AG

- $\mathrm{n} / \mathrm{a}$

- $\mathrm{n} / \mathrm{a}$

- Personal Development Time Management Goal Setting Making Good Choices

- Personal development.

- Physical health, character development, ag/FFA knowledge, FFA opportunities.

- Teaching methods, active involvement

- Teamwork, goal setting, FFA recruitment/facts, individual strengths and appreciation of others' strengths, prioritizing, and leadership.

- Teamwork

Leadership and character

I did NOT present enough workshops and this was the weakest area for me during the election process.

- The hot topics for workshops given by National FFA.

- The Workshop Topics provided by process

- They were all hot topic oriented.

- time management, character, world change

- Topics from the top ten list provided by NFFA

- Values

Self Worth

General Leadership

Time Management

FFA Opportunities

- Various leadership \&ag topics 
Question 18-What topics did you research during your candidacy preparation? (Check all that apply)

$\mathrm{Ag}, \mathrm{Ag} \mathrm{Ed}, \mathrm{Ed}$

Current issues in agriculture

International agriculture and extension systems;

My faith

Selection Process

Teaching styles

Question 21-Now that you have been through the process, what topics do you think are the most important to research?

everything was important

Knowledge about yourself

knowledge of self and your own unique strengths

Knowledge of the Selection process

Psychology of education

Research yourself- I think being able to answer questions with personal experiences is very important to the process. I should have spent more time analyzing my history and my past experiences.

Selection Process

The Selection Process

Under the new process, this prioritization changes greatly from year to year

Understanding and manipulating the process to your advantage

Yourself. You need to know that more than anything else. If you are a person of character, the other stuff can be taught to you.

Question 24-If you answered yes to question 23, what were the resources provided? (please list) 
- A lower credit load and flexible employment.

- A special problems class to work on writing skills, interviewing, workshops, American education, agricultural education, and FFA history. A National Officer Candidate enrolled in the same class to help me. A book complied by past National Officer Candidates.

- Advice

Time off to study

- Assistance with interviews and conducted visits with leaders on campus to learn more about agriculture and agricultural education.

- Coaches as well as interview sessions with professors

- College Professor

- Faculty help, also covered some of the costs. I also got independent study credit.

- Gave me 3 credit hours for preparation. Staff Support

- Help from University Professors

- I receive some assistance. If I had a question then I could ask my advisor for help in answering it but that was about it. I received very little help.

- I was able to gain 4 credits in an independent study for National Officer preparation, FFA and ATA advisors set up workshop training for me, facilities were made available for me to practice Stand and Delivers, teachers worked with me by excusing absences for National Convention and training conferences.

- I was enrolled in an independent study course to use as my preparation time.

- in my university the Agriculture Education professors were very helpful in lining me up with information about Parli-pro, and the history of agriculture education.

- Independent study courses that allowed for research that contributed to my prep and mock interviews.

- Information regarding agriculture education, speech critiquing and great supporters. 
- Meetings with faculty members to learn more about relevant topics, flexible class schedule, mock interview participants

- Practice with certain graduate students

- Professors interviewed me and offered advice.

- Professors to assist in mock interviews, a few informal conversations to gain ag/industry/education knowledge.

- $\quad$ received $2 \mathrm{hr}$. credit for time spent studying, advisor spent time mock interviewing, having discussion to seek understanding

- Staff meetings

- Students to interview with. Study class for 3 credits. Material professors received regarding Ag Ed and FFA. Contacts of local ag teachers.

- $\quad$ Support, Encouragement, Coaching

- Talked with advisor/professors who had helped with the process in the past. Was provided with FFA Board minutes.

- The College ambassador team participated in several mock interviews with me over the course of my training.

- The College of Agriculture provided the most resources. They helped arrange mock interviews and coaches, etc.

- The University itself did not GIVE me opportunities, but I found a lot of knowledge and help through courses I was taking in Agriculture and Natural Resources as well as through personal connections with professors.

- The vice chancellor of our agriculture college at Nebraska was extremely supportive. He offered me not only a wealth of agricultural knowledge, but also a list of contacts and advice on personal values.

Also: several professors offered their research documents, including the Horatio Alger FFA study, and many PowerPoint presentations on things like the proposed GALA for ag programs. 
- Their knowledge.

- Time

Question 26-As a candidate did you consult with any of the following for advice about the selection process?(check all that apply)

Board of Directors members (past and present)

I talked with past candidates but she was the last candidate under the old system and I was the first year under the new system and she offered little relevant help. The 2nd year I ran I consulted someone who had been on the nominating committee when I ran the first time.

National and state staff

Other past State Officers, State Staff

State adviser

State FFA Executive Director and my mentor

This past nom com member was from the mid 90's.

Question 27-Did any of the following provide you with feedback on areas of improvement? (check all that apply)

State FFA Executive Director, current and past State FFA officers

state staff

State Staff, Other past State Officer

This past Nom Com member was from the mid 90's

Question 31-How closely does your state nominating committee process mirror the national nominating committee process?

I was selected by the State FFA Advisory board, no interview process was given. This has changed since I ran. 
I was the only candidate.

Now it mirrors the process very closely but when I ran it was nothing at all close.

Was the only person interested in running my year so I did not participate in a candidate selection process

Question 34-What state are you from?

Alabama

Alabama

Alaska

Alaska

Arizona

Arizona

Arkansas

Arkansas

CA

$\mathrm{CO}$

Colorado

Colorado

Idaho

Idaho

Indiana

Indiana

Iowa

Iowa

Kansas 
Kansas

Kentucky

Kentucky

Kentucky

Maryland

Maryland

Massachusetts

Michigan

Nebraska

Nevada

Nevada

New Jersey

North Carolina

North Carolina

North Dakota

North Dakota

Ohio

Oklahoma

Oregon

PA

South Dakota

Tennessee

Texas

Utah

Virginia 
Virginia

Washington

West Virginia

WV

Wyoming

Wyoming

Question 35-What do you think was the most beneficial skill you received from your preparations as a National Officer Candidate?

- Ability to connect with all ages of people

- Agricultural Education Knowledge

- Ability to talk off the cuff, organize my thoughts, and speak intelligently about a subject. I also learned more about myself and much more able to handle constructive criticism.

- $\quad$-Ag knowledge

-Interviewing

-Self initiative to set up training opts

- Agricultural Issues knowledge.

- Beginning to know myself. Truly know myself. My weaknesses, strengths, likes, dislikes. And learning to be the best me that I could be. I believe a Candidate's only job is to show the nom com their true selves. If they do that the committee and can make the best decision.

- Being able to blindly contact people for information interviews.

- Being able to participate in interviews, having a good knowledge of myself and my values and standards, improved public speaking and facilitation skills, improved writing skills, improved knowledge of FFA procedures, improved understanding of current agricultural issues.

- Communication and interpersonal skills 
- Communication and interview skills when working with industry leaders and other adults. Self confidence and intrapersonal skills. I learned a lot about myself and the type of leader I was during my run for National Office. That knowledge about myself still benefits me today.

- Communication skills in all settings

- confidence and resiliency

- Confidence in myself.

- Critical Thinking Skills

- Determination I had to work very hard and confront several obstacles to get to be the NOC and I had to be determined to continue to run after being selected.

- Developing lesson plans for myself that met objectives that I created to match the national competencies.

- Diplomatic communication

- Discipline

- I improved my communication skills and further developed my leadership abilities.

- I learned a lot more about myself

- I learned how to explain/express who I am in a series of short conversations and practicums.

- I would say that the best skill I received, knowledge base of agriculture as a whole. the training helped me to become well rounded in all areas of agriculture.

- Interview

- Interview Skills

- Interview skills

- My ability to adapt to uncomfortable and unfamiliar situations. Even when I am outside of my comfort zone and around people I have never met, the skills I gained through preparation help me to perform.

- My interpersonal, time management, organizational, and interview skills.

- my interview and presentation skills, along with the knowledge I developed on the agriculture industry 
- My knowledge base about FFA and education in general greatly increased from the preparation. My impromptu skills also benefited.

- My own research

- Networking

- Networking

- Personal awareness

- Probably the most beneficial skill that I received was learning to seek the help of people in the industry.

- Reading my audience

- Realizing the foundation of why we run... Growth in students, the organization and ourselves.

- Simply obtaining the skills needed to survive the process. Running for National Office is almost an intense as an interview process can get. Learning how to manage myself mentally throughout the process has proved useful in subsequent endeavors.

- The ability to practice assimilating thoughts into clear, concise, memorable answers during mock interviews

- The ability to reflect on my experiences and specifically name what I gained from those experiences.

- The ability to reflect on my own personal characteristics, attitude and competencies. Also working with others to gain constructive criticism/feedback and learning best how to use and implement that feedback.

- The direct correlation with working hard and seeing the results of effort.

- The skill of FFA and educational knowledge

- Time management and my ability to interview.

- Understanding that I can fail and be strong throughout my failure

- Working with Corey Floruonoy

Question 36-What training would you have liked to have received that you did not get?

- mine was spatial, wouldn't change anything

- More training on the selection process 
- Any training would have been nice.

- Better understanding of the process and especially what the committee would be looking for.

- Big states had HUGE support and training. It was odd because the year I ran the top 6 membership states had their candidate get elected - Oklahoma, Ohio, Texas, California, Georgia, \& New Mexico. Plus- some of those candidates were running for the second time - Oklahoma \& New Mexico. These states had Association funded trainers who prepared them - which seemed unfair when coming from a smaller state that couldn't afford it. It made the process seem completely unfair also.

- Competency training and how to apply that to interviews, workshops, speeches etc...

- Competency Training

- How to speak naturally, not in "state officer voice"

- I can't really think of any. There is no set way to prepare in my state. I was free to prepare how I best saw fit. I really liked that freedom and flexibility. I felt my training was pretty well rounded. My written communication was probably the weakest part of my entire preparation.

- I still don't understand the Farm Bill.

- I wish that my state would have given me and my future and past National Officer Candidates some help in knowing about National Officer Candidate workshops and retreats.

- I would have like to know more about the process and what it is that the Nominating Committee is looking for in a candidate. I know that I have the skills to make a good national officer but I did not know how to show them I possessed those skills.

- I would have liked more training on how to give workshops. When I served as a state officer, we never spent a ton of time on training. We just did workshops. I learned after and while I was running for a National Office that there are specific things you can do in order to present a better workshop. I was least prepared for that portion of the process. 
- I would have liked to attend the training conference in Chicago, but it was too expensive. I wish I could have received more training in regards to mastering nervousness.

- I would have liked to have had more in-depth training to be prepared for behavioral interviewing. I would have also loved to have been given more opportunities to connect with professors and industry professionals about agriculture.

- I would have liked to have had training in the actual process of selection that Nationals uses.

- I would have liked to have more hands on training from my state. A more detailed schedule, more interviews from stakeholders in FFA, and work with other NOCs through the process.

- I would have liked to have received training in American Agricultural Issues. I wish I had also gained additional insight into the nominating committee process.

- I would have liked to receive more coaching about what to expect at the interview process.

- I would like to have worked with past national officers and trainers at workshops. I would have liked to have had the opportunity to work with someone who understood the process and could have explained it to me.

- Interview skills

- Mock interviews, guidance on what types of things I should have been studying or preparing for.

- More encouragement in developing workshop outline based on the 10 hot topics of the facilitation round; more structured meetings regarding agriculture issues

- More facilitation skills, not presenting skills

- More knowledge about written exam

- More personal development would have been nice. 
- More public speaking appearances

- More support from my state staff would have made the process much easier.

- More training on personal interview based on how the national officer selection process is run.

- More training with my state and more interviews and more narrow focus of area to study

- $\mathrm{n} / \mathrm{a}$

- N/A

- N/A

- On what the nom com is looking for

- Personal training--at times, I needed to give myself more personal encouragement.

- State resources were limited, with little to no external support from state university system and regional culture of non-cooperation amongst different state's candidates (compared to other regions). This limited the range of experiences available to build a pool from which to draw or receive feedback.

- Strengthening speech preparation

- The criteria always seemed slightly ambiguous to me. I was never entirely sure how the Nom Com was evaluating for these criteria. How do you evaluate someone's Passion for Success, for example? I am sure they have an effective process, but I wish I would have been slightly better prepared for exactly how these criteria are sought out.

- Training of the comps and exactly what the NomCom was looking for, like key words for example.

- training to help block out other candidates and focus on self

- What to do if not elected.

- Writing skills

Question 37-What most prepared you for the process? 
- Simply knowing you're what they're looking for or you're not

- conversation with state staff and university personnel

- Conversations with State Staff, teachers, students, state officers, and other stake holders. The conversations where I could ask questions and have them tell their opinion and point of view helped the most. From that, I was able to form my opinions and also got a very complete picture of how issues affected different parties.

- Conversations with willing mentors about my personal success and growth opportunities

- Experience as a State Officer

- Field experiences and personal interactions

- Getting encouragement from our state FFA staff to continue preparing, but also just living life as a 'normal' college student so I could just be myself throughout the preparation process and the selection process.

- Hard personal coaching...and a passion for the organization.

- Help from a previous candidate about the process and how it operated.

- hours of practice.

- I did not feel prepared once the process was over. I do not feel like I had the right training.

- I think that interviewing agricultural professionals prepared me the most because I received knowledge and information from a variety of sources. I understood the agricultural industry better and was able to use that knowledge (and the poise and interview skills I learned by visiting with those people) throughout the entire process. I also spent a lot of time practicing the stand and deliver portion of the process because I knew that being able to present a full extemp speech from memory would be a challenge.

- Interview and workshop practice

- Interviewing professionals in the agriculture, education, and business/industry.

- Interviews

- Meeting with different people who are important to the work of a National Officer--teachers, students, industry people, and those not connected at all with FFA and $\mathrm{Ag}$ Ed. 
- Meeting with members of Indiana Farm Bureau to discuss Agriculture issues. Presenting workshops to local Ag classes. Working closely with the Program Specialist in our state and talking with past National Officer/National Officer Candidates.

- Meeting with mentors

- Mock interview and process sessions

- Mock interviews

- Mock Interviews

- Mock interviews

- Mock interviews

- Mock interviews and practicing like it was real.

- Mock interviews were the most beneficial practicing I conducted.

- mock interviews, practicing facilitation and impromptu speeches

- Nothing.

- Personal interviews, and lots of them! Tons of study for the written exam, and lots of practice round robin conversations and stand and delivers.

- Personal reflection about my life and knowledge

- Personal reflection time to understand why I was running and how to articulate it to peers.

- Personally, being a state officer prepared me for the process. I think I was personally a good fit with the training I provided myself with my own understanding of the process. Additionally work with a professor named John Riley really helped.

- Practice interviews, talking to past National Officers and running workshops.

- Practicing

- Prayer and conversations with mentors / close friends

- Selection Process run-throughs

- Self research

- Speaking with past national officers helped me understand exactly what responsibilities I was preparing for.

- The best preparation I had was setting up my own training and working in reallife FFA events.

- The personal reflection time. My first year through I felt that it was all about the soft skills - knowledge, communication skills, etc. But during my training for the 
second time I decided to take a different approach and focus on my personality. Yes, I spent time with the knowledge and facts, but I mainly focused on my heart and why I was running.

- The thing that prepared me the best was working with a past nominating committee member.

- Time spent with agriculture industry representatives. They offered not only a wealth of information on agriculture, but they were extremely supportive of me running and gave great personal advice.

- Time with students.

- Understanding the process before I got to convention helped me prepare the most. I went through each activity that would be asked of me so as to not be caught off guard.

- Working at state department of ag summer before running

- Working with my coaches

- Working with past National Officer Candidates and the individual who had run our state nominating committee

Question 38-As you reflect back on your training program were there preparation methods or topics that you felt you spent too much time on? (Please list)

- Commodity prices

- Ag Issues

- Ag Knowledge

- Ag, FFA, Education knowledge

- Because I only have a few months (4 1/2) to prepare, I don't feel as if I over prepared for anything. I felt adequately prepared in all areas when I went to Indianapolis. It wasn't until afterwards that I realized I was underprepared in some.

- Farm Bill and team-related exercises

- FFA history/knowledge

- FFA Knowledge, Farm Bill, FFA/Ag History

- I don't believe so, I think that all areas helped me, but I do wish I would have studied more on all areas.

- I don't feel there were any methods or topics I spent too much time on. 
- I knew FFA history more than I really needed to. I also spent a lot of time studying current ag issues that were not on the test.

- I needed to spend more time studying.

- I spent a lot of time researching knowledge areas that weren't as vital as I expected.

- I spent too much time making sure I wanted to be a national officer. I played serious mind games with myself.

- I spent too much time on knowledge for the written test

- Mock interview preparation. While some mock interviewing is beneficial, too much caused me to over think my one-on-one interviews.

- $\mathrm{N} / \mathrm{A}$

- No

- No

- no

- No the amount I spent on topics was perfect

- No, I wish that I would have spent more time on each area.

- No.

- none come to mind

- none I can think of

- None, in large part due to introduction of Hot Topics system

- Not possible. Everything is valuable if you get elected or not. There's no such thing as too much knowledge.

- Not really. I spent about an hour a day studying. In the end I felt confident and well prepared. I simply focused around Agriculture Issues, Education, FFA, and personal development.

- Nothing really comes to mind

- Nothing. I wish I had just had some additional training in areas where I was weak and in understanding the process. 
- State Agricultural Issues

Leadership Training

- Studying random facts--only about $20 \%$ of them are useful, but I had to spend countless hours memorizing everything possible just in case it came up on the test.

- The knowledge areas - especially my first year running.

- There was no training process.

- Too much time prepping on the history of the organization/aged/agriculture. The quiz is basically worthless in comparison to the overall score. Instead, it mattered to attempt to guess what questions were going to be asked to better figure out the system and get points for your answers.

- Too much time spent on FFA History. That was the main topic, but I wasn't sure enough of the other topics to speak knowledgeably about them.

- Written Test materials (Ag ed issues, FFA issues, Ag issues)

Question 39-As you reflect back on your training program were there preparation methods or topics that you wish you had spent more time on? (Please list)

- all of them.

- American Agricultural Issues

Educational Issues

Self-Confidence

- Competency Training

American Education

- I wish I had spent more time with people with different perspectives on agriculture, not just large scale production people.

- I wish I would have spent more time focusing on the competencies and finding ways to utilize those competencies in each process/answer. 
- I wish I would have spent more time on everything. I went into the process at national convention feeling prepared but left realizing I was very unprepared.

- I wish I would have spent more time on industry visits and workshop presentation skills.

- I wish I'd have spent more time on preparing workshop ideas for that round.

- I wish that I would have spent more time on the stakeholder round in particular. I think this round might have hurt me in the process only because I did not speak of the correct points.

- impromptu workshop and speech skills

- Interview Round Preparation

- Interviewing

- Interviewing questions and answers Industry and Agriculture

- Interviews and talking with people in industry

- Interviews, public speaking and workshop presentations.

- Just knowing the process like the other candidates did.

- Knowing myself in and out Better techniques for behavioral interviewing Working more on my extemp speaking abilities

- Knowledge, and how the system works

- More facilitation round training Issues facing Agricultural Education More agricultural issues

- More personal time reflecting on who I am, with no one looking. I also wish I would have spent a little more time with FFA members.

- no

- no.

- No.

- One on One interview skills

- Speaking and writing

- The material on the test and extemporaneous speaking skills 
- The Passion for Success, Character, and Influence areas my first year.

- The personal interview questions were really geared toward your year as a State Officer, so I wish I had prepared more stories from that year specifically to share with the Nominating Committee.

- The SAE writing activity Stand-and-deliver practicum

Communicating "character"

- Understanding the process.

- wish I would have spent more time asking past nom com people how competencies were scored

- Workshop presentation

Ag education questions for the written test

- Workshop techniques

- Workshops, SAE writing

- Writing skills. I have never been a strong writer. I could have probably practiced it more.

- Writing, Facilitation

- Written Test

- Yes! I would have liked to have spent more time on most all of the interview round topics, but probably specifically current American and agriculture education issues, and agriculture issues.

Question 40-Other than being elected to National Office what did you expect to gain by going through the National Officer Selection process? 
- my intentions were to be $100 \%$ satisfied with the process before the election was ever announced. My growth as a person, sister, daughter, friend was more of a benefit overflow than even being elected.

- A better understanding of myself and clarity of my future vision.

- A great chance to lead the best youth organization in the world!!

- An answer to a personal question

- Being able to talk to business and industry people and to develop myself while helping others.

- Friends, Experience, skills needed to make a difference as a National Officer or through another venue

- Friendships, interview skills, and the experience of a lifetime

- Greater knowledge of Ag and Ag Education

- Greater understanding of FFA, education and Agriculture. Also self confidence.

- Growth as an individual

- Growth for others as well as myself.

- I aimed to conquer my fears and really get to know who I was. I wanted to have experience going after something really difficult to be able to share with other FFA members.

- I expected to build relationships with other candidates, network and grow personally. I also expected to increase my level of knowledge about the agricultural industry.

- I expected to enhance my presenting and speaking skills, which I certainly did. I also knew the candidate pool would be filled with high-quality individuals, and I expected to meet some awesome people with whom I shared much in common. This also was very true, and I look back at that time and those people with great fondness, and still keep in touch with many of them. I also expected it to be unrelentingly difficult. At the same time, I anticipated it to be very rewarding. I found it to be both.

- I expected to gain a lot of valuable leadership skills from the preparation. I also expected to broaden my understanding of agriculture, agricultural education, and the FFA.

- I expected to gain contacts which I did. I expected to learn about who I was as a person. I learned more than I expected. I expected to gain insight into what it takes to be in the "inside" world of FFA.

- I expected to gain friends to broaden my network. I also expected to have a quality experience and come out more prepared to handle other interview 
situations such as jobs because of the intensity of the National Officer Selection Process.

- I had no additional expectations.

However, I did learn a lot about myself and networked with some great people from different states and the National FFA.

- I hoped to discover more about myself and who I was. I hoped that it would help me figure out what I was mean to do with my life. It did all of these things and more.

- I hoped to gain a greater perspective on the agriculture industry, and to personally grow and gain skills from this unique opportunity

- I hoped to improve myself personally and professionally. This would help me improve public speaking, leadership ability, and self-confidence.

- I knew that it would be an intense interview process that would be valuable for any type of interview I would conduct after that.

- I saw it as an extension of the state officer experience with new expectations--I would be a mentor for state officers and students but also allowed to continue to learn from $\mathrm{Ag}$ teachers and industry people.

- I was hoping to meet around 50 of the most influential FFA members in the country and I was blown away by every person I met. I was also hoping to grow and learn about myself.

- Increased leadership and communication skills

- interview skills

- knowledge of self, connections through people. and knowledge

- Knowledge of the agricultural industry, experience in interviewing, increased leadership skills

- Learn about myself.

- Learn more about myself.

- Lifelong skills, public speaking skills, ability to think on my feet, connections

- Networking Interview Experience 
- New friends! I couldn't wait to interact with the other candidates. In addition, I hoped to come out with a higher level of character and a deeper understanding of my priorities beyond what the public eye sees.

- Personal and professional development (genuine and concise communication, drive and initiative towards an extreme commitment, and thorough knowledge of ag issues for future career opportunities); building friendships with other candidates; and the opportunity to let God work in the process (if I didn't run, $\mathrm{He}$ couldn't work in that situation.)

- Personal development of knowledge, competencies and networks Ability to expand leadership potential Personal experience upon which to continue pursuing life passions

- Personal growth

- Personal growth Relationships

- Professional skills and personal connections/networking.

- Relationships with other candidates, personal development, and a testing of my abilities. I wanted a sense of satisfaction in knowing that I did my absolute best to get elected.

- Self-Improvement, Lifelong friends, Experiences that I will never forget

- Social skills.

Job preparation and opportunities.

Friendships.

Better self understanding.

- Well, I didn't get selected but that is something I would have liked. I would also would like to have an even shot of getting the spot.

Question 45-After being a member of the process, what recommendations would you suggest for change?

- A group interview is needed for more accurate office placement and team dynamics. 
- After being a part of this process I would say that I would not want to be a part of the Nominating Committee because it is a very tough job. I think it is structured well it is just a difficult place to be. My thoughts on the selection process are that it is based on being the person they want you to be. I don't mean they want you to be someone you aren't but I feel the process lends itself to those who have the best prepared answers based on the competencies. I don't know how you would change the process because you have to have some way to narrow it down. I just feel it is an interesting process.

- Allow one more round of interviews to be included before the cut (ie. RoundRobin interview)

- An additional round where the NomCom and candidates could speak freely and restructure the "fun activity" so that the NomCom are not bunched together.

- Don't build a nominating committee solely out of members who gave up their chance to run for national office. Also, don't make the written exam just a few days before the actual process especially when the FFA website and information changes RIGHT before nationals.

- Easier Application Process

Less on competencies

- Eliminate the cuts. I feel that cutting the bottom half of the regions candidates is not fair, for example Southern region had 6 candidates and the eastern region had 13 candidates so the Southern region had to beat 3 other scores where I had to getter a higher score than 6 candidates. That's 3 more people they the Southern Candidates. Also the nom com came up to me after convention was over and they all told me they wanted to elect me to office that I am the type of person they want to put in the spot but since I didn't make it to the second round nor did they have a say of who gets to go in to the second round could they elect me.

- I can't think of any changes that would help the process.

- I don't believe the process fairly assesses a candidate at a holistic level, nor does it assess their ability to truly be able to do their "job" for the year. Also, it is frustrating for candidates that do not make it to the second round to only have been able to be with each nominating committee member a total of 15 minutes. Though I believe that most decisions are snap judgments, for the sake of all the 
hype that is made over candidates being the best of the best, I believe they do deserve a bit more respect, than what 15 minutes of time offers. Furthermore, I feel as if there should be a portion of the interviews that is focused on donor relations. This is a huge portion a NO's job and they need to be able to garner financial support, thus I think that should be assessed in the competencies.

- I feel that the process could benefit from allowing the Nom Com to have a bit more personal input. They are selected and trained because they have a valued and trusted opinion. The process does a good job at identifying the strengths and weaknesses of each candidate: however, a completely objective process does not allow for the Nom Com to input their trusted opinion.

- I felt that the SAE Writing exercise was a waste of time. I didn't feel like it added anything to the table for the nom com to evaluate.

- I liked the process. I had a great week at convention and felt the process was fair. There will always be people who slip through the cracks, if you will. And that is because not everyone's motives and intentions are where they need to be. There will never be a completely perfect system.

- I really feel like this is an effective selection process that allows for successful results. With any process like this, there are so many variables that come into play. The best things about this process is the mix of behavioral based questions to learn about individuals' character and the activities that put candidates in situations that that will actually be doing as an officer (stand and deliver, round robin, facilitation round).

- I think the current process is good but could be more effective. Sometimes the competencies are hard to prove and just because a candidate does not say one of the specific "buzz" words does not mean that they do not meet the competency. Unfortunately, it seems that sometimes candidates have been able to "rehearse" their answers to questions. I am not sure what to offer in that regards because there will always be those people. All in all though, I feel that the process is pretty good.

- I think the process is fine. Once elected officers are molded into what they need to be. Most years there is at least one officer (from my previous work with teams) that seems to have manipulated the process long enough to get elected and then really does not seem to fit with the team or as an officer. For that reason, I wish there were a part of the process that could be used to expose that underlying character. Many candidates are trained to play a part during the process and manage to get elected. Those end up being the people that are the awkward fit 
with their teammates. It's disappointing because they take the place of someone who may have really fit the position and office well.

- I think too much emphasis is placed on the test in the early rounds. I remember feeling significant pressure to do well on the exam, simply because so much weight it placed on it before "the cut". Equally disturbing to me as a candidate was how much of our "pre-cut" score was based on rounds that did not involve us interacting with the nominating committee. In my opinion, the information demonstrated on the test and written rounds is important, but not so important that individuals who have the right personality and skills to be an awesome National Officer could be excluded so early ( and I made it to the second round).

- I truly believe there should be no affiliation between Nom Com members and candidates. Also I believe everyone should be given the same information, that no trainer should set candidates up on ways to beat the process. I think that it should be geared more to the person's character and personality and ability to be able to perform speeches and be in pressured situations. Other information can be learned.

- It kind of stinks that some states have such a big edge on other states because they know the process. My issue with the process is that it is not always the response the candidate is giving but what words are stated in the response. I understand there has to be some type of non-biased way to score candidates but it is all about saying the right words so you can score higher.

- It seems like the people who do the best are the people who know the process the best.

- It would be great if there were a standardized preparation process.

- Make less predictable questions that people can have mocked answers for. Be sure to try and get genuine answers from candidates by structuring questions so they require genuine answers.

- Make sure you ask the question and really listen to their response when asked "Why do you desire to serve as a National FFA Officer?" Look for the most genuine answers. 
- More assistance to candidates on what to study and prepare for. My state did not assist me and running the first year of the new process made it challenging to prepare on my own.

- More evaluation on the individual's character: possibly through more one on one time. Also, I think it would be important for the nominating committee to see how every candidates interacted with the FFA members, before the first cut is made: whether that is through workshop facilitation or a short conversation.

- more time for all the rounds. additional rounds of one-on-one and group interviews so that the nom-com can better get to know the candidates and find their true personalities and skill sets

- NA

- National FFA should have additional resources for National Officer Candidates on the website. Running from a small state, I found it difficult to compete against those who came from a state that supported them with increased resources. I feel this lack of additional resources is a limiting factor for members of small states.

- No eliminations before the convention even starts. Introducing yourself as a candidate at the session after you've already been eliminated is very disheartening.

- None

- none.

- not sure

- Nothing.

- Nothing. This system is designed to find individuals that possess the deep down personality traits to lead the organization. The system doesn't worry about finding individuals who know everything and can speak really well - it wants those people that can walk into a room filled with any audience, make a connection and deliver results. It also wants to find people that are humble enough to know that they are not perfect and they will find success through growth .

- I think that it is a good process...but not perfect. The biggest flaw I see in the process is that each question is designed to measure certain competencies. If you answer a question very well but in the wrong direction (they don't tell you what competency they are measuring when they ask a question), you may get killed in that intended competency area. If you have more questions about what I'm saying 
here (from my own personal experience)- send me an email:

brooke.1.jameson@sendit.nodak.edu. I honestly don't know a lot about the behind the scenes of the selection process, so I'm not entirely sure if this is the best process. I think that the competencies and information gathered from the process should be used to assist the nominating committee members to make their decisions. The officers should not be selected solely by data.

- Take another look at the Round Robin rounds - they are meant to show a natural setting, although with people "standing in" for roles they do not actually play, I felt unnatural.

- The process is good to an extent, but it is set up to pick the "best 6 " not to pick the best team. In reality the team may not spend much time together throughout the year, but they must work together and uniformly to make the FFA look good. My suggestion would be to bring in a round or activity where candidates must work together to see if they are compatible.

- The process reveals 'real' people.

The only suggestion would be to not limit only 3 people coming from each region. Elect the best 6 candidates, not based on location.

- the process seems fair but those in big states who can afford trainers or have had previous national officers (in this process) were more likely to get elected. People are simply figuring out the system and becoming elected because of it. a different system is needed.

- The types of questions asked in one on one interviews do not give the nominating committee a chance to really see what kind of person you are.

-The star battery is not a good way to measure the amount of FFA and Ag knowledge that a person possesses. There is no way to determine how much knowledge a member has from this form for the simple reason each individual $\mathrm{SAE}$ is unique.

- There is still a persistent disparity in advancement of "small" state candidates. Nom Com members exhibit difficulty identifying difference between candidate potential and current candidate ability. This is an observation developed pre- and post-involvement in my own process year. This is likely an issue of training and guidance as well as "political" influence.

Allowing for an additional scored component for interaction with nom com prior to the first-round cut. 
Encouraging via programmatic components the formation of a candidate network prior to convention so that those who would like to share resources and collaborate in their personal preparation journeys have a support structure to do so.

- There needs to be a personal interview round before the first cut- I felt like the nominating committee didn't really know who I was yet and the questions in the One on One didn't get at what I have to offer. Questions in the One on One interviews were too specifically about the state officer year- all states run differently and some of the questions they asked simply didn't apply to me. We got to use computers for our essays and I think everyone should- handwriting things is archaic and doesn't give the nominating committee a chance to really see your writing ability.

- There's something wrong with a system where you can earn points by studying the desired traits of a National Officer and dropping the right words in an answer. Maybe we shouldn't know the exact traits that we're being scored on--I appreciate the transparency, but it's a little extreme and seems to undermine the goal of the process. We're looking for people with integrity, not people who know which example to give to feign integrity.

- We had the first year for the social event with nom com. It provided for inappropriate interaction with nom com and candidates. Lots of dancing and flitering with some candidates. Probably did not impact the final product but did not look good.

- You can't make FFA robots. The competencies are designed to find people who will say and do what FFA wants, not real people with real personalities. There are some great National FFA Officers, but they many times do not represent what FFA is about: down-to-earth relatable individuals. It should not be about who can nail a competency. There has to be balance between someone charming Nominating Committee and someone just understanding what the competencies are. Have processes that do not weed out a bunch of people right away. That's how you lose great potential National Officers. 


\section{APPENDIX D}

\section{State Staff Open Ended Responses}

Question 2-As your candidate prepares to run for a National FFA Office, who provides them assistance? (check all that apply)

Ag Business professionals

Business and Industry

Coached by Executive Secretary

Exec Sec

it changes every year

Personal Coach - selected by NOC

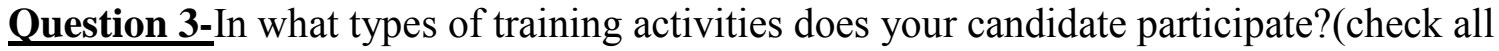
that apply)

Because the candidates preparation is self directed I don't have full info.

Question 4-Which interview situations do your candidate participate in while preparing to be a National Officer Candidate? (Check all that apply)

changes every year

Question 6-What types of interview skills did your candidates work to improve during their preparation? (check all that apply)

- can be any or a few of the listed depends on the student

- Connection between FFA Competencies and any given question or scenario

Question 8-What types of public appearances do you feel are most beneficial in preparing your candidate to run for National Office? (Please list your top 3)

- Conferences with FFA members to remain enthusiastic and connected as well as well-spoken with the target demographic. Speeches with 'outsider' groups to develop poise and an ability to articulate and communicate FFA key messages in a way that anyone can understand and find value in. Anything with sponsors or partners to effectively communicate the value of FFA and develop habits of strongly demonstrating commitment to FFA and member representation.

- workshop presentation

Group work 
- Meet \& Greets

Workshops with FFA Members

Speeches for FFA Members

- Chapter banquet keynote speech

FFA member leadership workshop

Attending Ag business annual meetings.

- Agriculture Leaders

Past National Officers (within 5 year)

Experienced Teachers.

- Candidate develops and presents Keynote for FFA conferences

- Interaction with college level ag students

Interaction with high school FFA members (workshops, speeches)

Interactions with sponsors

- Agribusiness groups

Members \& Teachers

Media

- Workshops with State Officers

Meetings with key stakeholders

State Greenhand Conference

- meetings of all types

political

- Workshops with student interaction

- Workshops, speeches, interviews

- State Department of Agriculture events

- Preparing and presenting workshops.

- interviews

small group discussion

workshops

- We currently only present them at our state convention.

- Working with students

Business and Industry Leaders

Key stakeholders

- Conduct workshops for current officers while staff evaluates (Facilitation). 
- Conducting workshops

Delivering speeches

Visiting with mentors/coaches/business \& industry officials

- Speaking to groups of students and business leaders.

- Meet with our governor, senators, and representative. Director of Ag, etc.

- each one is different so it is based on their needs

- Any chance to address an interested and diverse group with a short presentation.

Question 9-What types of public appearances do you feel are least beneficial in preparing your candidate to run for National Office? (Please list 3)

- Unsure

- legislative visits

- Just go and hang out with members

- Any appearance before the public is beneficial.

- 1.Past National Officer (greater than 5 years)

2.Members

3.Family and Friends

- I don't believe there is such a thing as bad practice.

- Forums

Small group discussions

Lectures

- Simple Chapter visitations

Attending county fairs

Working with Home Chapter

- all can be important to some degree

- Business and Industry Visits, political visits

- FFA Chapter events

- Mock interviews without the rubrics for the process used now.

- Keynote type speech

- We only do the above currently.

- Teacher organization

Civic groups

- Speaking at convention or event (short speech).

- Almost any that do not have a specific purpose 
- all experiences are beneficial for the candidate

- NA

- They are all valuable

- Addressing groups where they are totally confident and comfortable.

Question 11-If they presented workshop(s), what were the general topics of the workshop(s)? (List all you can recall, if you did not conduct workshops, put N/A)

- They present workshops derived from either competency areas or the ten listed hot topics for that year's selection.

- leadership facilitation

- They are dependent upon the hot topics for the year.

- Leadership skills for the future.

- Leadership, team building communication, and topic that are related to the national themes.

- How to develop workshops

Team building activities

Personal Mission Statements

- Leadership

Goal setting

Motivation

Attitudes

- Team Work

Resources for State Officers

Taking Risks

FFA Opportunities

Career Development Events

Supervised Agricultural Experiences

Careers in Agriculture

Conducting Chapter Visits

Conducting Committee Work

Building Relationships

- It varies by candidate

- Goal setting

Team Building 
Improving leadership abilities

FFA Opportunities

- FFA membership recruitment

FFA participation

- FFA opportunities, diversity, recruitment

- FFA involvement

- I can't recall. They select topics, usually.

- Student based

Leadership

Career goals

- Facilitation Techniques

General workshop on FFA

Mock workshops covering several topics

- Will be presenting a leadership workshop for district officer teams in September.

- Leadership

Communication

Goal setting

- Leadership - Team Work - General Agriculture Knowledge

- varies but Germaine to the audience.

- depends on what the hot topic is for the year

- Leadership and personal development

Question 19-After having candidates that have been through the process, what topics do you think are the most important for a candidate to research?

it would depend on the year and the topics for that year

Question 22-If you answered yes to question 21, what were the resources provided? (please list)

- Our agricultural education professors assist candidates through seminar time and utilizing aged students as resources. They also help to facilitate relationships between other faculty and the candidate, IF that candidate is currently a student at our state university. If they are enrolled elsewhere, it is harder to make the connection and build the relationships.

- Assistance with interviews, resource development and expert interviews. 
- $\mathrm{Ag}$ Ed professors provide informal support

- Staff access Interviews/meeting with college professors Practice interviews

- Agriculture education staff assisted in setting up mock interviews

- Provide resources

- They met with several Ag Ed professors and work on communication skills.

- interview opportunities

- Knowledge training and mock interview

- video tape workshops and interviews

Question 24-Did your candidates consult with any of the following for advice about the selection process?(check all that apply)

Everyone's experience is different so it is best for them to find their own success vs. basing it upon the opinion of others.

Agriculture Industry Leaders

Professors

Professional Association Staff

Question 25-Did any of the following provide your candidates with feedback on areas of improvement? (check all that apply)

University staff

Question 29-How closely does your state nominating committee process mirror the national nominating committee process?

We mimic the process as closely as possible but instead of utilizing students, we have a committee that is comprised of a mixture of ag, ed and FFA leaders, including at least one student. It happens in one day with written assignments and tests happening before the selection. We do utilize the competency weights in selecting our candidate.

Question 32-What state are you from? 

Alabama
California
Colorado
Connecticut
Idaho
Illinois
Indiana
Kentucky
KS
MA
Maine
Maryland
Michigan
Montana
$\mathrm{NC}$
New Hampshire
New Mexico
New York
NJ
Pennsylvania
SC
VA
West Virginia
Wyoming

Question 33-What do you think was the most beneficial skill your candidates received from their preparations as a National Officer candidate?

- They become exceptional communicators, but often the best LIFE skill they develop is the ability to connect and communicate information in a purposeful manner. Their ability to critically think is greatly improved as they learn how to identify the opportunity to deliver quality, targeted and persuasive information in multiple settings.

- critical thinking

- Stronger understanding of who they are and how they can contribute to society.

- Being able to speak out about the importance of American Agriculture.

- Agricultural Knowledge and agricultural education knowledge, as well as communication skills.

- Our candidates learn discipline and study habits. I will compare our process to a 4-6 unit college course.

- Ability to process information, time management, personal growth

- None that hadn't been provided when they were a state officer

- self discipline 
- poise and presentation of self

- Development of their influence as a characteristic

- Communication and presentation

- Interview tactics

- Research

- Focused disciplined training for a goal

- Focus

- Personal knowledge. They find out who they really are.

- all of it

- Leadership and character development.

Question 34-Other than being elected to National Office what would you like your candidates to gain by going through the National Officer Selection process?

- Networking opportunities, connections with additional training/representative opportunities available through FFA and their partners/sponsors, self-awareness and competency mastery.

- interpersonal skill that my help advance their employment potential

- Become an advocate for Agriculture as an industry and the process that allows them to have these experiences - Ag Ed \& FFA

- A passion for continuing to be an influence on our next generation of agricultural leaders.

- A feel of self worth. After students run for a National Officer and don't receive one they feel very low about themselves.

- I hope our candidate learns a lot about who they are and what they have to offer people.

- Become more well rounded individuals who are prepared to lead Kentucky agriculture.

- Same trait, skill and knowledge development that they gain as a state officer

- self confidence and self awareness

- seeing the potential in their skills and abilities towards future endeavors

- personal growth, increased knowledge, improved communication and leadership skills

- A sense of accomplishment rather than defeat if they are not elected. 
- Getting to know the other candidates, networking with nom com and learning from the experience to make them better interviewers.

- Agricultural and education knowledge, career interviewing skills

- networking

- Interview skills

- Self satisfaction. Knowledge of Agriculture, education and FFA.

- Maturity and sense of pride in self and others.

- Life Skills

- Development of the heart to serve and the ability and desire to do so.

Question 39-After being involved in preparing candidates for the process, what recommendations would you suggest for change?

- I think the process is excellent in that the information students are evaluated on is clearly outlined if you recognize it. Many states, I believe do not understand this. I believe the regions are slightly skewed as for equity as well - for example, the southern region traditionally has 6 to 7 states submitting candidates, comparatively to the eastern, central or western regions, it is possible that there are 3 times as many candidates running for the same positions from other parts of the nation and that after the first cut, there would still be more central region candidates than total candidates from the southern region at the start of the process. It's inequitable that 3 students are vying for the same positions that 8 students are competing for in other regions. The process, however, seems quite equitable and the staff and committee members are completely dedicated to selecting the best 6 students from across the country with the details within their control

- We have watered down the behavioral interview process and that needs to be strengthened.

- Either get rid of the Tuesday night "cut" or have something positive for the candidates that don't make the cut to do during the convention. The cut is the most negative event in the history of the most positive organization ever designed. Most have their parents, etc. there or coming and, with nothing to do if they are cut, with their dream shattered have a hard time enjoying the actual convention.

- Make the cut after the introduction of candidates, and have a facilitation practicum before the cut.

- I believe the rounds developed are excellent at highlighting candidate skill sets, however I feel that the competencies are in some ways a detriment to the process. Nominating committee members can fall in love with competencies that are 
extremely difficult to measure. It is easy to measure communication, critical thinking, etc. It is difficult for 20 year old committee members to measure accurately after 2 days of training areas like teamwork and character. Those areas are tough to measure in short small interviews. There is a major flaw to the system in those areas.

- Pick the best 6 . The effort to pick 6 who fit together is laughable.....

- Nominating committee retains biases throughout the process when a candidate errs or does well. Need one committee for each round. Narrowing the candidate field on Wednesday is unacceptable - many candidates have yet to have a full opportunity to display skills \& knowledge.

- The cut is a good idea, but there isn't enough face time with the candidates prior to the cut. Provide additional samples of training plans used by other states.

- not sure

- I don't how the process can be changed but the candidates selected need to be more down to earth with the ability to relate to and motivate members

- NA

- none

- $\quad$ satisfied as is

- All candidates should be allowed to complete all parts of the process. Elimination of candidates based off of a few areas potentially eliminates candidates who are strong in other areas. Unfortunately, the nominating committee is not able to evaluate all of their skills with the current "cut" process.

- NA

- I would follow the recommendations of the National Task force. This task force completed their work this past summer 


\section{APPENDIX E}

\section{Emails Sent to Candidates and State Staff}

\section{Dear State Staff,}

My name is Becky Berkebile and I am a graduate student at West Virginia University. As part of my graduation requirements I am conducting research for my thesis on the training methods used to prepare National FFA Officer Candidates. The goal of my study is to determine the multitude of methods used to prepare a candidate by surveying the candidates from the last five years along with state staff and comparing the results. Attached is my cover letter explaining in detail my study. It also includes the Zoomerang link to my survey. I would greatly appreciate your input in my research.

Thank you for your assistance

Becky Berkebile

\section{Dear State Staff,}

My name is Becky Berkebile and I am conducting a graduate study on the training methods used to prepare National FFA Officer Candidates for the selection process. On May 24th I sent you a request to participate in my study. If you have already completed my survey I ask that you please disregard this message and I thank you for your response. If you have not I am asking that you consider participating in my survey. Your responses will be greatly appreciated and will help to make my study a success. To make it easier I am including the link to my survey. http://www.zoomerang.com/Survey/WEB22CBRT23EC5/

Sincerely, Becky Berkebile Graduate Student West Virginia University

Dear Candidates,

Thank you so much for your support and willingness to assist me with my survey. Attached you will find my cover letter which includes a link to my survey which is uploaded to zoomerang. Once again thank you for all of your help in making my survey a success.

Sincerely, Becky Berkebile 
Dear Candidates,

On May 24th I sent you a request to participate in my study. If you have already completed my survey I ask that you please disregard this message and I thank you for your response. If you have not I am asking that you consider participating in my survey. Your responses will be greatly appreciated and will help to make my study a success. To make it easier I am including the link to my survey. http://www.zoomerang.com/Survey/WEB22CBRKJ39RL/

Sincerely, Becky Berkebile

Graduate Student

West Virginia University

Dear Candidates,

As some of you may already know, My name is Becky Berkebile and I am writing my thesis on the Training Methods used to Prepare National FFA Officer candidates for the selection process. Previously I sent you my cover letter explaining my study as well as a reminder email. Since I understand that often times emails become lost in inboxes or forgotten about I am sending another email with my cover letter attached. If you have already completed my survey I want to thank you and apologize for sending this email to you, as I have no way of knowing who has or has not completed the survey. If by chance you have not completed my survey, I would like to ask you to consider doing so. Each one of your opinions are important to me and will help to make my study and results more reliable. Lastly I would like to ask for your help in reaching other candidates from your state that ran between the years of 2006 and 2010. Some of the emails I have are no longer current and I would like everyone to have an opportunity to participate if they would like. I am including the link to the survey to make it easier for you to access and so if you are in contact with other past candidates you can forward this email to them. Once again thank you for all of your help in making my study a success.

\section{http://www.zoomerang.com/Survey/WEB22CBRKJ39RL/}

Sincerely,

Becky Berkebile

Graduate Student

West Virginia University 
VITA

Becky L. Berkebile

West Virginia University, Morgantown, WV 26506

Master of Science in Agriculture with a major in Agricultural Education and Extension. Course work specializing in: research, data analysis, extension and horticulture. Date of graduation December, 2011.

West Virginia University, Morgantown, WV 26506.

Bachelor of Science in Agriculture with a major in Agricultural Education and

Extension. Course work specializing in: animal science, plant and soil science, agriculture mechanics, leadership and communications. Date of graduation May, 2010.

Garrett College, McHenry, MD 21541.

Completed course work in General Studies upon transfer. Years attended: 2006-2007

Northern Garrett High School, Accident, MD 21520

Course work in Agriculture Career Cluster. Years attended: 2002-2006. Graduated May, 2006. 